\title{
studies in bilingual education
}

\author{
SELECTED PAPERS \\ from the \\ INTERNATIONAL SYMPOSIUM ON BILINGUAL EDUCATION \\ Hong Kong, 1976.
}

Editors

Robert Lord and Benjamin K. T'sou

Assistant Editor

Marie Arana-Ward

Language Centre, University of Hong Kong Distributed by Heinemann Educational Books, (Asia) Ltd. 


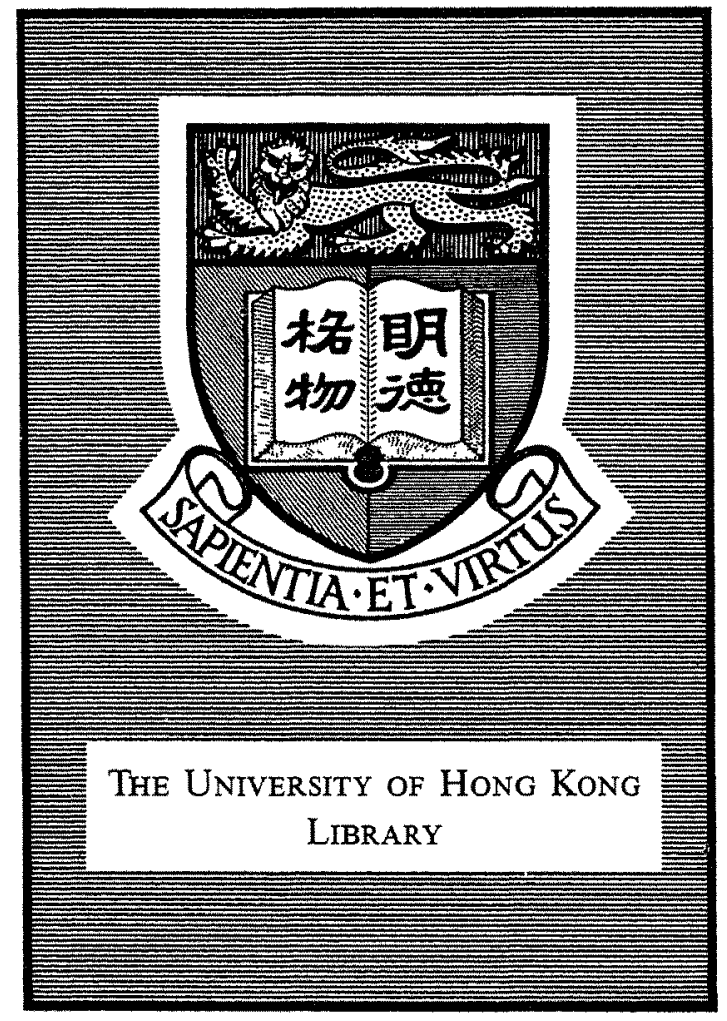


Nur wer fremde Sprachen versteht, versteht etwas von seiner eigenen.

(Goethe)

不識外文, 蜼棈母語

He who is ignorant of foreign languages knows not his own

外国語を知らないものは自国語をも知らない。

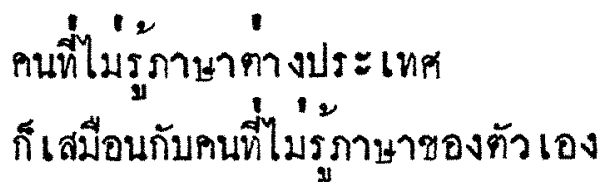

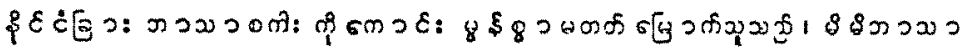

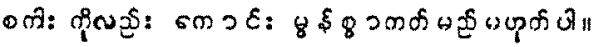

Seul celuı qui comprend les langues étrangères peut comprendre sa langue maternelle

Solamente el que comprende lenguas extrangeras puede comprender la suya 
(C) by Language Centre, University of Hong Kong. All rights reserved. No part of this publication may be reproduced without permission.

\section{本書版權屬香港大學語文㸴習所 所有。未經許可不得翻印或轉載}

Printed by: LAMMAR OFFSET PRINTING CO.

Flat A2, Bay View Mansion 17/F.,

Morton Terrace, Causeway Rd., Hong Kong. 


\section{INTERNATIONAL SYMPOSIUM ON BILINGUAL EDUCATION ORGANIZING COMMITTEE}

(Hong Kong, 1976)

R. Lord, Co-chairman

(Language Centre, University of Hong Kong)

B. K. T'sou, Co-chairman

(Language Centre, University of Hong Kong)

Yu Fong-ying, Secretary

(Language Centre, University of Hong Kong)

Chan Jachin

(Hong Kong Baptist College)

G. Schaeffer Fu

(Department of English, Chinese University of Hong Kong)

Kong Yun-fun

(Northcote College of Education, Hong Kong)

T. Leung

(English Language Teaching Centre, Hong Kong) 



\section{CONTENTS}

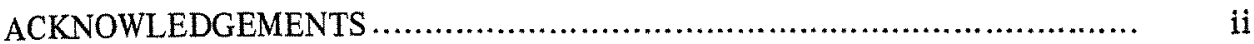

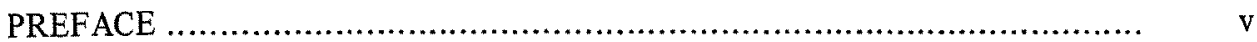

V. GENERAL INTRODUCTION........................................... 2

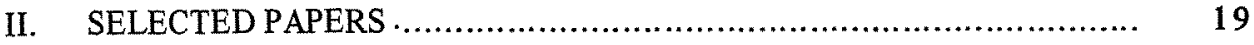

A. Opening Remarks

How Bilingual?

Kenneth Topley ....................................................................... 19

B. Bilingual Education in Perspective

Bilingualism under Pressure

Robert Lord ..........................................................................

Bilingual Education: A Socio-psychological Perspective

Eric Kvan .................................................................................... 24

Motivational and Environmental Factors in Bilingual Education

M. Alan Brimer ............................................................................ 29

S6rme Macro-sociological Issues in Multilingual Societies

Eddie C. Y. Kuo .......................................................................

Some Sociolinguistic Considerations of Bilingual Education for Asian Countries

Benjamin K. T'sou

C. Regional Reports

The Role of Kanji 漢字 in Japanese

Nobuhisa Tsuji

The Status of English in Relation to the Other Languages in

Primary and Secondary Schools in Malaysia

Lim Kiat-boey

Bilingual Education in The People's Republic of China

Alain Peyraube

61

Present Trends in the Sociolinguistic Situation in Papua New Guinea

Stephen Wurm

D. Bilingual Education in Practice

Bilingualism: The Role of the Universities

Lucille Ramish.........................................................................

Contrastive Approach in Bilingual Education

Tang Ting-chi....................................................................... 
Some Observations on Hong Kong Secondary Schools

Arthur Hinton

E. The Chinese Curriculum in the Bilingual Context

The Teaching of Chinese in Thailand

Prapin Manomaivibool.

日本的中文教學及其噮境 On Chinese Language Teaching in Japan

Yosunori Ohkochi.

漢語書面語所受罣方言和英語之干擾及對干擾之容限 Some

Problems of Interference and Tolerance in the Written Chinese of Hong Kong

Cheung Yat-sing

F. Testing and Assessment

Problems of Psychological Testing in Two Languages in Hong Kong Jimmy Chan

Public Examinations Go Bilingual for Hong Kong Primary and Secondary Schools

Lee Lai-min

G. Closing Remarks

Bilingual Education and Practical Necessity

Robert Lord, Co-chairman

An End to A Beginning

Benjamin K. T'sou, Co-chairman

SELECT BIBLIOGRAPHY

I. A Chronology of the Developments in Bilingual Education in Singapore Schools: 1951-1977

Loo Shaw-chang

II. Programme of the Proceedings

III. List of Participants

IV. Programme of the Asian Round Table Conference. 


\section{PREFACE}

The International Symposium on Bilingual Education was first conceived in the summer of 1976 . The area of bilingual education had long been a concern of linguists and educationalists in Hong Kong. It was decided, at this time, that the thinking and activity in this field had reached a stage where Hong Kong could contribute to and benefit from sharing its ideas and experiences with other concerned regions. Apart from the fact that Hong Kong seemed a suitable venue in terms of its long history of bilingualism, it was hoped that, by turning the focus on itself, Hong Kong would achieve the double effect of adding to the region's awareness of its practices in bilingual education, and profiting from a compendium of professional opinion. The Asia Foundation's interest and financial backing allowed the Symposium to be realized in December of the same year.

The collection of papers and the General Introduction presented in this book, then, relate the experiences and unique considerations of various Asian nations and institutions in implementing policies of bilingual education. Owing to a limitation of resources and a consequent restriction in the length of this publication, the editors have tried to select representative papers from the Symposium so that any overlapping of subject material will be avoided. The contributions not represented in this collection are acknowledged and discussed in the General Introduction.

The individual contributions published here are either the original manuscripts submitted at the time of the Symposium, or subsequent versions provided by the authors. The papers are essentially unaltered, with the exception that minor editorial changes have been made for purposes of consistency. In order to preserve the spirit of the Symposium, however, there has been no effort to edit the articles for consistency in style.

Papers by Tang Ting-chi and Stephen A. Wurm are included in this collection although, unfortunately, the writers themselves were unable for various reasons to present them at the Symposium. It is hoped that in future meetings the Symposium will enjoy an even more widespread attendance by representative Asian nations.

The 1976 International Symposium on Bilingual Education was followed immediately by the Asian Round Table Conference. Whereas the theme of the Symposium was broader in nature, the Round Table Conference concentrated on technical aspects of Chinese language and linguistics. The programme for this conference can be found in the Appendices of this book. 
GENERAL INTRODUCTION 


\section{GENERAL INTRODUCTION}

In many of the developing countries of the world, in much of Asia or Africa, a child commonly has to undergo a change in his linguistic repertoire in the transition from childhood to adulthood. The change usually involves going from the native language of the chird to the acquisition of at least one additional language, or additional variety of language, sometimes at the expense of the child's first language. Typically, this additional language is an official language which has higher status in society. This high language is frequently used in schools as the medium of instruction and in the conduct of official business. In such a diglossic society where more than one language or one variety of language has well-defined, non-overlapping societal functions, an individual, in order to better himself, must achieve mastery of the distinct varieties of language within the appropriate social domains. This is true of the Malaysian bey of Tamil parents, or of the Tamil boy in India; the Javanese child growing up in Indonesia; the Singaporean child of Chinese background and his counterpart in Hong Kong, or even in many parts of China; or-the child growing up in the highlands of Papua New Gunea. Exen-in an exceptionally homogeneous society such as Japan a child will be confronted by English and written Chinese in different ways.

The pressures that are brought about to promote such a change are usually economic and social, but there are also concomitant psychological and cultural implications. Thus, for example, the average child who now grows up in Hong Kong will be exposed to English as well as Mandarin neither of which is likely to be-his-native Ianguage. English is a must for him if he is to climb the economic ladder in the customary wäy, and Mandarin is likewise of growing importance because written Chinese is based more on Mardarin than on Cantonese. In all such cases some form of bilingualism is called for, and the need for bilingual education beyond simply teaching more than one language in school becomes apparent.

Bilingual education should be understood in an idealized way as the organized use of two languages as media of instruction in the school curriculum with the dual purpose of integrating the linguistic and cultural maturation of the child. Bilingual education must be distinguished from vernacular education as it is known and practised in many countries. In British India and in pre-independence Singapore and Malaysia, for example, vernacular education promoted the continuation of separate but coexisting societies. Similarty, in Canada, English schools and French schools, which could be considered under the rubric of vernacular education, were not oriented towards the cultivation of a single integrated society. The existence of vernacular schools among immigrant groups in the U.S.A. or elsewhere has often been seen as an opposing force to the development of a single integrated country.

The concept and practice of vemacular education, as opposed to bilingual education, have changed in recent years, and the concept and implementation of bilingual education have gained strong support in North America within the last decade. There is now very strong commitment to bilingual education in the two North American countries and numerous forums and research projects have been generated. This major educational movement has been gathering momentum outside of that continent as well, and 'not since the Renaissance has there been such a general growth of awareness that the educational process might best be served by offering it in the native language of the 
learner' (Troike and Modiano. 1975). This movement will certainly leave behind indelible marks in the field of education all over the world.

Undoubtedly, emerging nations will feel the impact of such a movement. Among South East Asian countries which typically have heterogeneous populations of diverse cultures and languages, two main trends are-in evidenee. First, there are the countries which have been promoting their respective national languages over both the official languages under previous colonial rule ( $\mathrm{eg}$ English) and other languages indigenous to their populations. Second, there are those countries which have basically adopted a policy of promoting English along with their respective national languages.

In the implementation of such policies there is always the crucial problem of the utilization of a First Language for transition into a Second Language (with or without maintenance of the First Language). This is one of the primary concerns of bilingual education.

While educators in Asia have become increasingly cognizant of developments in this area outside of the region, there has been little concerted effort to explore the implication of bilingual education for Asian countries. What are the social realities in Asian and South East Asian countries with regard to the roles of language in society? How best can an educational system prepare the child to go from the usually monolingual environment of the home to a linguistically complex and competitive adult world? What variables must be considered in policy-making and how are policies best made? What are the implications of different policies and how best to supplement them? How best should curriculum material be prepared from the primary level to the post-secondary level? What are the best teaching methods? How best can student progress be evaluated and against what kind of standards? How are teachers to be trained? What are the experiences that can be fruitfully shared? four specific aims:

The International Symposium on Bilingual Education was organized with

1. Tomamine becial problems bilingualeducation emerging; in selected countries in South East Asia and within the Pacific Basin where an official language exists side by side with one or more different national or native languages.

2. To bxing together experts in the fields of linguistics, sociology and bilingual education, as well as experienced teachers from both within and without the region for an exchange of views and experience.

3. To focus on the Hong Kong situation as an example of such a community.

4. To put into a publishable format the essence of the proceedings from this Symposium.

The Symposium was organized into different sessions. A summary of the papers presented as well as relevant discussion follows.

In his opening remarks Kenneth Topley, the Director of Education, Hong Kong Government, recalled that, though monolingualism is highly convenient, there exist few truly monolingual communities. Even where monolingualism does occur there is, he said, always a danger of serious cultural divergence being altogether masked, only later to emerge in sometimes virulent forms. Educationally inconvenient though it might 
be, bilingualism was never culturally limiting and tended to promote communication across cultural and linguistic boundaries.

Topley suggested that a taxonomy of the many different bilingual situations to be found in different parts of the world would be useful. But he emphasized that the aims of bilingual education would inevitably be limited by resources, local conditions, and the motivation of the learner himself. Of these motivation, he thought, was the most important. It would be unwise, as he put it, "to expect too much from too many.'

To specify aims in bilingual education was difficult enough, but the successful pursuit of these aims would make even greater demands on everyone. For this reason initial aims should be modest, Topley urged. Noble ideals, furthermore, might have to yield to more limited utilitarian aims. The upper limits to achievement in learning a second language were real enough, and were set to a large extent by the bilingual learner. It was possible perhaps in certain cases to become too proficient in a foreign tongue for one's own good.

Topley concluded his address by further emphasizing the need for limited aims and realistic expectations.

The opening address in the First Plenary Session was given by Robert Lord, Co-chairman of the Symposium. He proposed three overlapping classes of bilingual: the natural bilingual, who grows up in a mixed language community learning to use successfully the two (or more) languages of that community without undue strain; the bilingual by choice, who acquires one (or more) foreign languages up to a certain level and for particular purposes; and the bilingual by necessity, motivated, at some stage consciously, to acquire a second language by force of circumstances. Lord believed that the Symposium had largely to do with the latter category.

He drew attention to the very large proportion of the world's population who became bilingual, more or less successfully, not through any natural ecology, but as a result of pressures imposed upon them by the political, cultural and social situation in which they find themselves. The pressures, he said, were of three kinds: economic, educational, and cultural. Hong Kong, he claimed, was a particularly acute instance of a place in which all three pressures were exerted forcefully and in unison. Within these are the two conflicting cultural pressures of Westernization and Chinese tradition which add to the burden on the schoolchild and adolescent in such a situation.

The next speaker, Erik Kvan, thought that the previous speakers had been isolating language from the rest of social behaviour when such isolation was no longer possible. Psychology and sociology had been merging over a long period into a common field of social psychology. The much more recent growth of the disciplines of sociolinguistics and psycholinguistics had shown that language was impinging more and more upon the concerns of social psychologists. Language was but yet another aspect of learnt social behavioural patterns.

The study of language itself, Kvan said, had grown to resemble the social psychologist's approach to his own particular sphere. Languages were no longer thought of only in the conventional sense, as geographically discrete entities; but instead had become a complex of domains where sometimes the transition from one official 
dialect to another was less important than the switch from one domain of usage, code or register to another. The need for translation between these latter could be as great as between separate 'languages'.

All social behaviour, the speaker stressed, is the result of conscious selfmonitoring by each individual of his own performance. Social behaviour is the basic skill which is learned intensively in the pre-school years, and language learning has to be seen in the context of all this.

School in Hong Kong, the speaker went on to maintain, is a different kind of experience from school elsewhere. As in most other places social behaviour and the mother tongue are learned very largely in the home, but the second language can only in most cases be learned at school. Yet, in Hong Kong, no kind of learning is expected to take place at school. Even academic learning takes place at home, where there is a complete absence of second language (English) information. In order to be successful, bilingual education in Hong Kong, as anywhere else, had to start from the social and cultural learning patterns and accumulated experience of the typical schoolchild.

The attention of the Symposium was next turned to the role of language as a mediator of culture and knowledge, and to the constraints imposed by any language through its particularity.

Alan Brimer maintained that the learning of language entailed something different from and more fundamental than skill in adapting to social contexts and registers in adult life. Switching from one language to another meant a change in the speaker, especially when the roles of the separate languages were highly differentiated. The nature of the language used, the cultural context, and the pattern of social interaction together determined the individual's manner of coping with the world. We still racked, $\bar{h}$ said, an operationally sound theory of foreign language acquisition.

Therem then tollowed a brief review of what he claimed was definitely

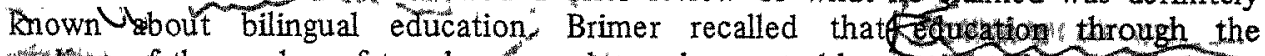
wedtum of the weaker of two langliages has a demonstrably aeferse effect upon what is Tugif as well as tipon progress in the language itself. No one method of teaching a langugs had been proved stperior to all others, and mixed methods were the general rule (f Curthermore, motuation had been shown to be necessary, if learning was not to artificial. In addition the teaching of language had to be related to objectives, not purely linguistic or communicatixe, but also ducational. Language, the speaker said, was much more than a skill, intimately connected as it was with the politics and culture of a particular language community. Mastery of a foreign language, he continued, also depended on how well the learner had mastered the mother tongue. The age at which learning of a target language began was far less important than the meaningfulness of the context in which it was acquired. Finally, it was evident that aptitude for the learning of spoken language was not related to general intelligence and this led to discrepancies between a learner's performance in the written and spoken language.

Brimer rounded off his address with a series of questions. How can motivation, he asked, be created, when the language learned fails to mediate a meaningful environment. At what age should education in the medium of a foreign language begin, and how did this question relate to the length and timing of the period in which the language per se is learned? How can the teaching of the spoken language be 
conducted in noisy classrooms without distraction ath distortion? And lastly, how could student and teacher engage in real dialogue when education takes place in a language in which neither is competent?

After this, Eddie Kuo switched participants' attention to Singapore, as well as to wher macro-sociological issues. Having pointed out that of the four existing approaches to bilingualism (which he gave as linguistic, educational, psychological and sociological, each with its different assumptions and theories) the sociological approach was the least developed, Kuo went on to characterize the sociological factors at play in any bilingual situation.

The existence of two different languages within a society, he said, signified gaps communication. A problem for the sociologist and language planner was the maintenañe of the minimum amount of communication necessary for a particular society to continue in existence. Language diversity also meant cultural diversity. And in a multilingual society there was always one dominant language. The sociologist was concerned, accordingly, with two major issues: Communicative integration and national identity.

Communicative integration, Kuo argued, depended on either the existence of a widely accepted lingua franca, or extensive multilingualism, or both, In Singapore there was no single lingua franca. Hence integration had to stem from planned multilingualism, in which a combination of English and one other of the official languages (Mandarin Chinese, Malay, or Tamil) would become the key.

The attainment of national identity, Kuo reminded the audience, was never easy or quick, and time and planning was needed to ensure that the necessary 'sentimental attachments' developed. English in Singapore did have the advantage, the speaker said of being culturally and ethnically neutral. At the same timethe praetice of multilingutism in Singapores torved to contain the potential divisiveness of language diversity.

Benjamin T'sou, Co-chaiman of the Symposium, ${ }^{*}$ rounded off the First Plenary Session by focusing on bilingual education as such.

He began by pointing out that the term bilingual education possesses a wide range of different meanings. For this reason it was advisable, he urged, to adopt a more general and informal definition of bilingual education.

Bilingualism, T'sou suggested, depended for its particular interpretation very much on the perspective one happened to be taking of it. For instance, what is undeniably the mother tongue for a linguist can, if it is socially less important, become the second language for the sociologist.

We needed to know, he said, under what circumstances bilingual education became significant or critical in a particular society, since this would entail policy and social changes.

Just as bilingual education could vary in meaning, so its goals could vary too. T'sou drew a distinction between symmetric and asymmetric bilingualism, the former implying $b i$-culturalism as well as $b i$-lingualism. He also mentioned transitional 
bilingualism, by which an individual starts out with one language and finishes by becoming competent in another.

Not only did the goals of bilingual education vary, said T'sou, but so also did the models. 'Assimilative' bilingual education produced transitional bilinguals, and 'pluralistic' models fostered cultural pluralism. He laid emphasis however on a third model which he said was rarely discussed: the 'divisive' model of bilingual education, in which a minority group is expected to become bilingual and also bicultural in the language of a dominant majority, and not the other way round. Biculturalism, and the social divisions that would ensue, could be avoided by having educational policy geared to a single culture, even in a situation where multingualism was the norm.

There was also the matter of language levels and registers, which were not mediated through the textbook. Home and social environment thus became as important as the classroom, since the content of language and the differentiation of content could not be taught in the latter.

Finally, T'sou said, choice of language was crucial. Language planning had to start from the realities of a particular situation. The wrong choice of languages in bilingual education could create or add to previously existing difficulties. When misconceived, bilingual education could only make matters worse.

The Second Plenary Session, which followed, was concerned with specifically regional aspects of bilingual education.

The Session began with a provocative and unusual case of bilingualism: The use of Kanji, borrowed Chinese script, in the Japanese writing system. Nobuhisa Tsuji presented a succinct account of the origin and development of writing in Japan, with special emphasis throughout on the bilingual function of Kanji and the Chinese cultural associations that have for centuries accompanied its use.

The speaker explained how Chinese radicals had lent themselves to Japanese graphs, which could be given only a Kun, or native Japanese, reading. He also showed how Kanji, despite a certain amount of obsolescence, performed an important function in the Japanese writing system and Japanese culture. But, through a tradition of Japanese sinology, sets of conventions had been anciently developed which enabled Chinese sentences to be given a Japanese word-order, and Japanese case-markers, inflectional endings, and other grammatical elements to be added. This system, known as Kanbun, the speaker said, is neither Chinese nor Japanese, but a bilingual hybrid of the two.

Despite the difficulties in learning it Kanji, along with the bilingualism inherent in it, would remain, Tsuji predicted, an important part of the Japanese writing system.

After this came a discussion of the relationship between Malay and English in primary and secondary school education in Malaysia, which highlighted a more general dilemma. Lim Kiat-boey explained that on the one hand a planned series of measures had been establishing Malay as the National Language, as the "fundamental instrument of national unity', but on the other hand the need for English as the language of international communication was evident and often reemphasized. 
Lim explained the steps by which Malay had superseded English as the medium of instruction throughout the assisted secondary schools, and how English as the medium of instruction in primary schools had been phased out. She also gave an account of the measures taken to ensure a high standard of English was main tained, through curriculum revision and development and through the retraining of teachers. Furthermore, residential English-medium junior science colleges had been created for Malayspeaking puils, with a view to correcting economic imbalance between the different races. In all schools the teaching of English continued to hold an important place in the curriculum.

There followed a report on Wifingual education in Singapore, given by Loo Shaw-chang. He began by maintajning that the multilingual policy of Singapore was not a burden to its citizens but an aetvantage, in that barriers be tween the different ethnic - groups had been broken down, and-that Singaporeans were rational in their approach to language issues. An individual's ability to use more than one language even lent prestige. Bilingualism, in there opinion of the speaker, had contributed to Singapore's prosperity and progress:

Loo then went on to single out what he regarded as the salient features of bilingual education hringapore. Bilingualedertation for most began in kindergarten. And this, sustained throughout the entire course of one formal education, ensured a high terminal standard of bilingualisn. The languages learnt at school also served as media of instuction, the mother-tongue remaining the medium for the teaching of cultured-based subjects, ape English, the second language, as the medium of instruction in science and technglogy. The two languages thus were not in conflict, but complemen tary to each othere

The chief problem was that English-medium schools had been gaining at the expense of Chinese-medimm schools, owing to the popularity of the former. Chinesepeaking students, especially those from rurar backgrounds, could not cope linguistically with the demands made upon them, and many had dropped out. But measures had recently been introduced, the speaker said, as a remedy, which entailed a reversion to monolingual education for weaker students.

The final report in this Session was given by Alain Peyraube, who turned the discussion towards the People's Republic of China.

According to Peyraube bilingual education in China, which propagates Pŭtōnghuà as the second language, can be considered in two parts.

The first concerns the national minority areas, in which the penetration of Pütōnghuà has been limited, though varying somewhat from one minority area to another. In none of the autonomous regions is Pütônghuà used as the medium of instruction in primary or secondary schools. Pǔtonghuă is learnt as a second language only at secondary school. Students entering tertiary education are sent to other provinces where they have to acquire Pütönghuă. Tertiary-level students are usually given probational linguistic training before embarking upon their studies. Conversely, Han Chinese who are sent to national minority areas to work are obliged to learn the local language.

The case of the Chinese dialectal areas has been more complicated. Although the introduction of Pútönghuà should theoretically have been easier, an incon- 
sistent policy over the past few years had hindered bilingual education. Bilingual education, Peyraube reported, had been successful only in the large or middle-sized towns where Pŭtönghuà was often the medium of instruction. It had not touched the peasantry, who had not been enthusiastic about it either. Progress in the last twenty years had been slow in being realized. Bilingual education had slipped into second place, since it had been recognized, Peyraube affirmed, that the campaign against illiteracy was to take precedence for the time being.

The last session of the first afternoon was taken up with concurrent group discussions on a range of topics.

In the discussion on the topic 'Language, Social Opportunity, and Language Choice' the point was made that language and education, whether in monolingual or multilingual societies, are stratifying elements. In monolingual societies however the medium of instruction is often a middle-class language; whereas in multilingual societies, of which there are several in South East Asia, there is available a language of wider communication which engenders communication between ethnic groups.

Another group, discussing 'Teacher Training and Bilingual Education', confined itself to Hong Kong. But a parallel discussion on a closely related theme 'Language and Educational Performance' - attempted a comparison of Hong Kong and Malaysia. In both areas language proficiency was related to proficiency in subjects other than language. The situation appeared to be better in Malaysia, in that here was a linguistically heterogeneous society, which meant that English, the language of instruction, was also the language used outside the classroom.

A fourth group concerned itself with 'Language, Attitude and Motivation.' Here the contrast was drawn between Hong Kong, where the pragmatic motivation towards the learning of English is marred by an ambivalence in attitude and other factors, and Singapore, where the ability to communicate in more than one language confers prestige.

Yet another group discussed 'The Bilingual Child', and ranged over the sort of questions that might be expected in any open-nded discussion.

Lastly, there was a discussion of 'Language Policy and Planning' which considered three aspects of this large question: how and by whom policy is determined; the social realities; and the need for language planning and policy.

From then onwards, the Symposium took the form of Panel discussions on various aspects of bilingual education.

The first of these Panel discussions took place on the morning of the second day of the Symposium, and was concerned with Bilingual Education and Curriculum Development in Post-secondary Education.

The session began with a paper by Lucille M. Ramish on 'Bilingualism and the Role of the Universities' with particular reference to Singapore.

After presenting a brief account of bilingual educational policy in Singapore she went on to describe the bilingual educational role of the Language Centre at 
Nanyang University. She considered that the needs of the student had to be the focal point of the English language programme, which should take account of the observed present and future needs of the student as well as his perceived needs.

The first consideration, said Ramish, was language as a tool for effective communication. Remedial language teaching meant correcting only those mistakes and shortcomings which interfered with communication and which could be corrected within the time available. Attention also had to be given to concept formation, she added. Too little was known, she said, about language learning, the development of thought and language in the child, and the effects of education in two or more languages.

Starting from Lambert's distinction between instrumental and integrative orientation in second language learning, the latter having been shown by Lambert to be the more successful, Ramish said she believed there was in a place like Singapore the dilemma of choosing between a less effective instrumental orientation in English without reference to Western culture, and a more effective but inherently more dangerous integrative motivation. She thought the dilemma was not as great as it might seem, inasmuch as English was no longer the language of any particular nation or ethnic group, and in that language, a living changing thing, was able to adapt itself to new environments and situations. English as a second language in Singapore was integrative, Ramish suggested, at least to the extent that it was a marker of membership of a social group whose linguistic capahilifies marked them as successful in their careers, culturally broad, and free from ethnic-diserimination.

Gail S. Fu's paper, which followed, made it apparent that English language teaching at tertiary level in Hong Kong had much in common with that of Singapore.

The presence or lack of motivation, said $\mathrm{Fu}$, were especially important in the Chinese University of Hong Kong, where she teaches. She suggested various ways of kindling motivation, and recommended that students be exposed to a language environment which was non-threatening, thought-provoking, and congenial. Students had to be-made to feel comfortable with their bilingual state and feel assured that their own culture and language, Chinese, was not at risk. In this way both their languages would be used more productively and without conflict.

Next came a discussion by Peter Barnes of one growing segment of the teaching of English as a Second Language, which has many implications for bilingual education - namely, English for Science and Technology (EST). He confined himself however to tertiary education in Hong Kong, and in particular to the fast-expanding Hong Kong Poly technic.

There were many serious difficulties in the way of EST Barnes explained. Among these was the overriding importance, not simply auxiliary status, of the ELT function, which would determine to a large extent a student's future career. There was also a difference between the teacher's predictions of the student's likely career, and the student's own prediction. An EST course had to take account of three things: the student's previously acquired English, the English the student needs for his particular curriculum, and the use he is likely to make of English in his career. A linear, structurally graded syllabus had, in his opinion, to be ruled out. 
In his experience Barnes said he had found the functional-notional approach the best. Yet EST introduced restraints. Topics needed to be not specific to the student's parent discipline, though at the same time they had to lend themselves to the kind and function of English being taught, and had to be intrinsically interesting to the student. There was in addition the temptation to overload teaching material with a surfeit of exponents of the function being taught, especially grammatical and lexical. Valid and reliable tests had yet to be devised.

Finally, Barnes called for a pooling of EST experience, resources and development among South East Asian countries.

This would have been followed by Tang Ting-chi's paper 'A Contrastive Approach to Bilingual Education,' but for reasons of a non-personal nature he was prevented from attending the Symposium.

Tang discusses, in detail, some applications of contrastive analysis to the teaching of English to students whose mother tongue is Mandarin. He believes that contrastive analysis is of positive value in bilingual education. In this way the replacement of monotonous pattern drilling would not mean a return to the grammartranslation method as it once was, but would take the learner into a new form of learning which would take account of cognitive learning, contrastive analysis, and translation as a method of applying it.

The last paper of this particular panel was read by Cheung Yat-sing,who spoke about interference between languages in contact.

The problem in Hong Kong was greatest, he believed, in written Chinese, which was exposed to interference both from Cantonese, at an informal level, and English, in more formal domains. He identified three different levels of syntactic interference in written Chinese, and graded them in terms of acceptability. The structural similarity between donor language and recipient language was considered as a function of syntactic interference.

Cheung also made reference to what he considered to be the possible applications of such an approach in the teaching of written Chinese at more senior levels in Hong Kong.

In the Open Discussion to the panel which followed Chan Che-sing raised several problems arising from the use of Cantonese in Hong Kong, including a tripartite relationship between Cantonese, Modern Standard Chinese, and Classical Chinese, which is still used in certain domains in Hong Kong. He also touched upon the type and degree of interference separately from English and Japanese.

Cheung replied to some of these points, amongst other things claiming that deletion and anaphora in local Chinese usage, though subject to interference from English, were nevertheless strictly limited in their operation by Chinese syntactic structure.

Other participants turned the discussion towards linguistic tolerance, claiming in turn that Hong Kong Chinese did naturally possess its own peculiarities, 
and that people were over-sensitive about dialectal and usage difference, looking for an theal of purity which, it was claimed, did not exist.

Barnes went on to warn against prescriptivism, which had nothing to do with the structures imposed upon learner and user. Godwin briefly extended this point to the teaching of English where, again, the teacher was faced with the application of norms. Hashimoto said that prescriptivism was also a problem in Japanese. Once Western terms and concepts were borrowed they took on a linguistic life of their own within Japanese.

Lord pointed out that both Hong Kong English and Hong Kong Chinese were, separately and together, tending to diverge as 'languages' from their parent stock. Prescriptivism, he said, would not affect this trend.

At this point participants recessed.

The first session of the next day began with the Panel on Bilingual Education and Curriculum Development in Primary and Kindergarten Education.

The first speaker, Sophie Hsia, painted a bleak picture of primary education in Hong Kong, both as a teacher and a teacher trainer. She singled out what she considered to be the limiting factors.

The first of these, she said,was environment. Classes were conducted in a formal atmosphere, and conventional behaviour was expected from schoolchild and teacher alike. The second factor, she claimed, was motivation. Many children in primary schools had little hope of entry into secondary school, and many of these who gained a secondary school place by competition could not afford to remain at school.

The speaker doubted whether there was any place for English in the primary school curriculum. The teachers themselves could not in most cases serve as adequate models. There was the danger of perpetuating a fossilized 'interlanguage', with no possibility of interaction.

Finally Hsia wondered whether the forthcoming abolition of the Secondary School Entrance Examination did not call for a reconsideration of objectives in primary education, and whether the adoption by a number of schools (38 in 1976) of an integrated curriculum should not also point towards a review of the separate teaching of English in the primary curriculum.

Next followed a paper by Szeto Wah, in which the emphasis was upon the unequal balance, in his opinion, between Chinese and English in Hong Kong primary education. He claimed not only that was English badly taught, but that the potential of Chinese as the mother tongue was inadequately exploited.

Szeto was pessimistic about recent changes in the examination system, in particular the abolition of the Secondary School Entrance Examination. This, he claimed, would only postpone the harsh selection exercise from Primary 6 to Form 3 of the secondary school, inasmuch as only forty per cent of students would be able to continue beyond Form 3. Assessment and selection for education beyond the primary level 
had presented serious problems in the past, as there has been no test of listening or speaking in English, but only old-fashioned grammar-style written tests, and uncreative tests in writing skills.

The speaker stressed that what was needed in the primary curriculum was a more even development of linguistic and communicative competence in both Chinese and English.

The third speaker on the panel was Stella Chan, whose view of the role of bulingual education in the primary school differed quite markedly from that of the first speaker.

Chan believed that the earlier English language was introduced into the primary school curriculum the better. A properly integrated primary bilingual curriculum was a means of advancing a child's education and his personality development as a whole, and was more than a mere acquiring of the elementary stages of a second language. Bilingual education would also, she thought, develop the social awareness and responsiveness of the child; but, again, only if the curriculum was well planned and the educational environment favorable.

In the discussion that followed Christopher de Linde spoke of the barbarism of the Hong Kong educational system, which treated children as potential dropouts. He blamed social attitudes for this. Other speakers thought that inequality of income was the cause. The remainder of the discussion centred around the place of English (as a second language) and, more widely, bilingual education in the primary school curriculum.

Arthur Hinton, speaking more widely about both primary and secondary education in Hong Kong, pointed out that there was no simple dichotomy between English-medium and Chinese-medium schools, but that at least four kinds of system could be observed in practice: (i) teaching and textbooks all in English, but scope of teacherpupil interaction highly restricted; (ii) English used in the main, with English textbooks. Teacher starts interactions in English, but pupils' responses in Cantonese; (iii) Language of instruction Chinese, but textbooks in English. Teacher spends some time translating the English texts back into Chinese; (iv) In Chinese middle schools, teaching in Chinese, using Chinese textbooks. Situations varied. In some classes discussion is lively, but in others the atmosphere is formal. This, the speaker said, compared interestingly with Singapore, where some part of the curriculum of Chinese-middle-sehoots-is-condtet splely in English. In Hong Kong the situation was the reverse.

Kvan thought that more attention should be given to the learningsituation in its totality. English could not, he implied, be viewed separately from Chinese, and English had tơ be taught within the context of Chinese, since defective learning in the latter was bound to result in poor learning in the former.

Ramish claimed that in Singapore increased exposure in the second language had resulted in a decrease in standards in both the first and second school languages.

The Panel which followed considered Bilingual Education and Curriculum Development in Secondary Education. There were three speakers, all from Hong Kong. 
After presenting a few facts about secondary education in Hong Kong the first speaker, Therese Leung, went on to compare secondary education in the Englishmedium 'Anglo-Chinese' schools and the Chinese-medium Chinese middle schools. She said that few secondary school-leavers could be considered anywhere near bilingual and stressed that the standard of English of the lower achievers was very poor. She ascribed the latter to inadequate exposure to the language, as English is not normally used in social contexts; and to lack of motivation on the part of the learner. She suggested various means by which some improvement could be achieved.

Leung emphasized that English was not competing with or undermining Chinese, but that proficiency in one language usually contributed to proficiency in the other. Nevertheless, motivation remained low. Perhaps this had something to do, she thought, with the teacher's lack of confidence ard slavery to the textbook and syllabus. There was also a need to make the English curriculum more practical and utilitarian.

Which was more important, the asked: for a child to be adequately bilingual or for notional standards of linguistic purity to be upheld?

Following this, Fung Yee-wang spoke about problems of implementing thoroughgoing bilingual education in Hong Kong.

He referred to Fishman's models of bilingualism and reviewed the various causes to which bilingualism might be attributed. After this, he reviewed education in Hong Kong, primary as well as secondary. He mentioned that students in Chinesemedium secondary schools had higher dropout rates than English-medium secondary schools. In the former more than half the students, he claimed, dropped out before finishing Form 5. Some students transferred_to English-medium schools in the hope of securing better careers.

Fung then went on briefly to apply Fishman's models to Hong Kong. After this he reviewed what he considered to be the various factors affecting bilingualism in Hong Kong, especially what he called the 'psychological' factors.

He concluded by stating that there were two questions to be resolved, as far as education in Hong Kong was concerned: (i) What attitude should educators and others adopt in promoting bilingual education? (ii) What should be the proper relationship between Chinese and English in bilingual education in Hong Kong?

The third and last speaker, Hinton, began by reiterating what he had said in the discussion at the end of the preceding Panel session, although in more detail.

He also went on to say that motivation was not automatically created when a public examination was around the corner. On the contrary, as a teacher trainer, he had observed that motivation depended most heavily on the teacher, who himself in some cases could be one personality to one group of pupils and a different personality altogether to another group.

Hinton said that he had also observed English lessons being conducted in Chinese-medium schools, where the response from the pupils was better than in com- 
parable situations in English-medium schools. There was however a vicious circle, to the extent that best teachers of English tended to obtain posts in English-medium schools, leaving by and large only the weaker teachers for the Chinese-medium schools, in which exposure to English was necessarily lower than in English-medium schools.

In the discussion that followed Hinton spoke of the gap in Hong Kong English-medium secondary schools between a particular phase in the English language syllabus and the subject materials a pupil might be expected to read in that language.

Kvan felt that earlier discussion had centred excessively upon English, and insufficiently on Chinese. He called for a bilingual educational policy in Hong Kong which would incorporate written Cantonese as well as spoken Cantonese, Modern Standard (written) Chinese, and spoken and written English.

Ramish said that in Singapore, where English is considered the second language, it is ranked two years below the first language in standard. But emphasis on increased exposure to two dafiguages had resulted in a decline in proficiency in both languages.

Assessment.

The afternoon session of the third day was devoted to Testing and

Jimmy Chan opened the session with a discussion of the problem of psychological testing in two languages, with special reference to Chinese and English in Hong Kong.

He began by saying that testing specialists are often at a loss to know to what extent and in what ways bilingualism interferes with the results of psychological tests devised for language situations of other countries.

Chan went on to describe an experiment which set out to compare Primary 6 pupils' performance on equivalent tests in Chinese and English. Though the words used in either language fell within the vocabularies of the children tested, performances on the different tests were significantly different. In the verbal reasoning tests, pupils on average performed significantly better when the test was in Chinese. Even though, overall, there was no significant difference on the numerical test, subjects performed better in the test using Chinese instructions when the rubric was lengthy.

He said that the results confirmed findings elsewhere that a child may be sufficiently bilingual for ordinary purposes and for attending an English-medium school, but he might still be handicapped when undergoing verbal tests in his second language. Chan finished by emphasizing that, in Hong Kong, Chinese should be the language used in all testing.

Lee Lai-min followed this with some useful facts and data on the bilingual versions of the Hong Kong Certificate of Education Examination, which is taken upon completion of Form 5, and on the controls established for ensuring equivalence of standard and replication of test items between the Chinese and the English versions of the various examination papers. 
He reported that, on common items in the multiple-choice papers of Syllabus A and B English language, Chinese-medium school candidates did less well than English-medium candidates. More interestingly, performance in Chinese language for the two categories of candidate, was quite similar. Only in Chinese Literature was there a significant difference, Lee said.

In the disscussion which followed, de Linde, the discussant, drew attention to the feed back effect of testing on education in Hong Kong which, he said, was much greater and more oppressive than elsewhere, because of social competitiveness and economic disparities. He went on to claim that techniques for testing and measuring ability to use a language were nowhere very advanced. This was, he said, particularly true for 'oracy', especially as far as Chinese was concerned.

The general discussion which ensued concentrated on the role of Modern Standard Chinese and Pütōnghuà in Hong Kong, and on the more general question of testing. In connection with the papers delivered during the session, Ho wondered whether it could be assumed that items thought to be equivalent in two languages were in fact equivalent. Secondly, Ho thought that the examination system itself, as outlined by Lee, guaranteed results which were predictable.

The final Panel Session of the Symposium, concerned with the Chinese curriculum in a bilingual context, began with a paper given by Prapin Manomaivibool on the teaching of Chinese in Thailand. This was a factual report of the vicissitudes of the teaching of Chinese in Thai schools and higher education over the past three decades. Manomaivibool pointed out that, although the demand for Chinese remained high, resources and trained teachers were not always available.

This was followed by paper on the teaching of Chinese in Japan by Yosunori Ohkochi. He pointed out that, in Japan, China is not a 'foreign country' in the same way as all other countries. He spoke of the increased interest in the modern Chinese language, over and above the more traditional interest in Classical Chinese, that had taken place since World War II. Though English remained the first foreign language, Chinese was now the second foreign language in most Japanese universities.

The third paper was given by Lo Wai-luen. As a concerned and experienced Hong Kong teacher of Chinese she said she was concerned with the dedine of the standard of Chinese. Whis was, she believed, partly due to the attractions of English, and also to its use as the medium of instruction in Anglo-Chinese schools. But the decline was also to be ascribed to the irrelevance of the Chinese syllabus, where the concentration was on Classical Chinese. Despite low morale among Chinese teachers, it was especially important for them to be in the forefront of a campaign for better Chinese, to solve the problem of linguistic interference (from English and Japanese) and to cultivate a sense of responsibility for the teaching of the mother tongue. It was not an 'anti-English' campaign that was needed, but one that would integrate the mother tongue and secondlanguage needs of the rising generation.

The last speaker was Mak Sik-hon, who provided some information about the evolution of the Chinese curriculum in Hong Kong education. Exposure to the Chinese language in the curricular situation was, he pointed out, restricted to the written language, as the spoken language was considered too impure to be taught. The total 
amount of exposure to Chinese was further reduced by the demands of the English language curriculum. He pointed to the need for teaching the practical and more direct uses of Chinese, as opposed to the outmoded formal styles. There was also a need for a wider range of reading materials to be covered in the classroom, especially contemporary materials.

Finally, Mak thought that the ratio of English to Chinese in many Hong Kong schools was heavily biased towards English. He did not think normal bilingual education was possible without this bias being corrected. He pointed to the need for curriculum planning, a kind that would reflect the needs of society and take account of what was considered to be needed in the opinion of representative members of the public.

Hashimoto, the discussant, highlighted what he considered to be a need for contrastive linguistic analysis in the teaching of second languages in relation to the mother tongue. He also implied that much more had to be known about the brain and how it functioned in relation to language learning, language use, and language selection. There was a greater or lesser learning load imposed on the brain by any system, and we ought to learn more about this, Hashimoto said. His remarks indicated that high priority should be given to neurolinguistic and psycholinguistic research, especially in the areas of literacy, and reading performance. 
SELECTED PAPERS 


\title{
HOW BILINGUAL?
}

\author{
Kenneth Topley
}

I am told that communication is a vital function in the world, and I have to agree with that. That language is the principal agent for communication I must accept. That languages reflect culture I agree. That languages have family resemblances to one another in some cases, and in other cases not, I accept. And, because of history, some countries and territories use more than one language within their boundaries. This is all terribly obvious. After all, is there any country which is truly monolingual? Some countries almost are. Certainly, in education, monolingualism would be very convenient, I think. It would be tidy at least. But it may not be ideal from every point of view, because monolingualism can conceal problems which ultimately have got to be met. Monolingual policies can paper over cultural differences but, eventually, cracks appear, and godfathers and other relatives emerge from them. I mean, if you see a film like The Godfather or read that book, what is really striking is that everybody in the story has had the same education in American schools, which serves to conceal the Sicilian community crouched in the middle of New York.

It is also obvious that bilingual situations are educationally inconvenient; though they do reflect certain cultural realities. So that a determined march toward monolingual education is not necessarily the best way to good communication. In any case you sometimes need to communicate beyond your boundaries. It is then that monolingualism can be a distinct disadvantage. The experience of different languages and, therefore, different cultures is not available in a useful form. So there could be some advantage in bilingual situations and, therefore, in bilingual education though it's still very hard work. (As the topic of the Symposium is Bilingual Education, I don't have to talk about multilingual education).

Bilingual situations are obviously of many kinds and I don't have the knowledge even to attempt the crudest taxonomy. I have a rough idea what happens in the Netherlands or Scandinavia, but I know nothing about South America. Perhaps some taxonomy of language situations may emerge from this seminar. Aims in bilingual education must relate, I think, to the linguistic situation (who speaks what and for what purposes), and should therefore reflect the linguistic aims of the society. So there are many possibilities, and to state aims or devise strategies requires a great deal of knowledge of a local situation. Moreover, good, useful, international generalizations are going to be very hard to make. I'll try one: 'There can be no such thing as full bilingual achievement. Therefore the aims of bilingual education must be limited aims.' Well, I'll start with 'limited by what?' and see what 'limited to what?' would mean. Bilingual education is obviously limited by resources, features of the specific linguistic map, and the motivation of the clientele. Who is going to teach it? How much does the learner want to learn, and for what purpose? How hungry is he? I tend to believe the last is very important - the motivation of the clientele. And I think it must be limited to what can be achieved without life-time linguistic dedication to achievement. I cannot imagine a society where

Mr. Topley is Director of Education, Education Department, Hong Kong. 
people spend all their time trying to learn languages. So, I will risk one more generalization - rather different - that one shouldn't expect too much of too many. If that phrase sounds familiar, I'm not surprised. It really follows indirectly (this 'not expecting too much of too many') from my dismissal of 'full' bilingualism as impossible, and 'near' bilingualism as implausible.

It will not surprise you if I say that stating aims for bilingual education may be difficult, but sticking to the aims will be harder still. The higher the aims as to standard and coverage, the greater the uncertainty about the achievement. So, I believe there is something positive to be said for setting modest initial aims, for only then will it be easier to check what progress is being made. Furthermore, you can avoid chaos and uncharted waste of resources. Certainly, in Hong Kong we are not satisfied with our linguistic achievements. A few achieve near bilingualism, and a fair number achieve a tolerable standard in two languages. More attempt this without success, and others forget through lack of practice. Certainly we would welcome any illumination on how to improve matters. On the matter of practice, one of the most alarming linguistic experiences in my life was when I went to see my aunt in France when she was 91 , and had lived for 70 years in France. She was a perfectly normal English woman. When I saw her at 91 , yes, she could speak French badly, but she had completely forgotten English. And that put the wind up me somehow, I don't know why. I think it's because we all have this thing about the mother tongue. If you lose it, it's something sacred that you've lost.

Having made some cautious commendatory remarks about limited aims, I feel faintly gloomy about the vision of eager students undergoing special immersion courses designed to develop within a limited period of time linguistic skills for, say, textile negotiations. What has happened to the noble vision of interrational understanding with which we all set out? I will say one thing about that noble vision which is slightly against it and therefore argues for our class of budding textile negotiators. How many people really want to learn two languages well, and are therefore prepared to do what is necessary to learn them? I'd like to be able to discuss politics in French and catch all the nuances. Why don't I do something about it? Answer: I am not prepared to make the sacrifices and adjustments. That is why. Do I really want to think like a Frenchman and gain a new soul, or do I just want to appear to, and will that satisfy people listening to me? Or even satisfy me. At this point I'll throw in my last two anecdotes.

There is a very good detective story by Wilkie Collins called The Moonstone. It is the first detective story ever written, and perhaps the best, as they say. In it, the suspect is a young man who speaks both French and English, and he is suspected because he has these two personalities. There has to be something funny about someone who can speak two languages. There's also a passage in Somerset Maugham's Summing $U p$, where he seems to say that there is only one other language worth learning (apart from your own), and that is French, and even that you shouldn't learn too well, otherwise you might be taken for a diplomat. (I don't imagine you would be taken for an academic.) So, if you are too good at languages, there may be something funny about you.

I have a feeling that limited aims in bilingual education are unavoidable Can you tell me how in such a situation we can avoid the drab and the ignoble? 


\title{
B. Bilingualism in Perspective
}

\section{BILINGUALISM UNDER PRESSURE}

\author{
Robert Lord
}

As the previous speaker has already pointed out, bilingual education is an enormously complicated issue. I am interested myself in one particular class of bilingual speakers, and would therefore propose a division of bilinguals into three classes.

Firstly there are those who could be called 'natural' bilinguals; that is, speakers who have grown up in a mixed language community without undue strain and have developed for most practical purposes the language skills they need. These I am interested in as a linguist, but they are not of primary concern to this Symposium.) The second group, to which the previous speaker wás perhaps alluding, consists of bilinguals like myself: bilinguals by choice, bilinguals by virtue of their more or less limited command of at least one foreign tongue. In ideal terms these bilinguals acquire their language or languages for special purposes (even if they are not always consciously aware what these purposes might be) and stop learning (again not always consciously) when their goals have been achieved. If they are adult they usually have a fair notion of what they might be letting themeselves in for, and know roughly, at any stage, whether to terminate, suspend, or prolong their endeavours. The keynote here is that the learner is, within limits, in control of the situation in which he finds himself. But, I believe, it is my third group of bilinguals that this Symposium, in the main, has to do with. These are the bilinguals willy-nilly; those who have no choice but to be bilingual. They are born, brought up, or are in later life 'acculturated' into socio-economic, cultural, and sometimes political environments which determine the individual's kind and degree of bilingualism, and may ultimately affect his sense of identity. As Blackwhite, the black writer in V.S. Naipaul's story A Flag on the Island, says: 'I begin to feel that what is wrong with my books is not me, but the language I use. You know, in English, black is a damn bad word. You talk of a black deed. How then can I write in this language?' (p. 182)

The third class - the 'bilinguals under pressure' - may possess certain affinities with the 'natural' bilinguals. In the latter case bilingualism is comparatively unproblematic; whereas in the former the natural learning process has been interfered with at intolerable levels, and as a result is transformed into an artificial process. There exists no sharp division between the two classes, however, and a natural bilingual can easily find himself a 'bilingual under pressure' by a slight shift in the social, economic and cultural forces that surround him.

We are talking about a very considerable number - millions, in fact - of human beings who become bilinguals on account of pressures exerted by the community in which they live, or perhaps even from abroad. They become bilinguals not in the normal course of things alone, but as a result of factors imposed upon them by the out-

Robert Lord is Professor of Applied Linguistics and Director of the Language Centre at the University of Hong Kong. 
sider, by alien, and alienating, pressures. I would therefore like to say a few words about these pressures. It is not my intention to produce a complete analysis. I want simply to single out three of the most important factors, which are nevertheless interrelated and overlap with each other.

The first type of pressure is economic. In order to achieve economic viability and mobility, an economic climate in which to prosper, an individual in a particular society may find himself obliged to learn his second language, or dialect, rather well sometimes exceedingly well. And there may be a few places dotted around the world in which a bilingual speaker is required to learn his second language better than his mother tongue (or dialect). In using the word 'better' in this context I am not thinking so much of fluency or communicativeness, but of something which relates to Bernstein's public language and elaborated code. (1971; especially chaps. 2 and 9)

The second category of pressures might, even more vaguely, be identified as the educational demands made by a particular community. In this context we may ask ourselves such a question as : Is social opportunity linked with education? And if the answer is yes, we should ask yet another question: Are particular educational goals generated by a wider socio-economic framework beyond and outside the community? If the answer to the latter question is also in the affirmative, then we can expect that the need to perform well and with sophistication in the second (or even the third) language may be all-important, and might even eclipse the prerogatives of the native tongue. Chris Searle (1972) has written eloquently about the ways in which, even after the end of British colonialism in the Caribbean, London still rules West Indian education through her examinations, textbooks and literary standards. This situation will not impose excessive strain if education is within the reach of only a tiny minority, an elite. Good teaching by (on the whole) enlightened teachers in favorable teaching environments can maintain the desired illusion up to a point. But when education, and particularly higher education, is placed within the grasp of the many, and when everywhere today education has become directly linked with social opportunity, social prestige, economic success, and so forth, we can only begin to calculate the strains imposed on the learner.

Lastly, we come to what I would call the cultural pressures; that is, pressures imposed by a culture. I use the indefinite article before the term 'culture' because I do not means culture with a capital $\mathrm{C}$ but culture in the sense adopted by social anthropologists. Cultural pressures, of varying sorts and degrees of intensity, are of course felt by the individual at every step he takes; first from the crib, then from the home, after that from school, and so on. (There is almost nothing a person does in his social life (and sometimes even in his personal life) through which these pressures are not felt. And when the pull of a particular culture and all its myth (I'm using myth in the sense employed by Roland Barthes (1972) and others), magic, and even a promise of salvation (the other direction from alienation), then language becomes but one dimension of all this, and exerts its own tremendous pull.

I do not intend to go on at tedious length, but I do wish to say that, if these three types of pressure are examined in relation to Hong Kong, then we shall discover that we are faced with a highly critical situation on all three counts. We shall see that the pressures exerted on schoolchild and advanced learner alike are extremely great. All our skill and care is needed to ensure that approaches to education, at every level in the educational system - teacher, parent, planner, educationist - are changed and improved; not too quickly, but also not too slowly. 
In conclusion, I would like to focus upon the unique situation we find in Hong Kong. On the one hand, we are constantly coming up against the word 'westernization'. The pull of the wider consumer world, all its glitter, attraction, and empty promises; the cultural sway of 'the West' is powerful and manifests itself of course not exclusively through the English language. But we probably have to reckon also with the probable impact of English, at cultural and semantic levels, on Cantonese and on the Chinese language in general in Hong Kong. On the other hand, we are able to observe a totally different and opposite cultural pull. I am referring to the weight of Chinese tradition, which in Hong Kong is a mixed and ambiguous one, with strata going right back at least to the Ching Dynasty. Students may be told they don't write Chinese properly; that it is full of mistakes and deviations. They do not know where to look for any norm. Who and where are the guardians of these norms? There is in some cases genuine bafflement. And when our student visits China he finds that even his spoken Chinese is not adequate for all purposes either. In Hong Kong to say 'I am Chinese' is to make a statement of a very complicated sort. On occasion, when it is said, it means: 'I seem to be losing my identity. Tell me who and what I am.'

Here then, on our doorstep, is a rare opportunity for bilingual education of a very particular kind, tailor-made for the particular situation, learning from problems experienced elsewhere, and based on a determination to serve the interests of international trade, communications and finance only secondarily, and the ordinary people themselves first. 


\title{
BILINGUAL EDUCATION:A SOCIO-PSYCHOLOGICAL PERSPECTIVE
}

\author{
Eric Kvan
}

When I received the honour of an invitation to participate in this ceremonial occasion, I expected that my presence in this group would be more symbolic than real; as it were, a declaration of the fact that, even if it was possible at one time, it is no longer possible to discuss languages, let alone education, without the participation of the people who are working in the fields of the social sciences: in psychology and sociology. In this context it is of course symptomatic that the Language Centre in the University of Hong Kong has found it necessary to establish a post for a sociolinguist, and is hopeful of establishing a course in psycholinguistics in co-operation with the Department of Psychology. It has come to be realized that we cannot any longer discuss language in isolation or, rather, we have become conscious of the fact that over the last century or two we have indeed not discussed language in isolation. When we have been talking about language we have always addressed ourselves to many more aspects of human activity than has been apparent on the surface of things. It is now obvious to us, in a manner in which it was never obvious before, that in order to have linguistics we must have sociolinguistics, and in order to have sociolinguistics we must have psycholinguistics. Indeed, in talking about sociology and psychology in connection with language, we find it impossible to distinguish between the two disciplines. Another example of the emergence of the new discipline, which is replacing the old models of psychology and sociology, is the new socio-psychology of which the study of language in all its aspects is an essential part.

In this context (representing the social dimension and capable of doing it singlehanded because of this new synthesis) I expected that my most useful contribution, within the limited span of time available, would be to point to the more underlying, wider issues than those immediately given in the title of this meeting and of our symposium. There are of course so many themes one would like to bring up at as early a stage of the proceedings as possible. I was glad to hear some of these many themes which I hope to bring before you being mentioned already by our first speakers this morning: the two Hong Kong educationalists par excellence, the Director of Education and the Professor of Education. This being the case, perhaps I could most profitably spend much of my allotted time on contradicting the earlier two speakers, so that we could have a truly dialectic situation from the very beginning of this symposium.

Now, it is of course possible, having simultaneously listened to the first two speakers and busily occupied my thoughts with what I could possibly say, that I did not really 'hear' what the speakers were saying. As I heard it, they were saying that the linguistic situation of people in these parts of Asia was something unique and different and separate from other aspects of their lives. The speakers seemed to be treating the question of language, and the tension between the languages, as something unique in our human experience. For the purpose of education and within the framework of the title of our symposium on Bilingual Education I think it extremely important not to take this point of view, not to make this our point of departure. Mr. Kvan obtained his Cand. Theology from the University of Copenhagen and is currently Head of
the Department of Psychology at the University of Hong Kong. 
Rather, the bilingual situation is just one example out of many, in the lives of each one of us, of having to learn patterns of action which conflict with one another. We frequently find we have to move very rapidly from one pattern to a completely different one. To use a different language, to say it in a different way, urban life presents us with many more stages than village society. In our daily existence we are moving very rapidly between these stages on which we are acting. (As the Chinese proverb has it, I believe, 'it is very easy to get on to the stage' - implying that it is very difficult to get off it again. As we all know, to close a conversation or a speech is extremely difficult; it is only in church we have the convention of an 'Amen' to signify to everybody that we have finished.) We move on to stages, we are forced on to stages and then we try to get off them again. In this situation the use of language is essential and inevitable. But it is only a part of the total pattern of actions which we are using and in which we are embedded at any one moment of time.

Of course, I cannot disagree with the previous speakers when they say that language has a unique and central position amongst all these patterns of action. The change from stage to stage is very often made manifest and effected by the very shifts in the language which we are using. In talking about language we must obviously not talk about language in the conventional sense only: English, Chinese, Cantonese and so on. We must also talk about language in the many other senses of the word which linguists have developed. Sometimes they do not call them languages, I think, but registers. On my visits to the sixth floor of the Library Building where the Language Centre is situated it took me a long time to really catch on to this, but I think that this is what they are saying. Where I would say language they would often say register. You may consider it a terminological squabble of little or no consequence, but I think it very helpful, at least from time to time, instead of talking of registers within a language, to talk about the several languages, one for each register - in the same way as I think it extremely helpful for us in Hong Kong to say that Cantonese is a language. Members of the Symposium may well get up in arms and protest: 'It is a dialect!' No, it is a language, a fully developed language, even if it has been reduced to writing in only the most perfunctory manner. And then it is the mother tongue for the great majority of the children in Hong Kong.

My reason for insisting upon talking about languages, wherever possible, is of course that I wish to stress and to make comprehensible, to myself and to others, the enormities of the shift which takes place when we move from one situation into another, from one stage to another and, therefore in all such situations, to stress the need for translation from one language into the other. All of us know about translation, and its difficulties, when we change from one language to another. None of us have any 'feel' for what the consequences are when you change from one register to another (unless of course you belong to the small group of people who play the organ, and even that analogy is not taking us to the real depth of the change involved). The need for translation, for interpretation and re-interpretation, is every bit as important between registers and dialects as it is between the major languages, where conventionally we would all agree that interpretation is necessary.

So we are all speaking many languages. We are all acting on many stages. What we are therefore inviting our pupils to do when they go through bilingual education is indeed to participate in major changes, but changes of an order and of a kind to which they are already accustomed in their daily lives. 
At this point it would perhaps be better if I returned to the original question I came prepared to address myself to this morning. With the Cerberus of a timekeeper watching, you need not fear that I only now begin my talk. Perhaps I can best do so by asking: Fundamentally, what can the socio-psychologist (the hybrid creature which I postulate) do, what can he contribute to our discussion? On the stage which the Chairman has outlined for us and to which our first speakers have already alluded, what can the next actor promise, what can he contribute to the dialogue which begins this morning, leading towards the very concrete considerations of bilingual education, motivation, syllabi and all the other topics, which you see on the programme for the following sessions?

I think the answer to this question does lie in the original quotation with which I had originally thought to preface my address this morning. It comes from the seminal work by Harré and Secord: The Explanation of Social Behaviour:

'Social behaviour is to be explained through the collection and analysis of personal and particular accounts. In general, social behaviour is the result of conscious self-monitoring of his performance by the person himself, in the course of which he contrives to assess the meaning of the social situation in which he finds himself, to choose among the various rules and conventions, and to act in accordance with his choice; correcting this choice as further aspects of the situation make themselves clear to him.'

Social behaviour is the result of a conscious self-monitoring of performance by the person himself. It could be exemplified by the way in which, at this moment, I am attempting to adapt my behaviour to the situation in which I find myself. One of the discomforts of the seat in which I am sitting at the moment is that I have only constructed the bare outline of the framework of the stage on which I am acting. I do not know how I am doing at all in this performance on this corner of the stage, and very little about how I am interacting with the other actors. I have already had to adapt myself to various aspects of the situation, like the other actors during the first few minutes of this morning's session.

As you will see, I have already made this kind of consideration the starting point for looking at our pupils. They are indeed engaged in a very skilled act when we first meet them. As professional educators we often find it unpalatable, and therefore difficult, to remember that formal education is a relatively unimportant part of our pupil's lives. Much education (in many ways the most important education) takes place before the insidious educator can lay fingers on the child. The real education, which begins at birth, is nearly complete before the child reaches school age, and continues during the greater part of the child's waking hours outside school. This sort of education contributes much more to the ability of the child to act on the various stages than the school ever will. If therefore you want to teach the child, you must do so within the totality of the registers, within the total assembly of languages, which the child has already developed. I think that this basic skill, the result of the child's progressive self-monitoring of his performance, should be taken extremely seriously.

To illustrate what I am talking about let me remind you how our pupils progress from Kindergarten to 小學 (PrimarySchool) to 中學 (Secondary School) to 大學 (University), and at the end of each stage going through a graduation ceremony( 畢業 ) to reach the next. There is here a unity of experience, of 學 (learning), different from the experience anywhere else in the world. Certainly very different 
from that part of the world where the concept of a university was first developed. Let me further remind you how our pupils at all stages refuse to be pupils only; how they understand the status of 學生 (student) in a manner very different from their contemporaries in Western Europe or North America. It is no full-time occupation. The Senate in this university has tried many times to impress upon the undergraduates that it should be a full-time occupation to be a student for the few short years they are here. Whatever we do, the students say 'no'; they vote with their feet and go out to work, taking parttime jobs outside, in the real world! In a large number of cases they do so not from financial but from social need. We, the teachers, are actors accing, interacting, with the students on that stage which is the university, but they look upon life in the university in a manner quite different from the way we are accustomed to a look at it. As a result, coming from other traditions, we perceive persons who try to adopt our styles and don our masks, and for brief moments act the parts we have assigneu to them. They have perhaps heard and read about these parts; yet, compared to students elsewhere in the world, they only act out very short-lived roles. We see them get off the stage and remove the mask as quickly as possible between each brief appearance, to move out on to the "real" stage within which the small stage is set. They do this in switching from one language to another (from English to Cantonese) in the middle of a sentence in a tutorial; and then back again for the benefit of the kweilo (foreigner) who (officially) does not understand anything but English.

If the teacher himself or herself has Cantonese as the mother tongue and

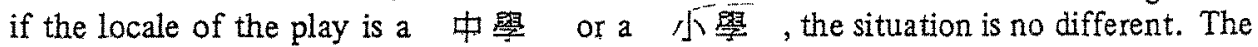
roles are equally formally designated, the teaching language equally different from the ordinary spoken language; and the occasional lapses into the 'real' vernacular to explain matters all go to emphasize the nature of the performance.

In short, from a socio-psychological point of view we are great complexity of stages within which the linguistic stage is only one. If we want to teach language, we must begin from the point at which our pupils are to be found, working within their kind of stagecraft. We must attempt to understand and acquire (or indeed recall from our own childhood) the immense skull which the children bring to bear on the classroom experience. In my view, this is a very profitable way of talking, profitable in a very proper sense of the word, of direct relevance to some of the most fundamental questions of Hong Kong schooling.

Why is it that children appear to learn so little in our language classes? This is one question which I think, we must all be asking ourselves. We are disapponted with the results when they get to University, and we try to remedy it. In fact the University acts as if a ten-week course can remedy what has not been done in ten yuars. I do not think this is an unfair way of formulating one of the ways in which we here are thinking about our own roles in the language-learning process. What is going wrong? Su very often we find that, if we compare the English of students who have come comparatively recently from other parts of China, their English seems to be better, even if they have learned English for quite a few years less than our own pupils and students. Why should that be?

For an answer to this question let us once again look inside the primary classroom at some of the other conventions which seem to rule performance. One of the strongest and most obvious conventions seems to be that the pupils are not expected, or expecting, to learn in the school situation. Teaching and learning have become dis- 
sociated. The teacher performs, frequently literally at the end of the classroom, as if he were acting consciously on stage, without much interaction with the pupils in the room. The pupls have a firm conviction, which is continuously reinforced by the teacher's behaviour: Teaching takes place at school, learning takes place at home. It is made quite clear to the pupils that their presence at school is unnecessary for learning. They go home to learn. When you then look at the situation from the linguist's point of view, you find that at home there are rarely sources of English information. The child brings home with him glimmerings of what has been going on around him at school, but he has_not really participated during those long school hours. The child has firmly learned that school is not an essential part of one's existence, but only a conventionally necessary part. With this background the pupils' behaviour at later stages becomes entirely understandable, and perhaps we then get an inkling of where our bilingual education goes wrong, where it should be altered, and how it should be remedied in the later stages. We shall not be able to make a significant contribution to their learning of language unless we acquire a deep respect for that which is so deeply rooted in the self-consciousness of the pupils, understand it and learn from it.

Within the short space of time available this morning it is not possible to carry the analysis beyond these few indications, barely touching upon the deeper structures underlying the obvious surface phenomena. We need a detailed description of the structures of the Chinese 'Tanguages' and of the English language, of the Chinese social structures and their English counterparts. I should have to bring in the whole galaxy of people who have been working on these lines, from von Humboldt to Whorf, and all their critics. We shall develop our descriptions in terms of stages and languages, and widen our understanding of what it is we are asking the students to do, from adopting a new set of muscle movements in the respiratory system to developing a deep empathy with people in distant parts.

We shall have to grasp the underlying cognitive structures of the learning set, of the self-understanding of our pupils, and build up a new reference model for their self-monitoring process; a model which seriously considers the pupils as inregral members of their family and society. One practical consequence of such an appraisal of the situation may well be a rejection of the one-sided emphasis on the oral approach, which is so effectively rejected by teachers and pupils alike, since it does not fit into the bifurcation of the educational process to which I have alluded above. Whether we shall be able to establish a different model for the self-monitoring process, which in some manner includes aspects of the information available in the classroom with regard to the oral skills, is a moot point.' Would the radio give us more direct access to the real learning situation of the student, to this solitude in the midst of the cacophony of noises which engulfs us all?

The questions are many, the answers few. The material with which we have to work is rich beyond description; richer than the material with which teachers have to work elsewhere in the world, because of the immense richness of the two languages involved in our bilingual situation, Cantonese and English, and because of the ingenuity and persistence of our pupils in constructing the stages on which our languages are unfolding themselves in their richness, meaningfulness and beauty. 


\title{
MOTIVATIONAL AND ENVIRONMENTAL FACTORS IN BILINGUAL EDUCATION
}

\author{
M. Alan Brimer
}

While I intend to talk about the topic announced I cannot help but reflect on what the previous speakers have said. I must begin by disagreeing to some extent with Mr. Kvan in his thesis, as I took it, that there is great similarity between the acquisition of registers and dialects and the acquisition of a foreign language. There are essential differences. The status of the first language we learn has particular importance. This arises because there is an almost indissoluble relationship between thought and language. The development of our knowledge of the world is conditioned in part by the character of the language in which we are reared. Of course it is bound up with the cultural context in which that language is acquired, but the nature of the language itself imposes certain constraints and certain boundaries.

Having said that, I would not dispute with him that the acquisition of any language must be understood in a social adaptive context. But there are problems that surround the bilingualism in one's life which are probably more acute than are implied in our adaptation to a particular social context where we need to acquire particular registers. I can try to instance this by describing just three conditions which I have encountered. The first is of a friend of mine who was born in Czechoslovakia and whose parents were German-speaking, although he was reared for the first few years mainly by a Czech speaking nurse. He acquired $\mathrm{Czech}$ from his nurse and this language was the medium for his dealing with domestic circumstances. At table he spoke German with his parents; and so, German became a language which dealt with formal situations. When he was old enough, he went to school in a French-medium school. So he learnt his French in the context of education. His adaptation to learning in a formal sense came through the medium of French. When his parents didn't want him to understand what they were saying, they used English. So he learnt English largely as a means of understanding the kind of things that adults didn't want him to know.

Of course what I am describing is social adaptation in the very broad sense in which Mr. Kvan has referred to it. Now what happens to someone who acquires his languages in what Mr. Topley and Professor Lord referred to earlier as natural contexts like this? These people develop their competences in languages and they extend them further, but their way of processing knowledge through the medium of each language is different, and it is true to say that in many cases they become actors within the languages they use; particularly when the roles of the languages are themselves extremely differentiated as in this case. When such people act, you can see them change. Their facial expressions change; their gestures change, as they move from one language context to another. This is very like the condition of adaptation to different social contexts, but the way in which the language mediates knowledge is itself very different from the condition in which we are dealing with the adaptation to registers in adult life.

Professor Brimer is Dean of the School of Education at the University of Hong Kong, and was formerly Head of the Research Unit in the School of Education in the University of Bristol. 
The second example is taken from my three years in Nigeria where I encountered a little girl who was the daughter of French parents and herself spoke only French up to the point where she started school in an English-medium school,at the age of five. She acquired English quite naturally in school, not because she was taught English in school, but because English was all around her and used by other children. She learned to read through the medium of English. At a later stage in her life, not very much later, by the age of eight, this particular school introduced children to French through the medium of English. This child, perfectly fluent in French, read French with an English accent and was very halting in her reading. She read English very much more fluently. Ultimately her adaptation to English education, or education through English, was such that she could not follow her education through a French school and had to be sent to a boarding school in England.

The third little anecdote relates to getting into a taxi in Paris going to UNESCO and the taxi driver saying to me 'Where do you want to go?' and my saying ' $\mathrm{La}$ Place de Fontenoy'. He said, 'You speak French then?' I explained my limitation and he said: 'Why is it that you can't speak French? I can speak English. How long have you spent studying French?' 'Something like six years,' I said. He said: 'Your French is very poor; my English I have acquired simply by talking to people in the taxi.' This is a not uncommon example of people who have acquired a language, for economic reasons perhaps, but certainly in particular social contexts where they had a motivation to learn that language. I have no doubt that his vocabulary was very limited,but the range of topics on which he could converse meaningfully was quite extensive.

We have looked at three situations where people were placed in different contexts in which the need to adapt was very considerable, but the kind of knowledge they gained, their way of being able to cope with the world was dependent on the nature of the language, on the cultural context and on the nature of the social interaction in which language learning occurred. Now, if we turn our attention to bilingual education which is the subject of our Symposium, I think that we should perhaps begin by recognizing what we know and then perhaps addressing ourselves to what we don't know. We know from fairly widespread experience that education through the medium of the weaker of two languages is damaging both to what is taught and to the weaker language. The evidence that John McNamara has presented (derived from Southern Ireland and from Canada) is very convincing, $I$ believe. We also know that no single method is a panacea for the teaching of a target language. Experience teaches us that,where a system attempts to promote one method, and believes that the method is happening, teachers are found to be using mixed me thods. No single method works infallibly. What happens is a function of the teacher and the particular children who are learning.

The next thing we know has already been referred to: to teach anything without motivational support is to degrade it to a level of inert knowledge. If we don't have the appropriate motivation to learn a language then it is likely to be degraded into artificiality, even if it is not an artificial language. Artificiality is transferred to the content of what is being taught. Fourthly, we know that language is not only a vehicle for thought or communication, but is itself part of thought, and that it has many objectives as many objectives as thought itself. Thus, the teaching of language must be related to objectives, objectives not merely of the language, but objectives of education. Next, and this has already been stressed, language is culturally and, I would add, politically linked, and cannot be treated as if it were inert. If we regard language simply as a body of competence, a body of skill to be acquired,then we mistake its nature. It is essentially linked 
in status both with the politics and culture of the language from which one starts, and the politics and culture of the language to which one directs oneself. Anyone who has had experience of education through the medium of French in West Africa will know that a sense of being educated through the language of a colonial power rankles very strongly in the minds of both children and teachers.

Next, the mastery of a second or foreign language is itself assisted by, if not totally dependent upon, mastering one's mother tongue. The ability we have, at the level of school, to acquire another language well, depends to a large extent upon how well we know our own language. Next, the age at which the acquisition of a target language commences is not so vital as the meaningfulness of the context in which the acquisition is vested. We used to think that to begin to learn another language as early as possible was desirable and, for that reason, while I was in West Africa one of the territory's leaders decided that he would introduce English as the medium of instruction at the age of five. That experiment was variously hailed as successful and disastrous. In my experience, it resulted in a totally artificial classroom situation with both teacher and pupils acting in a way which was quite irrelevant to any kind of life experience they had outside school. When we talk about the acquisition of a second language beyond the point at which it might be acquired within a socially natural context, then we must admit that the age at which one begins is not so vital as we once used to think. We can acquire other languages later in life; we don't have to do it as early as possible.

Next, we know that the ability to acquire a spoken language is not dependent upon more than a threshold of intellect. We don't need to select out those who are highly intelligent to acquire the language. It requires only a minimal level of intellectual competence, and so is within the grasp of the majority of a population. But to learn the spoken language requires, in addition, an ability to code the sounds of language, an ability which is differentiable from intellect itself and not all people are equally fitted in this way; so that the spoken language is more likely to present problems to a large number than the acquisition of a language in a written form. Lastly, we know that the ability to acquire competence in the written form of a language depends in some measure on the character of the written form of the language. We know here in Hong Kong that children learn to cope with a written language which is morphological in its nature, although some maintain that it has acquired phonological characteristics. This presents problems when such children turn to English, where spelling becomes vital; where the order in which letters appear in a word are keys to the way in which the word is pronounced and to its identity. Having learnt to cope with reading in one way makes it somewhat more difficult to begin coping in another.

Now, to finish, I want to pose certain questions: Questions which I think this Symposium might concern itself with. Firstly, one of the root problems of bilingual education: What conditions are necessary for the appropriate motivation of children to acquire a target language, when a meaningful environment is not mediated through that language? Mr. Kvan has referred to the fact that most language learning is seen as going on at home, and yet in Hong Kong homes there is no motivational support for English for the majority of children. We do need to know what the conditions are that can assist the motivation of children to acquire a target language in a meaningful way. Secondly, granted that at some stage of their education it may be necessary for 
children to follow their education in the medium of a foreign language, ought we to defer that stage as long as possible? Do we know enough to be able to say how long we can defer the education through the medium of a foreign language without losing out? Next, if it is possible to defer the foreign language medium until the secondary level, is it preferable to concentrate the acquisition in a short period, one or two years, or to distribute it over a number of years? This is a question to which Mr. Kvan referred.

Next, given the high noise pollution that sometimes accompanies learning in the more urban areas, and specifically in Hong Kong, by what means can the target spoken language be introduced with less distortion and distraction? One has only to go into classrooms in Hong Kong where English is being taught and used as the medium of instruction to realise the supreme difficulties under which children labour; where the only way in which the teacher can communicate with the children is through an amplification system such as this, but where it is virtually impossible for him to hear what the children are saying, unless he goes up to them. We do need to know by what means we can avoid this distortion and distraction of the language being used, whether Chinese or English in our case. Next, what are the strategies available to the student who is competent to follow instruction in the written form of a language, but not through the spoken form? We are well aware, here in Hong Kong University, that many of our students are more competent in the written form of the language than they are in the spoken form. Why? And if they are, what strategies of learning are available to them? If our intention is that they should learn something else, and language is incidental to our ultimate objectives, then by what means can these students be helped to develop appropriate strategies? Next, in what ways does enforced pursuit of education through the medium of a language in which both teacher and pupils are only partially competent in. hibit the formation of discussion skills among students? One of the things we notice particularly, both at secondary level and at tertiary level, is the difficulty that students and teachers encounter in entering into real dialogue. The time-lapse between hearing, understanding and being able to respond is quite considerable. This hesitation is not always attributable to the lack of skills in the language; sometimes it is the inhibition of discussion strategies at an earlier stage which holds them back. Professor Lord has spoken a good deal about this and has an interest in communication skills. There is only one last thing I would like to mention. After a quarter of a century at least of modern linguistic theory, modern linguistic analysis, and a much longer period of psychological analysis of language acquisition, we still lack an operationally sound theory of foreign language acquisition. Given this state of affairs, is it nevertheless possible to devise a workable strategy for language learning? Can we get at something which at least provides us with a sound operational strategy for approaching foreign language learning? 


\title{
SOME MACRO-SOCIOLOGICAL ISSUES IN MULTILINGUAL SOCIETIES
}

\author{
E. C. Y. Kuo
}

\section{The Sociological Approach to Bilingualism}

At the outset it is important to point out that, in this paper, following Weinreich (1953, p. 1), Haugen (1956, p.9) and Mackey (1968, p. 555), I make no distinction between bilingualism and multilingualism. Haugen justifies this usage by the assumption that essentially the problems involved in bilingualism do not seem to be different when a third or further language is added. In other words, multilingualism is merely a plural form of bilingualism. Throughout this paper, therefore, these two terms will be used in terchangeably.

A source of confusion in the concept of bilingualism comes from the fact that the term has been used to refer to the coexistence of two or more languages within geographical area a social group, or an individual's linguistic repertoire. Distinctions, therefore, should be made whether a specific reference is made to a bilingual society, a bilingual community, a bilingual family, or a bilingual individual. As a matter of fact, the relationships between the above concepts form an important area in the sociological study of bilingualism. In this particular paper my in terest is in the societies composed of linguistically heterogeneous populations. Such multilingual communities may or may not involve large numbers of bilingual individuals, although inter-group communication involving a lingua franca, which is an other tongue for at least one language group, seems inevitable.

Fraditionally, there are four major approaches to bilingualism - linguistic, educational, psychological, and sociological - each with different assumptions and theoretical foci. While the first three approaches enjoy long and fruitful academic traditions and are supported by an impressive amount of literature, the sociological approach is relatively new and as yet underdeveloped. This approach, however, is gaining popularity rapidly both in linguistics and sociology, evolving into a substantial area of sociolinguistics, or sociology of language as some sociologists prefer to call it. (See, for instance, Fishman. 1972a.)

In studying bilingualism, the sociologist of language is concerned with both the bilingual community and the bilingual individual. . On the micro level, he is interested in the choice of code by the bilinguals in different social domains involving different interlocutors. The focus is on the process of language behaviour in interpersonal relationships under situational constraints. Following basically the tradition of Guimperz, micro-sociological stu dies of language have been gaining popularity with recent development in ethno-methodology. Such a micro approach to language is similar to psycholinguistic research and is best described as social psychological study of language behaviour.

Dr. Kuo has a B.A. from the National Chengchi University in Taiwan, an M.A. from the University of Hawaii, and a Ph.D. from the University of Minnesota, all in Sociology. In recent years he has focused his research on the multilingual and multi-racial society in Singapore and is currently a lecturer in the Department of Sociology, University of Singapore. 


\section{STUDIES IN BILINGUAL EDUCATION}

This paper deals with a contrasting sociological study of language, the macro-sociological orientation. Unlike the micro-approach, the focus here is more on the bilingual community rather than the individual. The researcher strives to investigate and explain the characteristics of a bilingual community in relation to some social structural variables. Macro-sociological studies of bilingualism are exemplified by Fishman's study of ethnic language maintenance in the United States (Fishman et al. 1966) and Lieberson's study of linguistic diversity in Canada (1970).

Methodologically, macro-sociological studies rely heavily on the method of social survey to obtain quantitative data involving large segments of the population for statistical analysis. The measurement of linguistic variables such as language competence and language performance is typically based on self-report made by the respondents. The data is then correlated with other variables such as the social-political structure in the community or the social background (eg sex, race, religion, socio-conomic status) of the population involved.

Understandably, the problem of the relationship between self-reported language competence and actually observed or measured competence is questioned by both linguists and psycholinguists. Such limitations, however, are problems common to most social research using survey design. To some extent, such limitations in validity are compensated by the application of highly sophisticated statistical techniques for modelbuilding and hypothesis-testing, as can be found in some sociolinguistic studies published in American Sociological Review (for instance, Lieberson and Hansen. 1974; Angle. 1976) and American Journal of Sociology (Lieberson et al. 1975).

While this is no time to get into arguments on the merits and demerits of the use of aggregate survey data in sociolinguistic studies, it should be pointed out that the use of such data is necessitated by the focus of sociology of language on sociological variables at the macro level. Social cohesion, national identity, communicative integration, and social stratification would represent such variables.

\section{Macro-Sociological Issues of Bilingualism}

Language, as a system of codes, is essential in interpersonal, intragroup, or intergroup communication between individuals who share the same system of symbols. Finctionally, language also serves as a rallying point for group identity among those who speak the same mother tongue. Such feelings of language group identity, primordial as they may be, can be highly emotionally charged when contacts with members of other language groups are involved. At the same time, the relationship between language and cultural identity is so close that the learning of a language is often accompanied by a process of acculturation. Thus, while Lambert and his associates (1968) suggest that a distinction should be made between instrumental orientation and integrative orientation in second language learning, and Kelman (1971) points out the differences between instrumental attachment and sentimental attachment, similarly we can speak of language serving an instrumental function of communication and an integrative or emotional function of group solidarity.

Applying the concept of such functional dualism of language to the phenomenon of bilingualism, we see that a bilingual is a person equipped with extra facility to communicate with members of the other-tongue group. This improved ability to communicate and to establish contacts with a wider world is instrumental to occu- 
pational and economic advancement. Moreover, bilingual ability also leads to a better understanding and even a certain sentimental association with the culture represented by a second language. This is basically how Lambert and his associates at McGill University reach the conclusion that: 'An individual successfully acquiring a second language gradually adopts various aspects of behaviour which characterize members of another language-cultural group' (1968, p.473). Bilingualism therefore tends to lead to a lower level of ethnocentrism and greater social tolerance.

At the societal level, the coexistence of two or more language groups in a community generally implies the presence of certain communication gaps between people from different cultural-language backgrounds. The crucial problem then is how to maintain a minimal level of communicative integration so that the society as a whole can function smoothly. Economically, such communicative integration is necessary in the division of labour and efficient exchange of goods and services; socially and politically it is needed to maintain social cohesion and political stability.

Consequently, societal bilingualism imples the existence of barriers in communication which stem not only from language diversity but also from cultural differences in values, attitudes, etc. Since different language groups in a plural society tend to maintain a certain level of language group identity, societal bilingualism also implies a tendency towards intergroup competition or conflict. This also means that the development of a supra-ethnic national identity can be hindered by competing ethnic loyalties among a diversified population.

A closely related issue is the problem of social stratification and social mobility in relation to language competence and language diversity. For one thing, language group identity is almost always a stratifying factor in a multilingual society. A language group (often at the same time ethnically and culturally distinctive), for one reason or another, assumes a dominant position in economic status and social standing in the society; whereas other groups are in a subordinate position. While it is well known that even in a basically monolingual society the social background of a person can easily be betrayed by his tongue, it is obvious that the class stereotype of a language group and its speakers is much stronger and clear-cut in a multilingual society. Moreover, one language may be more instrumental than others in career advancement and social mobility. Consequently, in a multilingual society, all languages can perhaps be equal in law but never in actual practice. Some are bound to be more equal than others.

All the above issues are related to language policy, bilingual education being part of it. Political leaders in a multilingual society must look carefully into the language problem as a whole and formulate a language policy in such a way that social communication can be facilitated, social cohesion and political stability maintained, and national identity strengthened. To the extent that language policy itself is a political decision resulting from dynamic processes, both the process leading to the formulation of the policy and its possible social consequences deserve careful investigation by sociolinguists.

In the following, I will further elaborate on two major sociological issues in multilingual societies: communicative integration and national identity. The problem of language policy will be treated as an underlying factor common to both. Specific examples will be drawn from the Singapore society for illustration. 


\section{Communicative Integration}

Making one of the earliest theoretical expositions of the role of communication in national development, Deutsch $(1953,1966)$ suggests that language and literacy are important elements in social communication and mobilization, which are in turn basic measures of national development. He persuasively shows that communication is essential to the formation of a people, a community or a nationality, and that the degree of linguistic assimilation is indicative of communicative ability, which determines the level of national assimilation or differentiation. The problem of communicative integration moreover tends to be aggravated as economic and technological advancements force people of different backgrounds to come into constant contact with one another.

According to Deutsch (1966), linguistic and cultural assimilation in multiethnic states is a slow process that may involve decades and generations. -In contrast, growth in economy, technology, and societal structure (ie transportation and marketing systems) can be yery rapid. Deutsch sees a great danger in this differential growth pattern in national development. In his own words:

'Much of this economic or technological development may force
people into new and inescapable contacts with each other as workers,
customers, and neighbors - contacts far narrower, perhaps, than the
range of human relations that can be communicated within one cul-
ture; but contacts far wider than the relations which can be commu-
nicated in the absence of a common culture to outsiders. Linguis-
tically and culturally, then, members of each group are outsiders for
the other. Yet technological and economic processes are forcing
them together, into acute recognition of their differences and their
common, mutual experience of strangeness, and more conspicuous
differentiation and conflict may result.' (1966, pp. 125-126)

Apparently, Deutsch is pessimistic that mere contacts at the societal level whout meaningful social communication may lead to tension and conflict.

The maintenance of communicative integration in a multilingual society depends on either or both of the following factors: (i) a widely accepted lingua franca, and (ii) the extensive practice of multilingualism. Take the case of Singapore for instance. In my recent study of a sociolinguistic profile in Singapore (Kuo. 1976a), I found that there does not exist a highly communicative lingua franca in this island-state. Rather, there is a complicated set of linguae francde in practice. In inter-ethnic communication, Malay, especially its pidginized variant, Bazaar Malay, is used by the more traditional segment of society. In contrast, English is the common language among the more modern for more formal and official occasions. Yet for the population as a whole, except the use of the Malay language in Malay-Indian communication, neither English nor Malay is highly communicable. (See Kuo, 1976a, for more detail.) This dual pattern is paralleled by another dual system in the Chinese community, whereby Hokkien is used in the traditional sector in inter-dialect group communication, and Mandarin is steadily gaining status for more formal or official functions. English and Mandarin are thus High $(\mathrm{H})$ languages, whereas Bazaar Malay and Hokkien are Low (L) languages in Singapore.

Without a widely accepted lingua franca, communicative integration in Singapore depends mainly on the extensive practice of multilingualism as the guiding principle of the language policy. While this is obvious even to casual visitors, the policy 
of multilingualism is most clearly manifested in Singapore's bilingual education system, which has four types of language-medium schools, and in the availability of various language programmes and publications in the mass media. It is significant that Singapore's bilingualism and bilingual education emphasize the combination of English and one of- the other official languages (Mandarin Chinese, Malay, and Tamil). English is therefore being promoted as the major lingua franca for a greater role in the future. On the other hand the availability of mass media messages in various languages and dialects guarantees that most of the heterogeneous population can be reached and mobilized. (See Kuo. 1976 b.) Furthernore, competent bilinguats are mobilized to ocetpy strategic, though not necessarily powerful, positions to play the role of the social broker anicative integration in the society.

\section{Nationql Identity}

For most developing countries in Asia and Africa, the task of nationbuilding is constantly confronted with problems of ethnic and linguistic diversity. The presence of competing ethnic/language groups in these new states generally means that the establishment of a new nationhood requires the cultivation of a new national identity. The emerging national identity can be achieved either: (i) through an expansion and elevation of an indigenous ethnic/language identity imposing upon other 'less' indigenous and (usually) minority groups, or (ii) through the development of a new supra-ethnic identity treating various cthnic groups as having equal standing.) In either case, it is expected that the emergence of a new national identity is not likely to be natural or spontaneous. The crucial problem faced by most new multi-ethnic states is thus, the potential conflict between loyalty to one's speech community and loyalty to the wider national community. The essential question is how the two can be reconciled rapidly and smoothly to facilitate the process of nation-building.

According to Stewart (1968, p. 540), language planning policies of new states generally fall in to two types of strategies:

1. The eventual elimination, by education or decree, of all but one language, which is to remain as the national language.

2. The recognition and preservation of important languages within the national territory, supplemented by the adoption of one or more languages to serve for official purposes and for communication across language boundaries within the nation.

Of these two strategies, the first one clearly aims at eliminating linguistic diversity and is usually part of a more general policy aiming at the ethnic minorities' eventual assimilation to a 'national' culture. This appears to be the strategy being implemented in Mataysia. In contrast, the second approach is more tolerant of cultural diversity and usually reflects an official policy of cultural pluralism. This is clearly the belicy being adopted in Singapore today.

Kelman (1971) analyzes the problem from a socio-psychological point of view. (He points out that sentimental attachment to respective ethnic/language groups in a multilingual society poses a potential barrier to participation in the national system and to the development of a national identity He believes, however, that as long as the existing socio-political structure is effective enough to satisfy the basic needs of the individual and his ethnic/language community, the resultant instrumental attachment may eventually lead to a sentimental attachment to the new state and eventually to the emergence of a new national identity. 
Accordingly, in such new states, language policies ought to be based entirely on functional considerations:

'That is, in selecting languages for various purposes... central authorities ought to be concerned primarily with two issues: (1) how to establish and facilitate patterns of communication... that would enable its socio-economic institutions to function most effectively and equitably in meeting the needs and interests of the population; and (2) how to assure that different groups within the society... have equal access to the system and opportunities to participate in it.' (Kelman. 1971, p. 40)

Again, let me draw on the case of Singapore for illustration. In Singapore, English has been adopted as the de facto working language (Kuo. 1977), a policy that satisfies both 'issues' suggested by Kelman. On the one hand the use of English promotes economic progress for both the society as a whole and its individual speakers. On the other hand English is a non-native language in which none of the major ethnic groups is at an advantage over the other two. (The same observation can be made of English in India and Bahasa Indonesia in Indonesia.) The use of this 'neutral' language helps rule out any substantial inter-ethnic conflict based on the language issue in Singapore.

At the same time, the practice of multilingualism in education and mass media communication as in other aspects of daly-life, serves to neutralize the potentially divisive issue of language cleavages. It functions more to assure equality and to avoid conflict than to directly encourage national identity, since multilingualism also means continued attachments to ethnic culture and traditional values. Whatever transition (or expansion) is needed to progress from ethnic loyalty to national identity, the leaders of Singapore seem willing and patient to let the process take its slow but steady course. They can be confident that as long as economic development and political stability are sustained, the emergence of a national identity is only a matter of time, even though it may be a long time.

Language policy in Singapore therefore assists nation-building in the following manner: Instrumental attachments to languages are cultivated within the population. These attachments eventually lead to new sentimental attachments to the state, and hopefully to the emergence of a supra-ethnic national identity. According to Fishman, this is a state-into-nationality process of nation-building, involving a transformation from politico-operational integration to socio-cultural integration $(1972 \mathrm{~b}, \mathrm{p} .231)$. The case of Singapore represents an on-going experiment that has attracted the attention of many social scientists.

\section{Concluding Remarks}

Let me make some final notes to conclude this paper. I hope they sound more than apologetic.

Firstly, the case of Singapore is presented as an example (maybe a unique one) of a multilingual society. Singapore society is unique in many ways, and thus can provide some enlightening insights for social scientists in general. Nevertheless, it is so special that its experiences should be carefully interpreted and generalized in any attempt to apply them to other multilingual societies. Secondly, there are many important macro-sociolinguistic issues other than those discussed in this paper. Many more 
remain to be explored. Thirdly, although my personal interest is in the sociological approach to bilingualism, I would like to emphasize that the study of bilingualism requires inter-disciplinary efforts from linguistics, psychology, education, and anthropology, as well as sociology. Each complements the other, and none is superior. 


\title{
SOME SOCIOLINGUISTIC CONSIDERATIONS OF BILINGUAL EDUCATION FOR ASIAN COUNTRIES
}

\author{
Benjamin K. T'sou
}

\section{Sociolinguistic Realignment and Language Choice}

Bilingual education has become an increasingly current topic within the last decade in many parts of the world. Its mounting relevance for many countries in Asia, particularly South East Asia, is also gradually recognized. In the pre-World War Two period, which coincides with the colonial period in many cases, each of these countries usually had only a single official language, and it was usually a language from outside the region, such as English, French, Dutch or Portuguese ${ }^{1}$. On the other hand in the postwar era, sweeping political change has gone hand in hand with fundamental political and sociolinguistic realignments. This brought about an upsurge of new and urgent educational needs. Language figures prominently at this stage of development for it is indispensable to raising the level of literacy and, hence, to technological advancement.

That language has been an important adjunct to political tension and political realignment is evident in South Asia and in South East Asia. The creation of Hindi and Urdu out of basically the same language matches the division of British India into India and Pakistan. More recently Bangladesh, where Bengali is the national language, successfully ceded from Pakistan and became an independent nation. The language problems between Singhalese and Tamils have also become a serious political issue in Sri Lanka. The simple criterion by which the language of the majority of citizens is chosen to be the national or official language in a country is not sufficient, as can be seen in the choice of Bahasa Indonesia (Malay) and Filipino (Tagalog) as the national/offical language in Indonesia and the Philippines respectively. If the majority language had been chosen (Javanese in the case of Indonesia, and Visayan in the case of the Philippines) it could have become a bone of subsequent political contention. Other countries have availed themselves of other criteria and made their choice on the basis of commerical expediency (eg Singapore, where English is the official language) and historical prerogative (eg Malaysia, where Malay is the official language). ${ }^{2}$

It is sometimes difficult to apply a single criterion, and often several criteria contribute to the decision on language choice. Thus, in the post-war period many countries in this region recognized more than one official or national language all of which were taught in school and associated with other societal functions of a High Language. These include: India, Sri Lanka, Singapore, and even Hong Kong, which is not an independent country but which has recently recognized Chinese as an official language. In other countries where only one official language is recognized more than one language or more than one variety of language is very often important. Examples are: Indonesia (Javanese, Balinese, Papuan languages, etc), Malaysia (English, Chinese and

Dr. T'sou received his M.A. from Harvard University and his $P h . D$. from the University of California, Berkeley, both in Linguistics. His major research interest is in Historical Linguistics and Sociolinguistics. He was previously Assistant Professor of Linguistics at the University of California, San Diego, and has recently joined the Language Centre of the University of Hong Kong. 
Tamil), Taiwan (Mandarin, Taiwanese and English), Japan (Chinese and English) and Thailand (minority languages such as Malay and Chinese).

It may be useful to offer some generalizations about the typology of sociolinguistic realignments in South East Așian countries as familiarity with these will enhance the appreciation of problems peculiar to bilingual education in this area. In the case of Indonesia, Javanese is important. Though it has no official status, it is the language of the majority group. Papuan languages are also important because West Irian has been a recent territorial addition to Indonesia and allegiance of its new citizens from this region does not come about automatically and "must be cultivated. In Malaysia Chinese and Tamil are important languages because their speakers form significant minority groups, and English remains an important link with the outside world, if not / with its recent past. Taiwanese is a significant dialect/language in Taiwan because it is the home language of the majority of the residents there, and English has become the primary medium through which most of its vital external trade is conducted. English is equally important for Japan for the same reason. But Chinese is also significant for Japan because of the unique links between the written and cultural traditions of the two countries. Malay is important for Thailand because it has numerous citizens in the south who are of Malay origin. Chinese, particularly the Teochiu dialect, is also important because many of its affluent citizens are of Chinese descent, and their assimilation, though evident and assured, has been gradual.

The first type of realignment involves the replacement of an official language by another, where the former is usually a colonial language and the second an indigenous language. An example of this is Indonesia, where Dutch has been replaced by Malay (Bahasa Indonesia). A second example is Malaysia, where English is being swiftly replaced by Malay (Bahasa Malaysia). In such situations it remains a distinct advantage for the child who speaks the indigenous (and new official) language at home to acquire bilingual ability in both the new and old official languages ${ }^{3}$. On the other hand, the child who speaks other indigenous languages will need to acquire bilingual ability in at least his own indigenous language and the new official language and frequently ability in the former official language as well.

The second type of sociolinguistic realignment is the 'promotion' of an indigenous language to official language so that two official languages are recognized in the country. Examples are Hong Kong (where Chinese has been added to English), the Philippines (where Filipino is added to English) and India (mainly in the non-Dravidian states, where Hindi was added to English). Very often,in such situations the change is less drastic than those discussed previously and it tends to represent a transitional phase between the undesirable sociolinguistic situation (from a nationalistic point of view) in the pre-independence period and the more idealistic one in the post-independence period. In the latter case a single official language based on an indigenous language would be desirable from many points of view. ${ }^{4}$

The third type of sociolinguistic realignment is the 'promotion' of more than one indigenous language to official status so that three or more official or nationat languages are recognized in the particular community. Singapore is a good example, where three languages - Chinese (Mandarin), Malay and Tamil - have been so promoted. The quadrilingual policy is based on the need in the new Republic to give equal recognition to several significant groups (Chinese, Malays, and Indians [mainly Tamil speakers]) in the pluralistic society, and to grant their languages a status equal to English, the tradi- 
tional and pre-independence official language. As an additional recognition of the importance of Malay, on which the official languages of its two most important and powerful neighbours are based, it has had bestowed on it the status of a national language. This use of the term is at variance with other countnes, where a national language obtains its status mostly through recognition of the significant minority group which speaks it and is not normally used as an official language. Several states in Southern India, where Dravidian languages are spoken, also recognize these languages in addition to English and (sometimes reluctantly) Hindi. Very often, in these situations only two languages become important for any given group. This is true also of the People's Republic of China and the U.S.S.R. where a much larger number of languages of various significant national minority groups is granted special status. This third type of realignment involving three or more languages in the change is not a more general case of which the second type of sociolinguistic realignment is a special instance. It is often true that, in contrast to the second type, this type of sociolinguistic realignment does not readily lead to the first kind of situation, where only one language, albeit a newly designated language, has official recognition. In fact this type of multiple additive sociolinguistic realignment is usually the result of governmental policy to minimize the dominance of a single language.

follows:

This typology of sociolinguistic realignments may be summarized as

\section{Table I}

Typology of Sociolingurstic Realignment

\begin{tabular}{|l|l|l|}
\hline Type I & $\mathrm{L}_{1} \rightarrow \mathrm{L}_{2}$ & Substitutive \\
\hline Type II & $\mathrm{L}_{1} \rightarrow \mathrm{L}_{2}+\mathrm{L}_{3}$ & Simple Additive \\
\hline Type III & $\mathrm{L}_{1} \rightarrow \mathrm{L}_{1}+\mathrm{L}_{2}+\mathrm{L}_{3}+\ldots+\mathrm{L}_{\mathrm{n}}$ & Multiple Additive \\
\hline
\end{tabular}

It should be evident from all of the foregoing discussions that bilingualism is important in all three types of sociolinguistic realignment and bilingual education becomes an important means of facilitating the acquisition of the prerequiste linguistic skills.

\section{Some Basic Issues in Bilingual Education}

\subsection{Uses and Abuses of Billingual Education}

The concept of bilingual education is interpreted by many according to a wide range of possibilities. It ranges from one extreme, where any form of education in which the instruction of two or more languages is involved, to the other extreme, where the educational system utilizes two languages equally and aims to produce symmetric ${ }^{5}$ or balanced bilinguals who have not only full control of the structures of the two languages but also total communicative competence in each of two cultural contexts in which these languages are used. In the former extreme any educational system in which a second language is taught can be said to provide bilingual education. This is not really bilingual education as it is commonly under- 
stood today, for bilingual education seeks to go beyond the teaching of a second language simply as a substance or object of instruction. Instruction must be given in both languages, ie using both languages as media of instruction, and the two languages need not be used on an equal basis. Bilingual education may be simply understood as the organized use of two languages as media of instruction in the school curriculum with the dual purpose of integrating the linguistic and cultural maturation of the child.

Let us look at some examples of bilingual education. A child begins schooling in his mother tongue and subsequently the medium of instruction changes to a second language, usually the official language of the country. If the change is accomplished gradually, then we would have a case of bilingual education. If the change is very abrupt, then it can be said that the child has received bilingual schooling or has attended vernacular schools. Children who concurrently attend two schools, each in a different medium of instruction, may also be said to receive bilingual schooling but not necessarily bilingual education. The Jewish boy in America who attends Sabbath School where Hebrew is taught (in addition to his regular English language school during the week) cannot be said to be receiving bilingual education. 6 On the other hand, the Chinese boy in Singapore who attends an English school in the morning and a Chinese school in the afternoon could be receiving bilingual education if there are parallel (and mainly identical) curricula in the two schools. Cases such as the Indonesian student learning German at the University or the Irish student learning Russian in school would not normally be considered bilingual education.

There are also frequent and common problems concerning the definitions and roles of the two languages involved in bilingual education. From a popular linguistic or applied linguistic point of view, the first language is the first language the child has learned, or the mother tongue, which is commonly understood as the language of the mother. This need not be correct as the child may not be best in the language of his mother, especially in a heterogeneous population, where mixed marriages may be common. It would be more suitable to think of the first language as the language in which the child is most conversant and comfortable, and it may be appropriate to think of it as the base language for bilingual education.

On the other hand, from a sociological perspective the signiticant language or the first language is the one that has greatest importance in the rele society, which is usually not the base language (ie linguistically the 'first' language of the child) in the context of bilingual education.(Hong Kong/s a good example of a place in which English is not the native language of the population But it is the 'first' economic language. It may be appropriate to think of this-sociologically significant language as the target language. Where the base language and target language are not identical, or insufficiently similar, the need for bilingual education becomes evident. Good examples are the Tamil child in India and the Chinese child in Hong Kong and Singapore. Where there is a significant overlap between the base language and the target language it would appear that there is no need for bilingual education.

\subsection{Two Approaches to Bilingual Education}

There are two major approaches to bilingual education programmes. The first is the assimilative approach, whereby the minority groups would be better absorbed into the majority culture. It aims at helping the minority child to go from a mono- 
lingual environment in which the base language is the language of his home to an adult environment in the dominant society in which a different target language is the primary language. The target language is what is of ultimate concern in such a programme, and the base language becomes simply the vehicle for acquiring the target language. Very often the programme is not organized with the aim to promote maintenance of, or loyalty to, the base language, and the successful child in such a programme will have switched from his base language to the target language as the main if not only language in his linguistic repertoire. This is sometimes referred to as the Transitional Model $^{7}$ of bilingual education. Strictly speaking such a programme may be considered bilingual education only from the time when the target language is introduced into the monolingual base language programme to the time when instruction is given exclusively in the target language. This intervening period may vary, depending on the languages concerned and other non-linguistic factors. It may take from two or three years to five or six years. Bilingual education programmes for the majority of the Asian groups and many of the Hispanic groups in America belong to this category.

There are other manifestations of such an approach. One well-known example is the Maintenance Model of bilingual education, which often aims to maintain the child's initial and basic level of competence in the base language. In practice, the child's competence in this language often becomes stationary, if not retarded, in the face of improving competence in the target language. Moreover, his cultural maturation associated with the target language outpaces that associated with the base language. If the child is insufficiently literate in the base language, he is not likely to acquire literacy in this language at a later stage in school.

Within the narrow definition of bilingual education it would be incorrect to include such a programme under bilingual education, for its ultimate goal is not for the dual linguistic and cultural maturation of the child. Such a programme becomes an instrument for unidirectional assimilation. If it is implemented well, it will nonetheless provide a smoother transition for the minorities to go from being marginal members of society to becoming productive citizens. The justifications that have been offered are often based on the possibility of social burden and financial cost to the larger community, if the minority groups remain unassimilated. ${ }^{8}$

The underlying philosphy behind this approach is often known as the Melting Pot theory, by which society is seen as evolving from the total integration of all constituents (ingredients) whose individual characteristics have contributed to and merged into the single identity that emerges. The consequence of such an integration var1es for different contributing groups. Obviously, the minority characteristics will be submerged in a non-reciprocal way among the majority characteristics if there is gross disparity in the size and position of the constituent groups.

The second major approach reflects a fundamentally different conception of society: that pluralism is both desirable and possible and that bilingual education could contribute to the realization of such a society. While the two (or more) languages as well as cultures may not be recognized altogether on equal grounds or granted equal status, bilingual education under this approach aims to impede or even reverse the unidirectional assimilation of the minority language(s) and culture(s) to the major language and culture. This is sometimes called the Salad Bowl approach or pluralistic approach, for in a salad each ingredient, while re- 
taining its own character regardless of size, contributes to and enhances the richness of the whole. Under this approach the base language becomes one of two target languages for'as long as it takes the individual to gain maturity in both languages and cultures.

Various experimental programmes have been tried in which the medium of instruction alternates in a set curriculum on a daily basis. The aim is to produce balanced bilinguals who would be totally at home in both languages regardless of situation or context. When alternation takes place on a subject basis, subjects relevant to the child's own cultural maturation, such as his base language and history of his own people, will frequently be taught mostly in the base language. Other subjects such as the target language, social studies and science will be taught mostly in the target language. Such a system will produce asymmetric bilinguals whose linguistic skills are compartmentalized according to subject or situation.

The major differences concerning the disposition of the two languages involoved in both approaches may be schematized as follows:

Table II

\begin{tabular}{|c|c|}
\hline PLURALISTIC & $\bigsqcup_{\mathrm{BL}=\mathrm{TL}_{2}} \underbrace{\mathrm{TL}_{1}}_{\mathrm{TL}_{2}}$ \\
\hline ASSIMILATIVE & $\mathrm{BL} \longrightarrow \mathrm{TL}$ \\
\hline
\end{tabular}

The different models discussed under the two major approaches usually pertain to organized bilingual education. Along with these, there is a third possibility that is rarely discussed - Divisive bilingual education. In a situation where the beneficiaries of bilingual education are restricted to only the minority groups, it may turn out that the minority groups become bilingual while the majority group remains monolingual. A member of the bilingual minority will presumably have at his disposal a wider cultural base than a member of the monolingual majority, to whom this difference could become a cause for concern. ${ }^{9}$ Sometımes, this concern is manifested as doubts about the identity and allegiance of the former. In a country where a stable pluralistic society exists such doubts are usually not justified. One solution to this is to provide bilingual education for both majority and minority groups so that linguistic lines are crossed by all racial groups. This is schematized as follows: 
Table III

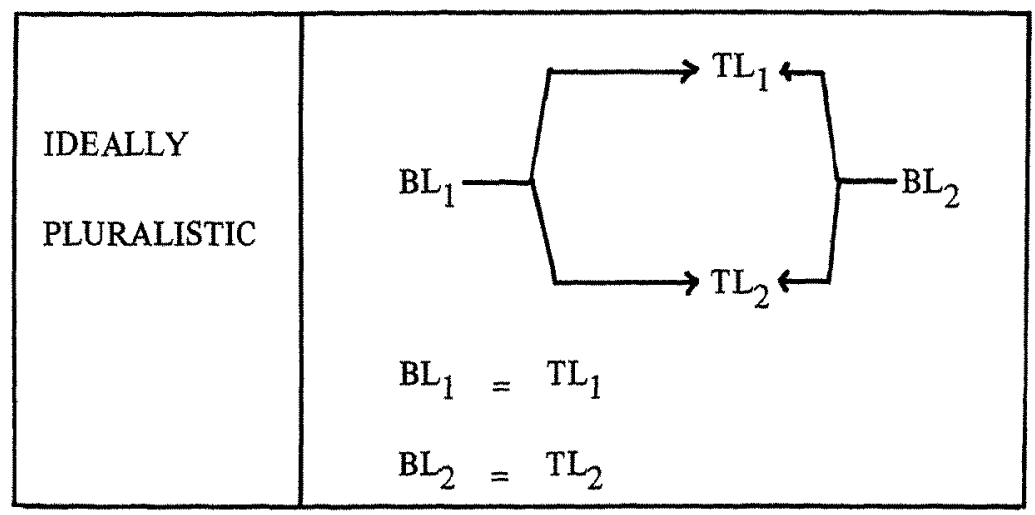

\section{The Curriculum in Bilingual Education}

\subsection{Language in the Curriculum}

A sample of curriculum organization of the different models discussed so far is given in Figure 1. In all six cases two languages are involved as media of instruction. In (a) an abrupt change is brought about and is deemed undesirable. In (b), (c), (d) and (e) both the base and target languages are used alternately. Concepts may be introduced first in the base language and immediately reintroduced and reinforced in the target language. The repetition may induce boredom but this may be minimized if flexibility in presentation is introduced. Straightforward translation and duplication of teaching strategies should be avoided as much as possible when the target language is used to reinforce the comprehension of the concepts first introduced in the base language. The alternation of the two languages may also take place on alternate days. This would avoid duplication in presentation and presupposes that the students have fairly equal control in the two languages. Such an alternative may be best applied to selective subjects or to more advanced students who have attained a basic bilingual ability. In practice it may be difficult to find qualified bilingual teachers who could teach equally well in both languages.

Case (b) differs from (c) in that the former emphasizes a solid foundation in the base language while the latter emphasizes control in the target language. Cases (d) and (e) involve equal exposure to the two languages in the curriculum, but (e) is obviously biased towards the target language, though equal time would be spent in the two languages within the overall curriculum.

The same is also true of both (e) and (f), but they differ from (d) by phasing out the base language. Case ( $f$ ) achieves this simply by subject over time, without going through an intermediate phase of using both languages alternately.

There are possible variations in these schemes. One example is the 'pull-out' classes sometimes found in certain schools in U.S.A. For some subjects, such as arithmetic, minority students, frequently recent immigrants, would be taken from one class to another (or to a corner of the same classroom) where a different teacher or a teacher's aid would go over the same syllabus for the subject in the 
SOCIOLINGUISTIC CONSIDERATIONS FOR ASIAN COUNTRIES

\section{FIGURE 1}

Base Language as Instructional Medium

Base Language and Target Language as Instructional Media

Target Language as Instructional Medium
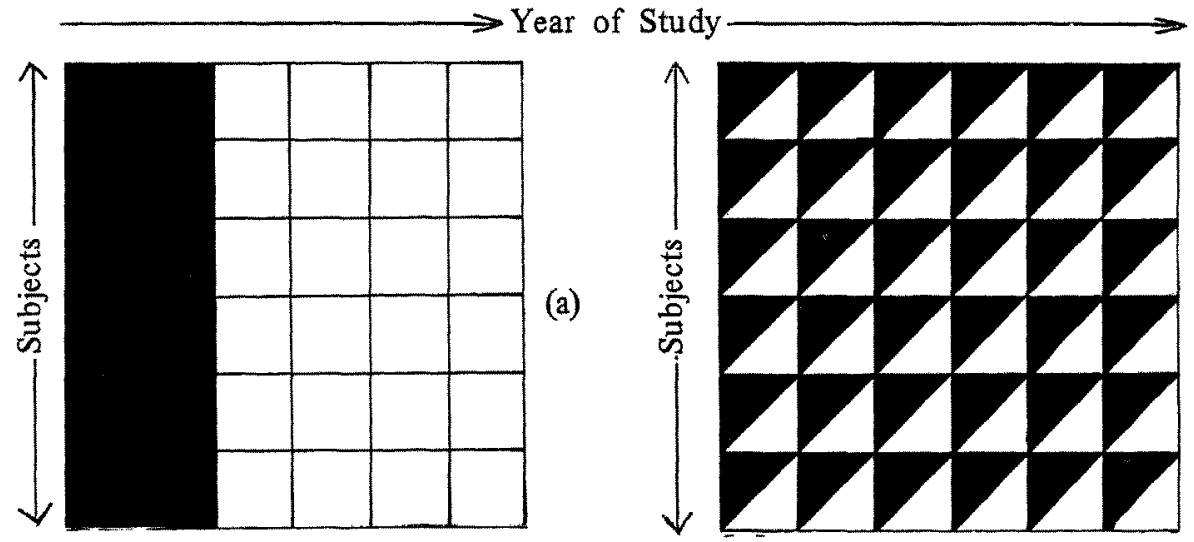

(d)

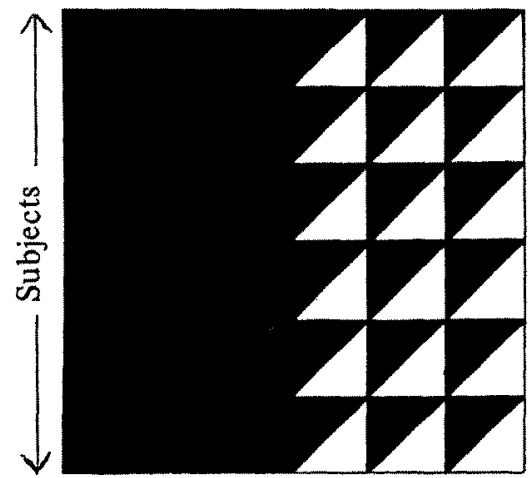

(b)

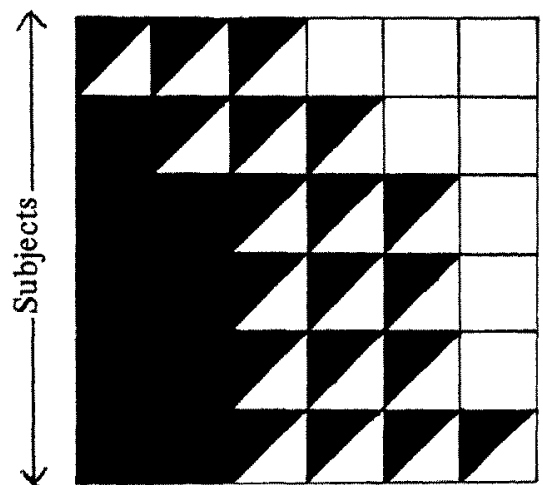

(e)

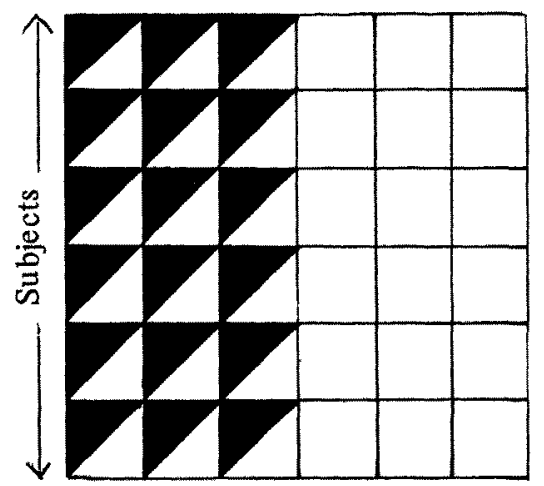

(c)

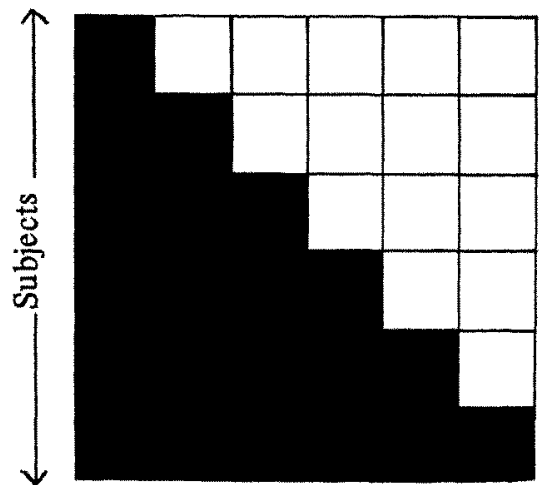

(f) 
children's home language. This is frequently found in small bilingual education programmes. This arrangement could fall under (e) or (f), but very often the arrangement is found to add psychological strain to the child. This is especially so in the case where a teacher's aid (a pre-credentialed teacher) takes a group of minority children to a corner of the classroom for special instruction. The other classmates may consider them to require 'remedial' coaching in a different language in order to remedy some deficiency. If this were the case then it would defeat the purpose of bilingual education.

\subsection{Language Norms and Language Content}

In each situation in which bilingual education becomes relevant it is not uncommon for considerations of language choice to be limited to only the standard languages. This is especially crucial in determining the norm for the base language. For example, in Spanish-English bilingual education programmes in America the difference between Puerto Rican Spanish and Chicano Spanish, and that between either of the two and Castilian Spanish is well recognized and an appropriate choice must be made. Similarly Okinawan Japanese (which is significant in Hawaii) differs from Standard Tokyo Japanese in significant ways, though perhaps the difference is less than between Toishan Cantonese (which is relevant to most Chinese-English bilingual education programmes in America) and Standard Cantonese. Moreover, Cantonese or any of the non-Mandarn dialects of Chinese differ from Mandarin in significant ways. In the case of the base language, if the standard language rather than the sub-standard language spoken in the home of the child is chosen as the medium of instruction, the differences may be sufficiently significant to cause grave harm to the child. Problems arising from the choice of norm have become serious issues in Chinese-English bilingual education programmes in California and elsewhere. The child whose home language is exclusively Toushan Cantonese and who enrols in a bilingual education programme which has chosen Standard Cantonese as the norm for the base language will encounter difficulties comparable to having the child learn through a third language. The same is true of imposing Mandarin as the base language on school children who speak a dialect at home and have had no previous contact with Mandarin.

While the question of norm is crucial for the base language, the question of language level and registers is equally important for the target language in bilingual education (as well as in any second language teaching situation). The following two sentences may illustrate this point:

(1) Do you think you can pass me the salt?

(2) Do you think you will buy the book when it comes out?

Both sentences are grammatically questions. However (1) is pragmatically a request and the hearer could respond affirmatively Yes, $I$ will and pass the salt, or negatively No, sorry, I can't reach it myself and not pass the salt. It would be inappropriate for him to respond to the sentence literally as a question and answer affirmatively Yes, I think I can pass you the salt, or negatively $N o, I$ don't think I can. In the case of (2) there is no clear request for the hearer to acquire the book when it becomes available. Rather it is more likely that the speaker means it literally, as a question. As a request (1) could take on please but (2) could not normally, as it is not a request. ${ }^{10}$ 
Distinctions between grammatical constructions, such as questions, and pragmatical constructions, such as requests, are not taught in textbooks, which only deal with grammatical structures leading to literal interpretations. Yet the differentiation is crucial for total communicative competence, especially in the target language whose use is normally not reinforced in the home. In the case of the base language the child is likely to have acquired his communicative competence in the home environment. There obviously remains much to be explored in bilingual education and, in particular, in the fundamental philosophy and implementation of bilingual education.

\section{Notes}

1. Spanish was very important in the Philippines for several centuries until the turn of this century, when Spain was defeated in the Spanish-American war. Subsequently English became even more important in the Philippines than Spanish ever was, as education became less elitist. German was also important in parts of Micronesia between the First and the Second World Wars, and Japanese displaced many of the official languages in many parts of Asia during the war.

2. These are not the only criteria, and each criterion may not be one that is applicable to all cases. Thus, in Singapore, besides commercial expediency, other criteria such as ethnic and cultural neutrality, as well as widespread use, played a part in the maintenance of English as an official language.

3. The Indonesian situation does not follow this generalization for two main reasons: (i) There was a marked absence of goodwill between Holland and Indonesia as the latter struggled to obtain independence from the former (Nationalism, it would appear, played a part in abolishing the colonial language) and (ii) English has become the most important international language, which provides additional pressure to play down Dutch there.

4. Since the post-independence official language is usually not identical to the one in the pre-independence period, an abrupt transition, as is the case in the preceding type of sociolinguistic realignment, may not be the most desirable. A compromise solution:

$$
\mathrm{L}_{\mathrm{A}} \longrightarrow \mathrm{L}_{\mathrm{A}}+\mathrm{L}_{\mathrm{B}} \longrightarrow \mathrm{L}_{\mathrm{B}}
$$

may be the long-term solution for the language planners, though the position of $L_{A}$ may be so entrenched that the second phase of planned change may not be realized within a short period of time. The prolonged retention of English in India is no doubt due in part to pressures from southern Indian states, whose speakers do not speak an Aryan language.

5. The distinction between symmetric and asymmetric bilingualism is discussed in detail in T'sou (1975a).

6. For a discussion of bilingual schools in U.S.A. see Anderson and Boyer, pp. 17-40.

7. This is also known as the Transfer Model. See Mackey (1972), Cohen, Troike and Modiano, and Anderson and Boyer, (pp. 88 and 90). 


\section{STUDIES IN BILINGUAL EDUCATION}

8. There is also a legalistic basis to justify bilingual education. The ruling on the Lau vs Nichols case by the Supreme Court of the United States was a turning point for bilingual education in the U.S.A. For a survey of the current situation in the U.S.A. see Geffert et al.

9. This becomes justified only if the children are given bilingual schooling where the vernacular school's syllabus has an orientation towards their immigrant parents' home country rather than the host country. See T'sou (1975a) for examples of such a situation.

10. The term please could be added to the end of the sentence as a marker for politeness. In this case the request is for the hearer to answer the question, as a literal question. Thus the following two sentences represent different requests:

(i) Do you think you will buy the book when it comes out, please?

(ii) Could you buy me the book when it comes out, please?

In (ii) please emphasizes the request for the hearer to buy the book for the hearer, but in (i) it simply marks a polite request for the hearer to reveal his intentions. 


\title{
C. Regional Reports
}

\section{THE ROLE OF KANJI 漢 字 IN JAPANESE}

\author{
Nobuhisa Tsuji
}

\begin{abstract}
Although it is generally thought that Japan is linguistically and culturally homogeneous, in fact the sociolinguistic situation in Japan is highly complex. For many centuries Chinese language and culture has played an integral part in the sociolinguistic history of the Japanese nation. The author of the article explores one aspect of this.
\end{abstract}

\section{Introduction}

Large areas surrounding China have long been exposed to her civilization. Some cultures in these areas, notably Korea, Vietnam and Japan, have not only been familiar with classical Chinese materials, but have been using (or have used until recent times), with some modification, Chinese script in the writing systems of their languages. Some aspects which are characteristic of (but not necessarily unique to) the Japanese case are:

(1) Traditional sinological studies have continued steadily down to the present era.

(2) Borrowed Chinese script, ie Kanji (see below), is presently extensively used in the mass media and in education.

(3) Despite the long-lasting familiarity with Chinese materials (mostly classical), the great majority of the Japanese have not had direct personal contact with the Chinese until the modern period. (This is due to the geographical isolation of the Japanese islands.)

\section{Japanese Orthography : A Case of Bilingual Writing}

The introduction of Chinese script (and therefore of Chinese texts) into Japan on a large scale dates back to the fifth or sixth century. Since then, the Japanese have used and gradually modified the Chinese script into their writing system. The modern Japanese writing system consists of : (a) Kanji 漢字 ,Chinese characters (with few exceptions) used for Japanese; and (b) Kana 仮名 syllabary which consists of syllabic graphs adapted and modified from Kanji to denote Japanese syllables phonetically.

\section{Multiple reading of Kanji}

Each Kaniz typically has two major categories of reading which are "bilingual' in origin : (b) On reading is based on the Chinese pronunciation of the Kanji at the time of its introduction; and (a) Kun 訓 reading is the native Japanese form with the meaning corresponding to that of the Kanji in Chinese. For example, 'mountain' has an On reading săn (Middle Chinese $*_{s a ̆ n}$ ) and a Kun reading yama which is the native Japanese form for 'mountain'.

The On reading is further subdivided into three major layers reflecting different periods of introduction and different source dialects of Chinese : (i) Kan On 漢音 is the most commonly used layer and is presumably based on the standard speech of Chang-an 長安 during the seventh and eighth centuries; (ii) Go On 吳音

Dr. Tsuji received his B.A. in Chinese Language and Linguistics from Keio University, Japan. He also received an M.A. and a Ph.D. in Linguistics from Cornell University. He is currently with the Depart ment of Languages at the Chinese University of Hong Kong. 
is an older layer and is based on some variety of 'non-standard' speech common during the Six Dynasties 六朝 ; and (iii) The much less common Tö-SōIn 唐末音 layer based on the dialects of Zhejiang 狾江 during the fourteenth century, but in a larger sense it refers to the $O n$ readings borrowed in small doses since the tenth century from various dialects. For example, Kanji 行 'to go, walk' (Middle Chinese * ang < Old Chinese **a'âng) has three On readings : (i) Kan On :- ko $(<k a u)$; (1i) Go On :- gyo (<gyau); and (iii) Tö-Sō In :- an.

Kokuji : ('Kanji made in Japan.') Few Kanji were actually created in Japan and they are called Kokuji 國 字. Although the radicals (or graphic components) of these Kokuji are of Chinese origin, their particular combinations of radicals do not exist in Chinese script. For example, Kanji 拤, consisting of radicals 'mountain', 上 'up and 下 'down' has a Kun reading toge 'mountain trail' only, but has no On reading like the rest of Kokuji. (There is no Chinese pronunciation as the source.)

Summary (see Diagram I below) : All Kanji excluding Kokuji have an On and $K u n$ reading. Within the On reading, the great majority of Kanji have at least $K a n$ $O n$, and many have Go On readings. Very few have Tó-Só $I n$ but, when they do, it is usually along with the Kan On and Go On.

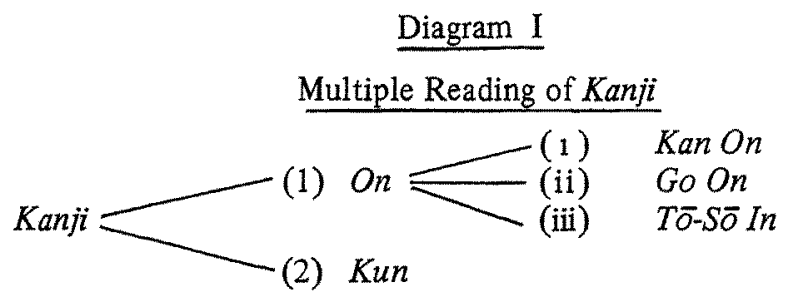

\section{Kanbun 漢文 ('How to read and understand Chinese without really learning it')}

The Chinese classical materials provided not only models for the writing system, but they were also a rich source of information on Chinese civilization, and they have continued to be read by the Japanese throughout history. The Chinese texts, however, have not been read generally in the Chinese language, but through a set of conventions developed by the traditional school of Japanese sinologists. Today the technique of 'deciphering' Chinese texts is known as Kanbun. The basic principles of the Kanbun conventions are:

(1) Rearrangement of the words (or morphemes) of the original Chinese texts into Japanese word order;

(2) Addition of Japanese case-markers, inflectional endings and other grammatical forms which are necessary or convenient for deciphering the texts.

Thus, the end product of the Kanbun conventions is neither pure Chinese nor Japanese, but a 'bilingual' hybrid. This Kanbun tradition, however deformed it may appear as a case of 'bilingualism,' has provided the Japanese with a practical and efficient means of reading about the Chinese civilization (and about other cultures via China) for more than fifteen centuries.

\section{Kanji Today}

By the end of the World War II, approximately 2,500 Kanji characters were taught in schools and about 2,500 to 3,500 were used in newspapers. Today 1,850 
Kanji are taught in schools and used in newspapers and many of them have been graphically simplified. Yet, the complexity of the Japanese writing system as briefly explained above is no doubt a handicap at least on the technical level of reading and writing, and wider use of the systematic Kana syllabary would lessen the burden of Kanji learning. In addition, a good number of Chinese loanwords which are naturally written in Kanji are becoming obsolete and less relevant to the younger generation, although they have enriched Japanese culture in the past.

Although the technical difficulties in learning Kanji as mentioned above are, and will remain to be, points against it, Kanji as part of the modern Japanese writing system provides more pros than cons :

(i) Words (or morphemes) represented by Kanji can be used much more productively and concisely in writing than those represented by Kana. Besides, if words are represented only in Kana, a good number of homonyms would not be differentiated in writing.

(ii) Doublets of literary vs colloquial words are often and conveniently written in singular Kanji representations.

(iii) Although many words (and higher level forms) written in Kanji are becoming obsolete for the younger generation, the layer of Japanese vocabulary which 1s of Chinese origin is still large and important. (In fact, many words of this layer are so 'internalized' in Japanese that ordinary speakers would not realize their origin when they use them.) 


\title{
THE STATUS OF ENGLISH IN RELATION TO THE OTHER LANGUAGES IN PRIMARY AND SECONDARY SCHOOLS IN MALAYSIA
}

\author{
Lim Kiat-boey
}

When we discuss the relative status of languages in the education system in Malaysia, we should bear in mind that there are three major races: Malays, Chinese and Indians. One may therefore say that there are three languages: Malay, Chinese and Tamil. But historical events have made English one of the main languages in everyday use. In such a situation a common language is of paramount importance, especially as there are no geographical boundaries to separate one major language group from another.

Malaysia has decided to use the National Language as a means of bringing about unity among the different racial groups. Article 152 of the Federal Constitution says:

\begin{abstract}
'The National Language is Malay, and Parliament has the right to decide the script in which it may be written (Romanised script is the official script, but Jawi may be used). Until 1967 English will continue to be the alternate official language; and, until then, it must be used in all Parliament Bills and Acts. Similarly, both Malay and English may be spoken in Parliament and The States Assemblies, but English remains the language of The Supreme Court until Parliament decides otherwise.'
\end{abstract}

The fostering and development of the National Language is one of the main objectives of national policy in the country. It is regarded as a fundamental instrument of national unity. For this reason education in the Malay medium is free in primary and secondary schools.

When Malaysia achieved independence, the education policy of the Federation was defined in Section 3 of the Education Ordinance, 1957, as follows:

'The educational policy of the Federation is to establish a national system of education acceptable to the people as whole which will satisfy their needs and promote their cultural, social, economic and political development as a nation, with the intention of making the Malay language the national language of the country whilst preserving and sustaining the growth of the language and culture of peoples other than Malays living in the country.'

Dr. Lim received her B.A. in English and a Diploma of Education from the University of Malaya in Singapore. She also received a Diploma in Applied Linguistics from Edinburgh University, and a Doctorate in Education from Harvard University. She was previously Associate Professor in the Faculty of Education at the University of Malaysia, and has recently joined the staff of the Regional Engish Language Centre in Singapore. Her major research interest is in language learning and teaching. 
Malay was to be a compulsory subject in all schools since it was the National Language. To make sure that it was taught, a knowledge of Malay would be a requirement for admission to all fully or partially assisted secondary schools and for entry into government service. English would be compulsory because of its utilitarian value. The pupil's own language, ie Chinese and Tamil, would be taught in primary schools where parents of fifteen or more children in a school requested it.

The main features of this policy were found suitable for the needs of the country by the Education Review Committee of 1960 and the policy has, with some modification, been in force to this day.

The national system of education today provides six years of universal free elementary education, the age of school entry being six. At the secondary level, education is no longer free, but all pupils who have had six years of primary education may go on to the three years of lower secondary education. At the end of this stage a national examination determines who are to be given places in the upper secondary classes. After two years in upper secondary school the pupils sit the school certificate examination. Those who plan to go for further studies and whose school certificate examination results qualify them for places in Form 6 continue in school for another two years.

According to the policy defined in 1957 , the six-year primary education was provided in four media: Malay, English, Chinese and Tamil. Parents could choose the medium of instruction for their children. When children from non-English-medium primary schools wanted to change over to English-medium secondary schools, they spent an extra year in a Remove Class to increase their proficiency in English. In 1968, Physical and Health Education, Art and Crafts, and Music began to be taught in Malay in Standards One, Two and Three in English-medium schools. This pattern of primary education continued until 1970.

At the time of independence, secondary education in assisted schools was offered only in the English and Chinese media. There were no Malay secondary schools until 1964, although from 1958 there were Malay-medium secondary classes attached to Malay primary schools and to English-medium secondary schools. With the policy of establishing fully-assisted national secondary schools only in the Malay and English media there has been a gradual elimination of the assisted Chinese secondary schools. In 1961 there were still 22 fully-assisted and 38 partially-assisted Chinese secondary schools. From 1962 onwards, assisted Chinese-medium secondary schools had to change their medium of instruction to English or Malay in order to qualify for financial aid. Therefore, except for independent and night schools, Chinese-medium secondary education was discontinued. There has been no assisted Tamil secondary school in this country.

$I$ indicated above that until 1970 primary education was provided in four media. In that year the policy of withdrawing English as a medium of instruction was begun. Why and how did this happen? As indicated above, at the time of independence it was written into the constitution that Malay would be the National Language and English the official second language. It was also decided that a transition period of ten years (1957-67) would be allowed for a gradual switch from the use of English to Malay for administration and education. It turned out that the changeover in language use was not proceeding at the anticipated pace for the nationalists, who were understandably impatient to express their independence from a language that reminded them of their erstwhile subservience. At their instigation, firmer steps were taken to ensure that Malay 
superseded English in administration and education. In the latter sphere, English was withdrawn as a medium of instruction.

Several changes came into effect in the school system in 1970. Firstly it was decided that, beginning with Standard One in 1970 and going up the educational ladder by one grade every year, Malay would replace English as the medium of instruction. This meant that by 1975 there would be no English-medium primary schools in the national system of education (although Chinese- and Tamil-medium primary schools are allowed to continue.) It also meant that by 1982 all secondary education (apart from private institutions) up to Form 6 (or pre-university classes) would be conducted in Malay. Tertiary education would have to follow suit. Secondly it was also decided that History, Geography and Civics were to be taught in the medium of Malay beginning from Standard Four. This meant that only Mathematics and Science would continue to be taught in English in Standard Four in 1970, since the other subjects (as indicated above) had been taught in Malay up to Standard Three. Another decision towards strengthening the position of the National Language was to replace the Cambridge School Certificate from 1970 onwards with the Malaysian Certificate of Education, for which a pass in Malay, but not in English, is compulsory. The equivalent certificate for Malay-medium students, the Sijil Pelajaran Malaysia, also requires a pass in Malay but not in English. In the classroom, then, English would be given less weight by the pupils, if not by the teachers.

It would appear from the above that the status of English is currently being depressed in relation to Malay by the authorities. It is no longer the medium of instruction in elementary education and by 1982 will cease to be so in secondary education. Though English is a compulsory second language for every pupil and is still used at present as a medium of instruction in some secondary classes, a pass in it is no longer a condition for obtaining the school leaving certificate. There is, however, a certain ambivalence in the official attitude towards English as a second language which is not surprising. While the spirit of nationalism and national pride call for use of the National Language, the need for English as the language of commerce, international communication, science, and technology cannot be denied. Hence, while the authorities and the media espouse the use of the National Language as a sign of the people's loyalty and as a tool to forge national unity, the importance of learning English and of maintaining a high standard of English is emphasized in speeches by Ministry of Education officials at school functions and seminars.

The repeated encouragement to study English is not mere lip service to the country's official second language. The desire to maintain the standard of English is sincere enough, though dropping the required pass in English from the school leaving examination (particularly in an examination-conscious school system) is bound to militate against the maintenance of standards. Syllabuses have been conscientiously revised and improved, teachers retrained, and materials devised to maintain the standard of English. National pride has even relaxed so far as to allow the establishment of English-medium junior science colleges (actually residential secondary schools focusing on science and technology) specifically for Malay pupils only. Such colleges intend to correct racial imbalances in the economic advantages which seem to accompany a science education. The cream of the Malay student population is directed to these schools. Another institution of learning meant only for Malay students, the MARA Institute of Technology, also uses English as a medium of instruction.

Another indicator of the importance accorded officially to English is the amount of time given to it on the school time-table: 
Table I

Primary School ${ }^{1}$

Pre- 1970 time allocation in number of minutes per week

\begin{tabular}{|l|c|c|c|c|c|c|}
\hline \multicolumn{1}{|c|}{ Language } & \multicolumn{5}{c|}{ Standards } \\
\hline \multirow{2}{*}{ National Language } & I & II & III & IV & V & VI \\
\cline { 2 - 7 } & 180 & 180 & 180 & 200 & 200 & 200 \\
Medium of instruction & 420 & 420 & 420 & 400 & 360 & 360 \\
English (second language) & 180 & 180 & 180 & 180 & 200 & 200 \\
Pupils' own language & - & - & 120 & 120 & 120 & 120 \\
\hline
\end{tabular}

Table II

Secondary School ${ }^{1}$

Time allocation in number of minutes per week

\begin{tabular}{|l|c|c|c|c|c|c|c|}
\hline \multicolumn{1}{|c|}{ Language } & \multicolumn{7}{|c|}{ Forms } \\
\hline \multirow{3}{*}{$\begin{array}{c}\text { National Language/English } \\
\text { Language } \\
\text { Medium of instruction }\end{array}$} & Remove & 1 & 2 & 3 & 4 & 5 & 6 \\
\cline { 2 - 8 } & 720 & 160 & 160 & 160 & 160 & 160 & 80 \\
\hline
\end{tabular}

Since the Ministry of Education has stressed the need to maintain the standard of English obtaining when English was a medium of instruction, syllabus committees have fought for more time for English in their revision of English syllabuses. However, an increase of time for English entails a similar increase for Malay. The new allocation of time to English is given in Table III below.

We have been looking at the status of English in school from the official point of view. Let us now look at it from the consumers' point of view. Here the enrolment trends in schools of various media in the years 1947-1969 are revealing. Table $I V, V$ and Figure $I$ show these enrolment trends. 
Table III

Post-1970 allocation of time for English Language

\begin{tabular}{|c|l|c|}
\hline \multicolumn{1}{|c|}{ TYPE OF SCHOOL } & LEVEL & TIME \\
\hline $\begin{array}{c}\text { Malay-medium } \\
\text { primary }\end{array}$ & Std. I-VI & 300 mins. per week \\
\hline $\begin{array}{c}\text { English-medium } \\
\text { primary }\end{array}$ & Std. I-VI & 300 mins. per week \\
\hline $\begin{array}{c}\text { Chinese/Tamil-medium } \\
\text { primary }\end{array}$ & $\begin{array}{l}\text { Std. I-II } \\
\text { Std. III } \\
\text { Std. IV } \\
\text { Std. V-VI }\end{array}$ & $\begin{array}{l}120 \text { mins. per week } \\
160 \text { mins. per week } \\
200 \text { mins. per week }\end{array}$ \\
\hline $\begin{array}{c}\text { Form Remove from } \\
\text { Chinese/Tamil } \\
\text { medium }\end{array}$ & Form Remove & 200 mins. per week \\
\hline $\begin{array}{c}\text { Malay-medium } \\
\text { secondary }\end{array}$ & Form 1 -3 & $\begin{array}{l}240 \text { mins. per. week } \\
240 \text { mins. per week }\end{array}$ \\
\hline $\begin{array}{c}\text { English-medium } \\
\text { secondary }\end{array}$ & Form $4-5$ & 240 mins. per week \\
\hline
\end{tabular}

Table IV

\begin{tabular}{|l|rrrr|}
\hline \multirow{2}{*}{ Medium } & \multicolumn{4}{|c|}{ Primary $^{2}$} \\
\cline { 2 - 5 } & 1947 & 1957 & 1967 & 1969 \\
\hline Malay & 164,528 & 441,567 & 591,560 & 603,410 \\
English & 45,174 & 130,360 & 289,056 & 326,306 \\
Chinese & 139,191 & 310,458 & 355,771 & 378,679 \\
Tamil & 33,954 & 50,766 & 79,203 & 80,750 \\
\hline
\end{tabular}

Table V ${ }^{2}$

\begin{tabular}{|c|c|c|c|c|}
\hline \multirow{2}{*}{ Medium } & \multicolumn{4}{|c|}{ Secondary } \\
\hline & 1947 & 1957 & 1967 & 1969 \\
\hline Malay $^{+}$ & - & 2,315 & 128,069 & 134,889 \\
\hline English & 12,510 & 48,235 & 286,254 & 333,927 \\
\hline Chinese $^{++}$ & 2,692 & 30,052 & - & - \\
\hline Tamil & 93 & 440 & - & - \\
\hline
\end{tabular}

+ Secondary education in the Malay medium started in 1956.

++ Assisted secondary education in Chinese stopped in 1961. 
ENGLISH AND OTHER LANGUAGES IN SCHOOLS IN MALAYSIA

FIGURE 1

HISTORICAL TRENDS IN ENROLMENT BY MEDIA ${ }^{3}$

(1957-1968)

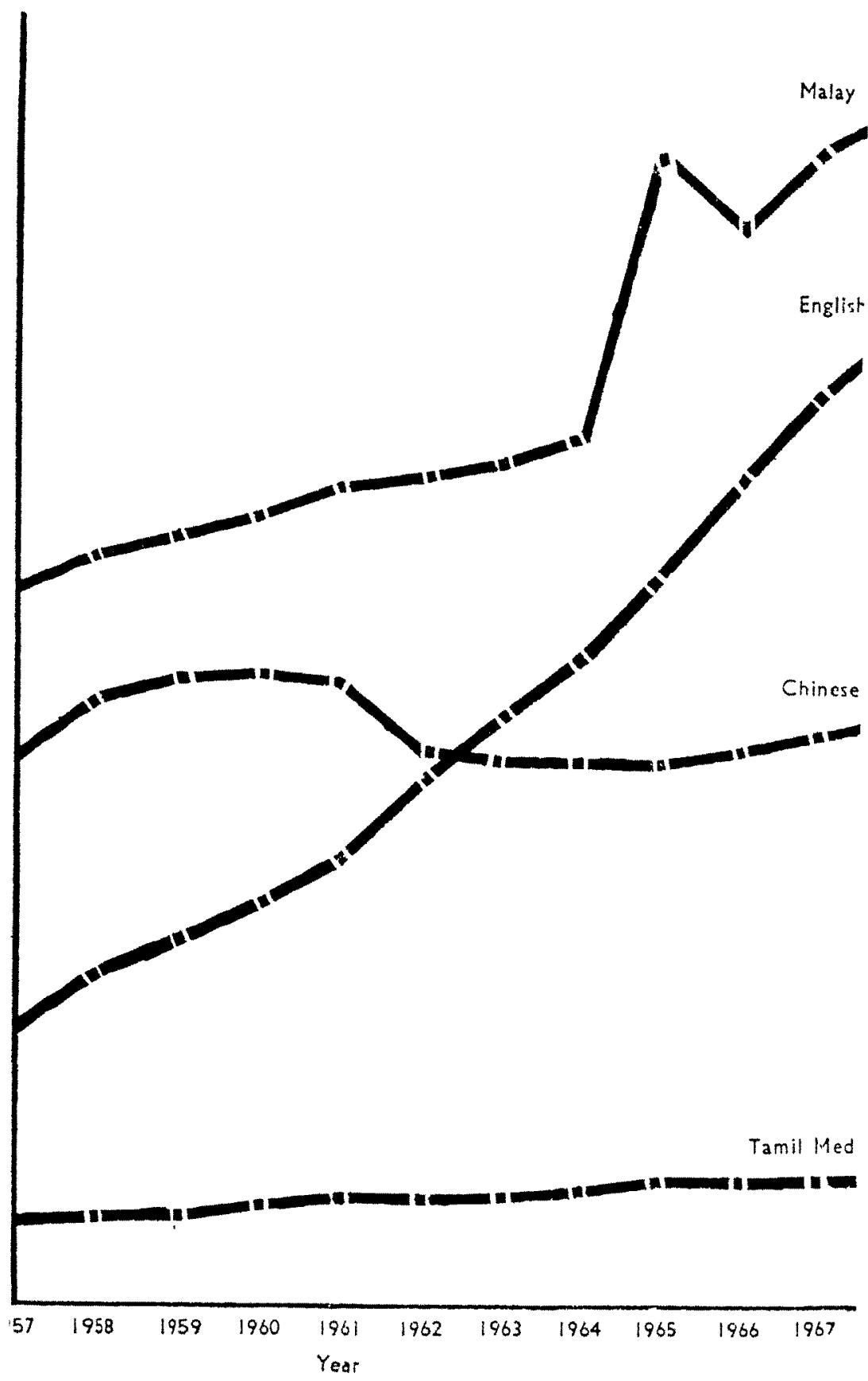


To summarize, it may be said that English as the official second language of the country is given importance in the school curriculum. Every pupil is required to learn it, though it is no longer compulsory to obtain a pass in the English section of the school leaving examinations. However, English is no longer a medium of instruction in the primary school and will cease to be a medium in the secondary school by 1982 . Chinese and Tamil are still used as media of instruction in primary education but they are not compulsory subjects in the school curriculum for everyone. Malay as the National Language is given priority. It is compulsory for everyone to learn it and to pass it in the examinations. Certain occupations require a credit in Malay in the school leaving examination. The status given to Malay is a consequence of its being the National Language and, as such, a tool of national unity in Malaysia's multiracial and multilingual society.

\section{Notes}

1. Figures taken from Education in Malaysia, p.23.

2. The figures are obtained from Educational Statistics of Malaysia 1938-1967; and Musa, B. and Harun, S., 1970.

3. Reproduced from Education in Malaysia, p.12. 


\title{
BILINGUAL EDUCATION IN THE PEOPLE'S REPUBLIC OF CHINA
}

\author{
Alain Peyraube
}

Not much information is available on the practice of bilingual education in The People's Republic of China since it is now impossible to carry out any field work, whether in the national minority regions or in the South (Eastern) dialectal areas. Therefore, the few remarks that I will present today will be very general.

The problems involved in bilingual education in China are dealt with by the Education Bureau and especially by the Committee for Language Reform 文字改 革委員會 headed by Ye Laishi 葉賴士.1 The tasks of this Committee are threefold; they are the same as those defined by Chou En-lai in 1958, ie (i) the simplification and classification of characters, (ii) the popularization of the Common Language (普通話 Pưtónghuà),(iii) the teaching of the Chinese phonetic alphabet 嫨語拚音 and the extension of its use.

The second task is, of course, the most important one for bilingual education. It is through the popularization of Pütonghuà that many people can acquire a bilingual education. This Common Language has been defined as follows : (i) its pronunciation is based on the Peking dialect, (ii) its grammatical rules are those found in the báihuà 白 話 writings (vernacular literature), (iii) its vocabulary has been borrowed from the Northern dialects 北方話. The Northern dialects cover three-quarters of the geographical space where Chinese is spoken, which represents more than $70 \%$ of the Chinese speakers, or about five hundred million people. Apart from the area of the Northern dialects where bilingual education does not pose a problem because the dialects are closer to the National Language, we have to draw a distinction between the areas of the national minorities and the dialectal areas. It should be understood, of course, that the Chinese dialects are so different from the Common Language that they can be considered separate languages as far as the problem of bilingual education is concerned.

\section{The National Minority Areas}

Apart from the Han Chinese, the 54 national minorities represent 6 per cent the whole population of China but occupy 50-60 per cent of its territory (Dictionary of Usual Chinese. 1973). In these regions the penetration of Pǔtönghuà is very slight and bilingual education is consequently limited. This is not only true of the immense territories of Inner Mongolia, Tibet or Xinjiang, which are autonomous regions, but also of the regions where the national minorities are more in contact with the Chinese population, $e g$ the Lìsù 僳 僳 in Yunnan or the Mùlăo 伀佬 in Guangxi, etc. However, where the national minority languages do not yet have a writing system (this is, for instance, the case for the Mùlăo language but not for the Lisù language which used to be a non-written language, and for which a Pinyin based orthography has been created recently), bilingual education is facilitated since phoneticization and schooling are necessarily carried out in

Dr. Peyraube received his Maitrise in Literature and Linguistics from the University of Bordeaux III and his Doctorat de III cycle in Linguistics from the University of Paris VIII. He also studied Chinese Language and Linguistics for two years at Peking University. His major area of research is Chinese dialects. 
Pǔtōnghuà. Actually, the results are quite varied. The children going to school can at least read and sometimes write Mandarin, but when they have completed their schooling and remain in their family and local communities they forget rather quickly most of the Pütönghuà they have learned. Only a few of them who leave their native villages for other regions will have a complete bilingual education.

As for the important national minorities like Zhuang, Tibetans, Uighurs, Mongolians, etc, the teaching in primary and secondary schools is conducted in the minority languages in question. The State Council asked all the schools of the nation to use Pütonghuà as the medium of instruction but the policy in minority language areas is different. So, in all the autonomous regions the local national minority language is the language of instruction in primary and secondary schools. There, school attendance is more widespread since there is no conflict between education and the socio-cultural values of those minorities. The students can also learn some Pütónghuà, but only when they are sent to secondary schools, where (in the same way as the Peking students who learn foreign languages such as English or French) they have two Pütönghuá classes a week, ie four hours. But there are very few secondary schools, in spite of an increase in the past few years. In 1965 there were only seven secondary schools and 1,970 primary schools in Tibet, and 315 secondary schools for 7,015 primary schools in the autonomous Uighur region in Xinjiang. In 1974 there were 2,600 primary schools for 120,000 pupils in Tibet (the number of secondary schools is not known) and 854 secondary schools and 10,051 primary schools in the autonomous Uighur region in Xinjiang. ${ }^{2}$

If the students have the opportunity to be sent to specialized institutes or universities, they will have a chance to learn more Putōnghuà as, according to Mao Tse Tung's instructions in 1958, 'All the cadres must learn Pưtōnghud.' Because of the very limited number of high schools and universities in the national minorities areas (in Tibet, for instance, there are only two high schools, one normal school and an institute for nationalities), the students are generally sent to other provinces when they need to study Pütônghud. During the years 1971-1972 four hundred Tibetans were sent to superior schools, mostly in Peking and Shanxi. They encountered many language problems and had to go through probational linguistic training. In Peking they are generally sent to the Central Institute for Nationalities 中央民族學院 where they first learn Pǔtönghuà for one year, before going to Peking universities or other universities to study scientific or literary subjects. Their situation is quite similar to that of the foreign students who study Chinese intensively at the Peking Language Institute 北京語言學院 for approximatively one year before going to the universities of Peking, Nanking, Shanghai, Canton or Shenyang. The students coming from national minority areas can also stay three years at the Central Institute for Nationalities. There they acquire general political training before going back to their native provinces, where they will eventually work as local representatives of the Central government. These students will be true bilinguals.

Others potentially acquiring bilingual education are Han Chinese sent to national minority areas to work. In 1974, 389 teachers from Shanghai (85), Henan (35), Liaoning, Jiangsu and Hunan were sent to Tibet. 2 They were required to leam the language spoken in the areas to which they were sent. But this is mostly the case for the young students 知識青年 who settle in national minority areas. They outnumber the teachers sent to those regions. Since the Cultural Revolution 110,000 young people from Shanghai have been sent to Mongolia and have stayed there. In 1976,24 graduate students from superior or technical schools of Peking were sent to Tibet. 


\section{BILINGUAL EDUCATION IN THE PEOPLE'S REPUBLIC CHINA}

Finally, one must mention the cases of some national minorities such as the Manchus who are almost completely assimilated to the Han Chinese in both their language and customs, or the minorities like the Hui (回) who probably never had a separate language and who differ from the Han Chinese primarily in their religion (Hui people are Muslim). For them, of course, there is no problem of bilingualism.

\section{The Dialectal Areas}

With respect to the dialectal areas (Wú 吳，Xiāng 湘，Gàn 贑，Kèjiā 客 家，Yuè 粤 and Min 閩 ) ${ }^{3}$ mainly localized in Southern China, the penetration of $P \breve{u}$ tônghuà has been easier and bilingual education more widely spread. This is essentially due to the fact that the socio-cultural values of the Southern Chinese are closer to those of the Northern Chinese; they belong to the same civilization and use the same script (this was not the case for the national minorities). But until now the efforts of the Committee for Language Reform have not been really successful. Owing to a rather inconsistent policy these past few years no real achievement can be seen. A strong movement hostile to the concrete measures taken by the Language Reform Committee and the State Affairs Council in 1958 has been a hindrance to the implementation of an efficient policy concerning the popularization of Pütónghuà.

The present authorities explain the insufficient results using the argument of a permanent 'struggle between two trends'. The 'village of the three families' 三家村 兒 (Wu Han, Deng Tuo and Liao Mosha), Lu Dingyi and Liu Shaoqi first, then Lin Biao and Chen Boda, and now the 'gang of four' (especially Jiang Qing) have been accused of promoting such aphorisms as: 'If we do not popularize Pütōnghuà in the next hundred years, it will not kill anybody.' This has given birth to an 'ultra-conservatism' and a 'pessimism' among many cadres, who thought that 'the popularization of Pưtónghuà is necessary but so difficult to realize!' This 'conservatism/pessimism' of the cadres has inevitably created a mass reaction against $P \breve{u} t o ̈ n g h u d$. Parents rail against their children who speak Pŭtonghuda at home: 'Stop speaking this Pekinese jargon. Have you forgotten your ongin?' Teachers claim that 'popularization of Pütönghuà has nothing to do with the mathematics teachers and only concerns the language teachers.' Peasants criticize cadres or intellectuals speaking Pütönghuã : 'To speak Pütōnghuà is to stand away from poor and lower middle class peasant;' 'We are neither afraid of heaven nor of hell, we are only afraid of the cadres speaking P̌̌tönghuă( 天不怕, 地不怕, 只怕幹部講 普通話 ). ${ }^{4}$

The above reactions against Pütönghuă have been criticized lately as the 'three fears' 三怕 : (i) The fear or difficulty of being too old to learn; (ii) The fear of speaking incorrectly and appearing ridiculous; (iii) The fear of lowering the quality of teaching (Guangming Ribao, 25 May 1974.)

Let us now try to evaluate how successful the popularization of Pütonghuà and consequently bilingual education has been. Comparing today's situation with that in 1957 we can observe that not much progress has been made. In 1957,721,000 teachers of primary and secondary schools learned Pütonghud, more than two million people listened to the phonetics lessons in Pütonghuà on the radio, and more than five million booklets dealing with the popularization of Pütönghuà were sold (Wu Yuzhang, 1958). Many linguists visiting China have been impressed by the popularization of Pütonghuà among the young Chinese in some dialectal areas. In actual fact the situation is merely satisfactory only in relatively large towns where the young Chinese have obtained a successful bilingual education and can speak Pütönghud, if only with a dialectal accent. 


\section{STUDIES IN BILINGUAL EDUCATION}

However, as the Chinese themselves say, it is necessary to focus on the countryside because peasants comprise about 78 per cent of China's population. In the countryside, young people have not received a good bilingual education. When they go to school the only course they take in Pütonghuà is the language course. Other subjects (mathematics, history, etc) are taught in dialects. People's Communes like Jinshan (in Jiangsu) are all too rare. Published in the 17 December 1973 issue of People's Daily, the story of this district was considered a model worthy of study. In 1972, in four brigades out of a total of 23 , the teachers of primary and secondary schools were using Pütönghuà. At the end of 1973 it became the language of teaching in most of the schools and 85 percent of teachers were able to speak Pütōnghuà.

Currently, much effort is being made to popularize Pưtōnghuà as an official language at political meetings. This has been quite successful and gradually the use of Pǔtonghud in political or intellectual speech increases. However, it is never used as a familiar language (with family or friends). Having learned P̌̌tónghuă, a Han Chinese coming from dialectal areas knows essentially what the Chinese linguists call written language 書面語， which is also the language of politics. But he has many difficulties in understanding a speech in spoken Pütōnghud $\square$ 語 , whose lexical heritage has its origin in a different dialectal stock.

This then is a brief overview of the practice of bilingual education in China. For the Chinese it does not pose a very important problem. The nation is still focusing on education as such because, while there has been noticeable improvement in mass literacy since the Cultural Revolution, there still remain a large number of illiterate people in the whole of China. It was reported in a conference given at the University of Peking on 7 December 1973 that results of previous efforts to reduce illiteracy among the young peasants throughout China still have fallen short of expectation. Various figures on illiteracy within this group have been reported within China, the lowest of which varies between 40 to 50 per cent. * This is the main problem that has to be solved before the question of bilingual education concerning young Chinese who live in the national minority areas or in the dialectal areas can be tackled.

\section{Notes}

1. For the activities of this committee see Milsky (1973) and Lehmann (1975).

2. Information taken from issues No. 12 (27 April 1972), No.41 (15 October 1973), and No. 33 (19 August 1974) of Pékin-Information.

3. Chinese linguists in the People's Republic of China presently divide the Chunese dialects into seven dialectal groups: Northern, Wú, Xiāng, Gàn, Kèjiä, Yuè and Mín dialect. The population considers generally that there are 'eight great dialects' (八大方言), the Min dialects being divided into two groups: Southern Min （閩南）and Northern Min（閩北）. 
4. For the above citation, People's Daily（人民日報 ） 17 December 1973; and Guangming Ribao (光明日報) 10 June 1974 .

This latest aphorism has been recently created from the following well-known one: 'We are afraid neither of heaven nor hell. We, are only afraid of a Cantonese speaking Mandarin.' ( 天不怕, 地不怕, 只怕廣東人講官話)

*Editorial Note: These figures have not been confirmed officially. Other figures are available which conflict with this information. It is likely that controversies about literacy figures will remain for some time to come. The major problem has to do with the definition of literacy in the Chinese context. Two not unrelated approaches can be followed: (1) by minimum number of years of schooling, or (2) by minimum number of characters in the individual's repertoire. Figures from for the first ap. proach are readily obtainable, but given uneven standards of education throughout the rural areas and interruption during the Cultural Revolution, the meaningfulness of such figures is reduced. On the other hand, figures from the second approach are much harder to come by and may also be open to question as to what may be considered the minimum standard - whether it be in the active or passive repertoire of the individual. 


\title{
PRESENT TRENDS IN THE SOCIOLINGUISTIC SITUATION IN PAPUA NEW GUINEA
}

\author{
Stephen A. Wurm
}

\section{Introductory Remarks}

The area stretching from the Timor-Alor-Pantar Islands and Halmahera in the west across the New Guinea mainland and adjacent islands to the eastern end of the Solomon Islands in the east is known as the New Guinea Area. This area is the linguistically most varied and complex of any comparably small part of the world, with over a thousand languages located in it. Of these, the greater part are found in the newly independent country of Papua New Guinea.

\section{The Indigenous Languages in Papua New Guinea}

The number of distinct indigenous languages in Papua New Guinea is about 760 . Most of these languages are spoken by small to very small speech communities comprising from a few dozen to a few thousand speakers each. Only a relatively small proportion of these languages have more than 10,000 speakers, and the most widely spoken language, Enga, spoken in the highlands area, has only about 150,000 speakers.

\section{Lingua Francas in Papua New Guinea}

This extremely complex language situation has been a favourable background for widespread bilingualism and multilingualism. It is not at all surprising that it has also led to the emergence of a number of lingua francas in the area as soon as social situations developed in which there was a need for intercommunication across several language boundaries - especially intercommunication going beyond that with neighbouring language communities. In what is the area occupied today by Papua New Guinea, three distinct situations of this kind occurred in the past, which led to the development of three different types of lingua francas, at least two of which have been brought into existence directly through the impact of the modern world. In addition to these, English, a fourth lingua franca, made its appearance as a result of planned introduction.

\subsection{Missionary Lingua Francas}

One of these three types of lingua franca is constituted by the missionary lingua franca which resulted from the adoption of certain local languages by various missions for their activities, including education. In most cases, the missions did not pay very much attention to selecting a language for its potential suitability as a lingua franca, ie taking into account the number of its speakers in contrast to those of other languages of the area, examining its close relationship or dissimilarity to neighbouring languages, evaluating the potential prestige of the tribe

Professor Wurm obtained his Diploma and D. Phil. in Linguistics, Anthropology and Oriental Studies from the University of Vienna and has worked in the areas of Sociolingtistics and Anthropological Linguistics, with particular reference to Pacific and Oceanic languages, and Turkic languages. He is currently Professor of Linguistics at the Advanced School for Pacific Studies at the Australian National University. 
speaking it, etc. Often, these factors were not known when the missions were first established in certain areas, especially in the early days of missionary activity in what is today Papua New Guinea. The missions were more concerned with whether the mission locations for the intended missionary activities were suitable. The language of the location chosen was then adopted as the mission language. As a result, some of the missionary lingua francas in Papua New Guinea were quite suitable candidates for adoption in the light of the factors mentioned above; whereas, with others, this was not the case.

With the expansion of the activities of missions beyond the boundaries of the areas in which the languages which they had adopted as 'Mission' languages were tribally spoken, and with the continuing use of these languages by the missions in the linguistically different neighbouring areas, the use of these languages was artificially extended, at least for matters relating to missionary and church activities, as well as for associated activities such as education. This fact made these languages regional lingua francas, but their currency was largely restricted to speakers who belonged to a particular social orientation, ie the orientation represented by the missions involved, and their activities. At the same time, the tribe whose language had been adopted by a mission as the church language and missionary lingua franca, and also the language itself, tended to rise in prestige in the eyes of indigenes who were not committed to that particular mission and church (unless they were committed to a different mission using another lingua franca). Such indigenes were sometimes inclined to look towards that tribe, the successful mastery of the lingua franca and, as a result, the mission itself, as a source of possible economic and other advantage. This situation sometimes led to the spread of a missionary lingua franca to an adjacent area - Kâte, one of the three church languages used by the New Guinea Lutheran Mission, is such a language (Wurm. 1966a).

When English was adopted as the language of primary education in the midfifties, this brought about (see below 4.7) a decline in the use, and the narrowing of the functions, of missionary lingua francas. Events in recent years caused them to recede more and more before the onslaught of New Guinea Pidgin, and to a much lesser extent Hiri Motu, in a number of instances.

\subsection{Hiri Motu}

The second type of lingua franca in Papua New Guinea is represented by Hiri Motu (formerly called Police Motu). This language is a native-based pidgin language which came in to being as a lingua franca used within and by the native police force in British New Guinea, ie Papua, around the turn of the twentieth century (Dutton and Brown. 1976). Hence its name 'Police Motu'. Before that time, ie in preEuropean times, a special trade language (or languages) was (or were) used by members of the Motu tribe, who lived in the present-day Port Moresby area. On their frequent trading expeditions to the west, to the present Kerema coastal area in the Gulf District, they bartered clay pots, shell ornaments and stone axes for sago, canoe logs, and other products. This trade language, of which we have only few and unreliable records, may well have been a simplified Motu (an Austronesian language) with a high lexical content from the Papuan, ie non-Austronesian languages of the Kerema area, with some structural modifications reflecting that Papuan influence. 


\section{STUDIES IN BILINGUAL EDUCATION}

Whether the lingua franca adopted by the police force represented a new development unrelated to the trade language mentioned above or whether it was a continuation of one (or more) of these or a modification of it, it is difficult to say without evidence. Dutton and Brown (1976) mention, however, that it seems likely, in view of the fact that the police force consisted largely of Papuans from outside the area of Motu proper, that some form of the trade language, re-lexified with Motu vocabulary, formed the basis of the new lingua franca, which is not readily comprehensible to speakers of Motu proper if they have not previously been exposed to it (Wum. 1964).

Over the years, the language spread as a far-flung, but still regional, lingua framca through most of Papua. Between World Wars I and II its encouragement as a lingua franca and its use by the police force and administration officers led to the elimination of Pidgin in Papua for that period. Since the end of World War II, and particularly during the last decade, Police Motu had more or less rapidly been receding before New Guinea Pidgin in Papua and losing its importance in many areas. This development was a consequence of the rapid spread of Pidgin as a lingua franca throughout Papua New Guinea, and of the influx of Pidgin speakers into areas which Police Motu used to dominate. The unwillingness of most Europeans living in Papua to learn Police Motu, and their decided preference for Pidgin (of which most Europeans in Papua New Guinea had at least a rudimentary knowledge) can also be assumed to have aided this development. In recent years, since the rapid progress towards self-government in Papua New Guinea, and independence in 1975, the New Guinea Government took more or less conscious steps to influence the respective positions of Pidgin and Police Motu. For instance, the prevalent use of Pidgin as a debate language in the Papua New Guinea House of Assembly, in contrast to Police Motu, which was hardly used though equally admissible under the rules; the much more extensive use of Pidgin than Police Motu in the news media; the encouragement of the use of Pidgin in primary education, etc. All this seemed to be a bad omen for the future of Police Motu, which in very recent times has, however, made a strong recovery. In parts of Papua it has been adopted as a symbol of self-identity, and has been chosen as a rallying point for the separatist movement in Papua. As a result, Police Motu - now renamed Hiri Motu - has sharply risen in prestige, and also in the numbers of its speakers. Indigenes from Pidgin areas who live in Port Moresby, for instance, and who for many years have found it unnecessary to acquire a knowledge of the language now face social situations in which there is heavy pressure on them to know Hiri Motu; and its knowledge is rapidly spreading amongst them. Mastery of Hiri Motu or Pidgin is now one of the pre requisites for Papua New Guinea citizenship and, in general, the language is now treated officially by the Papua New Guinea Government as a major common language, equivalent to Pidgin.

\subsection{New Guinea Pidgin}

The third type of lingua franca in Papua New Guinea is represented by New Guinea Pidgin. Contrary to earlier views (Wurm. 1966a) which held that New Guinea Pidgin owed its origin directly to Queensland Plantation Pidgin, itself a descendant of nineteenth-century South Seas Pidgin English, recent research by Mühlhäusler (1975a) has shown that the influence of Queensland Plantation English upon the development of New Guinea Pidgin has been secondary and more indirect, ie to a greater extent via the main recruiting areas of contract labour for the 
South Seas plantations. At the same time, Miuhlhäusler was able to establish that the earliest form of a stable New Guinea Pidgin was found in the area of the Duke of York Islands, to the north of the Gazelle Peninsula of New Britain, around 1882. Mühlhäusler holds the view that the establishment of this earliest form of New Guinea Pidgin owes its origin to the development of a stabilized plantation Pidgin on Samoa. Recruitment for the Samoa plantations was, after 1879 , from the Duke of York area, and the first labourers returned there from Samoa in 1882. This is the year in which the first plantations were established in the Blanche Bay area of the Gazelle Peninsula of New Britain, and on Bulea, with labour from Bougainville and New Ireland. It seems plausible to suggest that experienced ex-Samoan labourers were employed as overseers. The newly stabilized language seems to have subsequently gone through an enrichment of its lexicon from Tolai and German in the adminstrative centre of Rabaul, on the Gazelle Peninsula. With the spread of administrative control and pacification through much of German New Guinea, Pidgin was spread through the area by the police and administration. In the wake of pacification, intercommunication across tribal boundaries became important, and New Guinea Pidgin became nativized. Its primary function evolved as a linguistic tool for intertribal communication, which resulted in its becoming an expanded pidgin very close to the speaker's first language in its range of expression and functions.

When German New Guinea was taken over by the British and Australian forces in 1914, New Guinea Pidgin was firmly established in the area. Its stabilization, nativization and spread continued thereafter, and regional dialects and distinct social dialects began to develop. The Catholic Mission's efforts toward the standardization of Pidgin in the fields of orthography, lexicon and grammar had the result that two standardized Catholic Mission dialects (mainland and islands) developed, because of differences of opinion held by the Catholic Missions in New Britain on the one hand, and in Alexishafen near Madang on the mainland on the other. Also, the standardization and description by the Catholic Mission tended to lag behind the linguistic developments in spoken Pidgin, and resul ted in the emergence of a kind of archaic Church Pidgin. At the same time, towards the midthirties, Pidgin began to spread in the Highlands. Its main source was the anglicized Pidgin spoken by many patrol officers and other members of the administration.

World War II brought about a fundamental change in the social structure of Papua New Guinea and led to the emergence of new social patterns in which Pidgin was to have new functions (Mühlhäusler 1976a). The importance of Pidgin was suddenly recognized by the Australian authorities, and the pre-war social barriers between indigenes and Europeans broke down, especially as far as members of the armed forces were concerned. Pidgin began to function as a means of expressing solidarity among all racial groups in Papua New Guinea. At the same time, there was a large-scale use of Pidgin in war propaganda, with a view to strong social control. In addition, the large-scale recruiting by the armed forces of indigenes from many, often remote, areas as carriers and labourers led to an increase in the number of the speakers of Pidgin, and resulted in its spread into new areas:

After the end of World War II, Pidgin continued and accelerated its spread through Papua New Guinea; a regional dialect became stabilized and nativized in the Highlands; and Pidgin began to make inroads into the realm of Police Motu, 
the first steps towards which had already taken place during the war years. The breaking down of the social barriers between indigenes and Europeans, initiated during the war. continued and resulted in the gradual change of Pidgin from a low-caste language to one suited for new roles in the changed Papua New Guinea society.

In the mid-fifties an event of fundamental importance took place on the Papua New Guinea sociolinguistic scene: English began, for the first time, to play a major role in regard to the indigenous population, with primary schools switching to English as the main (in the Government schools the only) medium of instruction. Indigenes were beginning to be encouraged to learn and use English. At the same time, in 1953, the United Nations Organization called upon Australia (Hall. 1955) to discontinue the use of Pidgin in the then Trust Territory of New Guinea. This constituted an unrealistic and ill-informed pronouncement, because the Australian administration had no control over the use at that time of the nativized lingua franca, whose main function was to serve as a means of intercommunication within the indigenous population. The pronouncement did however have the effect of strengthening the pro-English language policies of the administration; though, after that time, the spread of Pidgin accelerated at an ever-increasing rate, both geographically and with regard to the widening of its social functions. A new social dialect of Pidgin - Urban Pidgin - which had previously had only a limited existence, became well established and developed. New styles such as written style, style of radio announcing,etc emerged. Regional dialect development, especially in the Highlands, first reached a peak during the early sixties, but subsequently there was a gradual neutralization of regional variants of Pidgin as a result of the increasing mobility of the population, and the widening impact of mass media. English influence on Pidgin steadily increased, in particular on Urban Pidgin. Creolization of Pidgin began in some areas, though it had little influence on the form of the language, for sociolinguistic reasons. The children who were and are speakers of creolized Pidgin had to conform to forms of Pidgin which already constituted a nativized, extended pidgin in constant daily use in inter-native communication situations.

During the seventies, the expansion of the functions of Pidgin accelerated: Pidgin became the first and main debate language in the Papua New Guinea House of Assembly. It was more and more used in the news media, and began to be used again in primary education. It became the intrinsic means of expression of a new 'contact culture', which lies between the traditional culture and European culture, embodying elements from both, but remaining different from both of them. With the extension and spread of this sub-culture at the expense of tradition, the functional and geographical role of Pidgin increased, and Pidgin entered into a diglossic relation with English in urban environments. Social dialects became clearly established, with Rural Pidgin and Urban Pidgin the main variants, and Bush Pidgin and Tok Masta (the broken English spoken by Europeans) as fringe forms (Mühlhäusler. 1975b, 1976b, c). At the same time, the stabilization of Pidgin, and its regional and social-dialectal uniformity, was eroded in some areas, with fluidity and variability appearing at an increasing rate. This development is largely attributable to the powerful influence of English, and to the fact that, due to the lack of insight into the nature of Pidgin and insufficient coordination in what little language planning there was, the necessary linguistic extension accompanying the functional extensions of Pidgin took place in an ad hoc way 
(Mühlhäuser. 1976e). This arbitrary extension has endangered the continued existence of Pidgin as a separate language through the gradual destruction of its basic underlying rules.

\subsection{English}

When discussing lingua francas in Papua New Guinea, English must also be briefly mentioned. Sociolinguistically, it differs fundamentally from the languages mentioned so far in being a language directly introduced into the area by the colonial rulers and masters whose language it was. In this context it besame a lingua franca as the result of strict language planning and control.

At the same time, in Papua New Guinea, English has not in any form been subject to language planning actions aimed at changing or enlarging its content and structure (disregarding some very limited attempts at the use of Basic English in Papua New Guinea). However, English constitutes the target and lexifying language for at least one of the two major lingua francas of the area, viz. Pidgin; Hiri Moru also being affected, though to a much lesser degree. The pervading influence of English has already exerted a decisive influence on the linguistic structure of at least one of the main social dialects of New Guinea Pidgin - Urban Pidgin.

\section{The Sociolinguistic Position of the of Languages Papua New Guinea Today}

\subsection{Introductory Remarks}

The discussion of the various sociolinguistic types of languages in Papua New Guinea, as given above in sections 2 and 3 has touched upon a number of the sociolinguistic factors connected with these diverse language types. The present sociolinguistic position and relationship of the various language types encountered in Papua New Guinea can be seen to be as follows:

As has been pointed out above at the beginning of section 3 , widespread bilingualism and multilingualism has been a characteristic feature of the Papua New Guinea area. This statement is more than ever valid for the greater part of the population of Papua New Guinea today, which can be said to live in a culture of multilingualism. About half the population is bilingual in a local language and Pidgin. This half of the population has, in addition, at least some knowledge of English or Hiri Motu, or both, as well as of an additional local or missionary lingua franca. Apart from this, at least passive bilingualism and multilingualism in local languages is quite common. Other members of the population may be at home in one or several local languages and Hiri Motu, with a knowledge of English often added to this. In fact, the basic education system, as envisaged for Papua New Guinea under today's language policy, aims for at least a bilingual education in a local language and one of the two major lingua francas, Pidgin or Hiri Motu, with English playing a part on higher levels as the third language (see below 4.7). As a result, educated Papua New Guineans are, as a rule, at least trilingual, though often they may know more than three languages.

A counter-balance to this situation is observable in the 'contact culture' mentioned above in 3.3 , whose means of expression is Pidgin. This sub-culture, which is 
rapidly growing and is typically modern Papua New Guinean, is characterized by a conscious rejection of all that is traditional, including the local languages. This results in many Papua New Guineans adopting Pidgin, not in addition to their local languages, but as a replacement (Mühlhäusler. 1976d). With this culture, Pidgin has entered into a diglossic relation with English in urban environments (as has been pointed out above in 3.3), but many of the members of this sub-culture lack a knowledge of English. The increasing creolization of Pidgin is another factor with a tendency towards restricting bilingualism. It is closely connected with the spread of this sub-culture and is also a consequence of the increased mobility of the population. Members of different language communities intermarry with increasing frequency, and as husband and wife have Pidgin as their only common language their children learn Pidgin as their first language and often do not learn a local language.

The social roles and functions of the sociolinguistic types of languages found in Papua New Guinea today are fairly clearly definable, even though their mutual relationships are quite complex. With all the types two distinct facets of their use can be distinguished: one of them pragmatic, and the other emotionally based.

\subsection{Social Roles of the Local Languages}

The local languages are the languages used in day-to-day activities in village life, against the background of a traditional or at least semi-traditional setting. They are the languages used in homes by members of families, even if they are removed from the village setting. This usage, though still largely pragmatic, extends to the emotional side, in assuring and strengthening the internal cohesion of families and their ethnic links with their home village and home area.

On the emotional level, the local language serves this same purpose for members of a speech community who are removed from their homes and who use their local language as a powerful means for asserting and signalling the ethnic bond between themselves and their speech community. In this respect the local language has a growing importance with the increasing mobility of indigenes in Papua New Guinea. It helps them to maintain links with each other and with their traditional culture and home. This is only true as long as their tradition and culture does not succumb to the steadily strengthening influence of the new Papua New Guinean 'contact culture' mentioned above in 3.3 , and as long as their local language is not replaced by Pidgin, the specific language of this 'contact culture.'

Recently, local languages have again become admissible for the purpose of elementary education, and are used for this purpose to a limited extent (see below, section 4.7). The government and its agencies responsible for education appear to be motivated in this by their desire that members of the population should not lose their links with local traditions within the framework of the new Papua New Guinean nation. This respresents another social function of the local languages which is, at least in part, emotionally based.

\subsection{Social Roles of the Missionary and Local Lingua Francas}

The various missionary and local lingua francas which have been current in New Guinea have, in recent years, lost considerable ground to the two major lingua 
francas as well as to English. Their use continues to some extent in church and associated religious activities. Their continued use on the secular level is today not often purely pragmatic, ie serving the purpose of intercommunication between speakers with differing local languages, but tends to be somewhat emotionally based. It asserts and emphasizes the common membership of the speakers to a particular cultural institution (in this case the mission) which employs a certain lingua franca.

\subsection{Social Roles of Hiri Motu}

On the pragmatic level, Hiri Motu is widely used in Papua ie the area of the former Territory of Papua. It is used as a means of intercommunication between speakers of different local languages, and is also quite extensively resorted to in the news media. Both these usages are on the increase at present in some areas, and their rapid decline in other areas has been checked. As already pointed out in 3.2, Hiri Motu was rapidly giving in to Pidgin until it received a powerful emotionally based boost as a result of the awakening of Papuan local nationalism, culminating in Papua political separatism (Wurm. 1976a), and as a consequence of the adoption of Hiri Motu as a symbol of regional self-identity by many of the inhabitants of Papua. In spite of the much smaller number of its speakers (something over 200,000 ) when compared with the number of the speakers of Pidgin (well over a million), its emotional and political vitality has become so strong that the government has refrained from officially giving greater support to Pidgin than to Hiri Motu, and is officially treating the two languages as equivalent for public purposes.

\subsection{Social Roles of Pidgin}

The situation surrounding Pidgin is much more complex than that of the other sociolinguistic types of languages in Papua New Guinea. Its use has both pragmatic and emotional aspects; but, in addition to this, it has to be looked at in its role as the linguistic vehicle of the new Papua New Guinean 'contact culture' mentioned above in 3.3. At the same time, the picture is complicated by the presence of two main and two fringe social dialects of Pidgin (Mühlhäusler. 1975b, $1976 \mathrm{c}$ ) and their respective functions (see above, 3.3 ). The situation is also affected by the latest trends in the development of Pidgin (which are beginning to lead to the possible destruction of Pidgin as a separate language) and the gradual breakdown of its reputed value as a great lingua franca, ie its far-reaching uniformity (see 3.3.).

The basic and main function of Pidgin is essentially pragmatic. It is a general means of intercommunication between Papua New Guineans, who speak hundreds of different languages. As a language used by the news media, the administration and government, it can reach orally and in print well over twice as many members of the population of the country as all the other combined lingua francas put together, including English. In the local government councils, the written records of meetings are mostly kept in Pidgin (Mïhlhäusler. 1976c) (except for areas where Hiri Motu is firmly established as the lingua franca), even if the council debates themselves are in local languages. For the rural population, Pidgin is the only link with the outside world and the only means of access to new ideas. For the administration on the lower levels, Pidgin is a totally indispensable tool for carrying out its work, and the rural populations use Pidgin as their only effective means of access to the administration. 
With regard to written Pidgin most of the materials produced in it have until now been issued either by missionary or government and administrative agencies. As a result of this, Pidgin constitutes a powerful tool for social control in the hands of such agencies.

On the emotional level, Pidgin is viewed by a large portion of the rural population of Papua New Guinea as a unifying link which gives the people some feeling of solidarity and a higher level of identity. This is reinforced by a frequent feeling of apprehension by the Pidgin-speaking population who know no English, that they would be left behind if English were to take over.

This leads many Papua New Guineans to see Pidgin as a means of self-identification, as their own language. It is a language which symbolizes all that is Papua New Guinean, and of which they are jealously proud. This attitude manifests itself in many different, though interrelated, ways: Papua New Guineans expect Europeans residing in their country to know Pidgin well. Its mastery (or that of Hiri Motu) is one of the requirements for Papua New Guinean citizenship. They resent being addressed by Europeans in bad Pidgin, and tend to speak Pidgin to each other whenever possible, especially in situations in which the speaking of Pidgin was frowned upon or banned until recently (in high schools and in the University of Papua New Guinea). They look upon Pidgin as the means for expressing their deepest feelings and as the vehicle of national self-expression. These attitudes culminate in the strong feeling among a number of Papua New Guineans that Pidgin should be the national language of Papua New Guinea. Pidgin enjoys predominant usage in the House of Assembly as the language of debate (Hull. 1968) (though pragmatic considerations also seem to have played a part in this). It has been reintroduced as a language of instruction in vocational training; its use has been resumed in elementary and adult education (Wurm. 1976a); and the indigenous forms of Pidgin are emerging in creative writing (Laycock. 1976).

As has been mentioned above in section 3.3, Pidgin is the inherent language of the new Papua New Guinean 'contact culture.' It owes its origin to the uncritical rejection of traditional values and attitudes, and the inadequate copying of European culture. There are sufficient differences between the contact culture and the other two cultures for the carriers of this new culture to be denied access to both.

As has also been pointed out in section 3.3, local dialects of Pidgin have largely been neutralized today as a result of the increasing mobility of the population of Papua New Guinea, but social dialects have become clearly established.

Of the two fringe social dialects mentioned in section 3.3, Tok Masta is the name given by Papua New Guineans to the type of Pidgin spoken, more so until recently than today, by most Europeans living in Papua New Guinea. It is not really Pidgin at all, but a special register of English which is based on the speakers' erronious assumption that Pidgin is similar to English baby-talk. It is unstable, full of unpredictable simplifications, difficult to understand and is used for giving orders and maintaining social non-intimacy. In present-day Papua New Guinea it is destined to disappear soon because of its linguistic instability and its colonialistic connotations, and also because the government expects all Europeans resident in the country to be fluent speakers of good Pidgin. 
The second fringe social dialect, Bush Pidgin (Mühlhäusler 1976c), is the form of Pidgin spoken in varying forms but characterized by heavy first-language interference. It is found in remote areas of Papua New Guinea where Pidgin is not dominant, and is used only for limited communication with outside groups. Its functions are complementary to those of the local languages, and its use has no influence on the structure of the society of its speakers. It serves to maintain nonintimacy between different groups using it for necessary intercommunication (Muihlhäusler.1976d), and its users remain in a marginal position in the society of Papua New Guinea.

Of the two main social dialects, Rural Pidgin has been characterized by Laycock (1969) as 'fluent but unsophisticated, coastal rather than highlands, and Melanesian rather than English.' It is by far the most widespread social dialect and variety of Pidgin, and has been adopted as the standard form of Pidgin for a large number of (very predominantly mission-controlled) publications including the widely read Wantok newspaper. For these two reasons it seems to be the obvious basis for a future standardized form of Pidgin to be used throughout Papua New Guinea.

Rural Pidgin is today the most stable of the Pidgin social dialects, though it has also been subject to some of the destructive influences mentioned above. In particular, a number of new vocabulary items have entered it. However, its grammar has remained relatively free from English influence.

The social setting of Rural Pidgin is the rural community, away from the big towns but not isolated from their influences. European ideas, mainly through the Missions and the Administration, are well known in the areas in which Rural Pidgin is spoken.

In its functions, Rural Pidgin not only serves as an important tool for intertribal communication across linguistic boundaries, but also as a vehicle of cultural change and socialization, in part through being the medium for educational and administrative institutions. As a means of thought expression in some fields of thinking which are new, Rural Pidgin is taking over part of the functions of the local languages.

The other main social dialect - Urban Pidgin - constitutes the Pidgin spoken in the large urban centres and also includes the varieties of Pidgin spoken by those Papua New Guineans who have a fair knowledge of English. As a result of this, Urban Pidgin and English are in a diglossic relationship and carry-overs from English structural patterns are frequent, especially in pronunciation and vocabulary, but also in grammar. The lasting presence of and pressure from English has produced uncertainties in Urban Pidgin usages and fluctuations in its grammar. This has led to the beginnings of a breakdown in the mutual intelligibility of Rural Pidgin and Urban Pidgin. In its functions Urban Pidgin is comparable to Rural Pidgin, but its function as a vehicle of cultural change and socialization goes much further than is the case with Rural Pidgin. It serves to reinforce group solidarity, has become the vehicle of nationalistic tendencies, and enhances group prestige. It often serves as a replacement for the local languages and has a tendency towards creolization as a result of the high incidence of intertribal marriages, especially in urban centres, as has already mentioned in 4.1 . 
It deserves mention that a field of application of Urban Pidgin in which the destructive influence of English is particularly in evidence is its use as a debating language in the House of Assembly (the Papua New Guinea Parliament) and as the language for political, economic and other discussions relating to a European cultural background. The numerous new concepts spoken about in these situations are referred to by terms which are in almost all instances straight borrowings from English, often forms which in their lexical structure violate the structural principles on which the lexicon of Pidgin is based. The elaborate rules of word-formation in Pidgin would make possible the creation of new terms for these concepts which would be in keeping with the rules of Pidgin lexicon (Mühlhäusler. 1975c, d; Wurm, Muthlhäusler and.Laycock.1976). However, in the absence of systematic standardization and language planning efforts in Pidgin, the wholesale borrowing of English terms has, to the detriment of the language, been the line of least resistance for Pidgin speakers.

\subsection{Social Roles of English}

The role of English in Papua New Guinea also has its pragmatic and emotional sides, but its very special role as the target and lexifying language for Pidgin as mentioned above in section 4.5 must be stressed.

On the pragmatic side, English is used as the language of higher (secondary and tertiary) education, as the language of law and high-level administration, and for communications with the world outside Papua New Guinea. As the language known by the elite of the population it is, on the emotional level, viewed by many Papua New Guineans, including parents of children at elementary school age, as the sole key to economic wealth, progress and power. As such they are eager for their children to become proficient in English. This attitude towards English is beginning to diminish as a result of frequent disappointment in such hopes.

However, a proportion of the English-speaking elite has been indoctrinated against Pidgin by previous English teachers and earlier Australian administrators, and they tend to overestimate the importance and potential of English for Papua New Guinea.

\subsection{The Role of the Various Language Types in Education}

This brings the discussion to the question of the role in education of the various sociolinguistic types of languages found in Papua New Guinea. While education for Papua New Guineans used to be predominantly in local languages or in lingua francas until the mid-fifties (Wurm. 1966b, 1971), the education policy of the Australian Administration at that time took a decided step in the direction of concentrating on English as the sole medium of instruction at all levels of education, including the elementary. In Administration schools, this policy was strictly adhered to, and mission schools representing more than 80 percent of the student population in Papua New Guinea (Spate. 1966) continued to receive subsidies from the Administration only if they maintained minimum prescribed standards, ie English as the medium of instruction. Many missions responded to this by arranging for parallel classes, one of prescribed minimum standard with English as the medium of instruction, and one of a standard too low to qualify for Administration subsidy, with a lingua franca or a local language as the medium of instruction. 
The wisdom of the policy utilizing only English for elementary education was questioned by the present writer (Wurm.1966b), and it was argued that it had been demonstrated that indigenes who were made literate in their own language first, and received their elementary education in it, gradually switching to English for the purpose of more advanced education, achieved better results than other indigenes of similar age and background who had received their entire education in English from the start (UNESCO. 1953). Nevertheless, the English only' education policy continued. It had serious drawbacks: In many instances teachers and pupils could not communicate effectively at the beginning of the teaching process, and this education process produced large numbers of school-leavers for whom a knowledge of English was almost entirely irrelevant. Also, many Papua New Guineans were alienated from their tradition and culture as a result of this education policy and, not having fully understood and embraced European culture, found themselves in cultural limbo.

As Papua New Guinea was heading rapidly towards self-government and eventual independence the linguistic side of the education policy of the Government again changed dramatically. For the purpose of elementary education all sociolinguistic types of languages are now admissible and it seems that the persons responsible for this radical change in language policy in education intended the first elementary education to be in the local languages as far as possible. One of the two major lingua francas, Pidgin or Hiri Motu, could be used simultaneously or sequentially, and English would be added at a more advanced level. Part of the reason for the decision to encourage the use of local languages in elementary education from the start appears to have been the government's desire to counteract the danger that children in Papua New Guinea might lose contact with their traditional cultures (see 4.2 above). Many of the local languages have developed written forms, predominantly through the efforts of workers of the Summer Institute of Linguistics, and primers and teaching books for elementary education now exist in them. Nevertheless, the task of using the local languages for elementary education faces enormous practical problems owing to the great multiplicity of languages in Papua New Guinea. In practice a limited number of local languages today play a role in elementary education, and also in adult education. In the great majority of cases, however, one of the two major lingua francas, mostly Pidgin, is used and English still continues strongly. Pidgin still faces the problem of a lack of general standardization (Wurm. 1976b) - the one existing standard form (see above 4.5) is not generally used. Higher education is, in practice, entirely in English and, because of this, the exclusive use of languages other than English in primary education would create serious obstacles to children wishing to pursue higher education. Also, the attitude of many parents in Papua New Guinea wholook upon English as the sole key to wealth and economic progress (mentioned above in 4.6) constitutes an obstacle to the extensive use of other languages in elementary education. This attitude, however, is now weakening as many parents arc finding their hopes disappointed.

The practical aspects of the policy concerning the linguistic side of education in Papua New Guinea still require a period of testing and trial. Not until this is achieved will any policy assume a shape which is fully able to meet the linguistic complexity of Papua New Guinea. 


\title{
BILINGUALISM: THE ROLE OF THE UNIVERSITIES
}

\author{
Lucille M. Ramish
}

\section{The Bilingual Education Policy of Singapore}

The history of bilingual education policy in Singapore dates back to the 1956 Report of the All-Party Committee of the Singapore Legislative Assembly on Chinese Education, which took a strong stand on the value of vernacular languages, the cultures they represented, and the way they could contribute to the unity of Singapore as a nation. It proposed the teaching of all languages; that at least two languages from English, Malay, Mandarin, and Tamil should be the media of instruction in schools; that language teaching should be of the best possible standards, 'so that the future Educational System of Singapore will produce students equally conversant in two, if not in three of those languages'; that primary education should be bilingual and secondary education trillingual; and 'that through furthering the interests of Education, Bilingual and Trilingual, everyone can assist in the overall aim to build a Nation out of racial groups with different cultural backgrounds and languages, whilst ensuring that full educational opportunities will be given to all our children, and progress towards Self-government and Independence achieved.'

Following elections in 1959 the new government presented its educational policy to the Legislative Assembly, pledging provision of facilities for the study of local languages, with the aim of making pupils bilingual and, if possible, trilingual, accepting Malay as the National Language, and as the second language for all non-Malays, thus serving as the integrative factor in the formation of a national identity.

In 1965 Singapore became an independent nation with the task of uniting her multi-racial, multi-religious, multi-lingual, multi-cultural population into a strong and loyal people. In 1966 the study of a second language was made compulsory in all secondary schools. Second language exams were included in both the Primary School Leaving Examination and the Singapore-Cambridge General Certificate of Education Examination although a pass was not required,and from 1969 the second language papers have been set and marked at a level two years below the students' first language. Subject teaching in the second language was begun in 1968, with Science and Mathematics being taught in English in non-English medium schools, with the hope that "by using the second language as a medium of instruction children would be exposed to the language for a much longer period and moreover would be compelled to speak it, write it and use it as a tool of communication.'

The government of Singapore has recognized the value of language as an integrating factor and has laid great stress on the need for Singaporeans to be bilingual or multilingual. In an industrialized society such as Singapore, foreign investment provides employment and training in technical and managerial skills as well as contri-

Dr. Ramish obtained her B.R.E. (Religious Education) and B.A. in Greek Studies from Gordon College in Boston, and her Ph.D. in Applied Linguistics from Brown University. She has been the Director of the Language Centre of Nanyang University since 1970 and she also teaches English at the Institute of Education, and at the University of Singapore. Her major research interest centres on Applied Linguistics. 
buting to greater economic prosperity. To be able to avail oneself of such opportunities one has to have some means of communication with the investors, the trainers, or the employers. Japanese, West German, British, and American companies are advertising daily for individuals with the requisite skills and training, and with bilingual or multilingual competence. English in its role as an international language is recognized as the lingua franca. ${ }^{1}$

Urbanization brings about a redistribution of ethnic groups as more and more families have moved to urban centres, leaving the villages or rural communities which often reflected a racial composition. In urban housing, as we have in Singapore, families of different ethnic and linguistic backgrounds find themselves neighbours, sharing the same environment and mutual responsibilities for each other's welfare. The urban dweller finds he needs a means of communicating with his neighbour and, without a shared linguistic code, misunderstandings and offenses are multiplied, creating tensions, mistrust, and divisions.

Pressures for bilingualism, or multilingualism, are therefore increased in an urbanized, industrialized multi-racial society, and governments which are sensitive to the needs of their people endeavour to equip the individual for his role in such a society by providing within the educational system the language training he needs. In Singapore this language training begins in Primary 1 and continues through tertiary level studies.

\section{The Language Centre, Nanyang University, and its Role in Preparing .Bilingual Citizens}

Nanyang University was established in 1955 to provide university education for students from Chinese-medium schools. However, with the changing political, social and economic conditions Nanyang University has had to change, becoming a truly national university, open to students from all language streams, and contributing to the training of bilingual citizens. To this end the medium of instruction has been changed to English, and greater responsibility has been placed on the Language Centre to serve the needs of the University community.

\subsection{Function of the Language Centre}

The Language Centre as a service arm of the university was established in 1967 and entrusted with the responsibility of providing all language-learning opportunities for the entire University community. Its primary function has always been to provide English language courses designed to meet the needs and interests of the student population.

In order to fulfill its function effectively several questions must be answered:
a. What is it that creates students needs?
b. What creates student interest?
c. What should determine course offerings?
d. What should determine course content and methodology?

\subsection{Student Needs}

Student needs are the outcome of complex variables such as family and 
home background, educational background (including previous study of English and level attained), social environment (both school and community), career objectives, etc.

Our students are generally between the ages of 18 and 22 . Ninety-eight per cent are Singaporeans; forty-three per cent are women (as compared with thirty-five per cent in 1969); men have generally completed two years of National Service in the Singapore Armed Forces. Ninety per cent are from the Chinese stream of education and they have studied English as a 'second language' for 10-12 years. ${ }^{2}$

That our students have needs is to state the obvious; to define these needs and devise programmes that will effectively meet these needs is the challenge we face.

In a recent exercise on the relation between active and passive sentences given to some of our classes, students were required to identify the actor, the action and the object or receiver of the action in a series of sentences, and to rewrite the sentences. I was a bit stunned when I read on one student paper: Passengers are served the stewardess and coffee. However, my reaction was different from one of the men on the staff with whom I shared this. His question: Which airline is that?

Any assessment of student needs must consider (i) observed needs, present and future, and (ii) felt needs, present and future.

\subsubsection{Observed Present Needs}

The degree to which a student falls short of the English language proficiency necessary for effective and efficient learning constitutes his present need in the university context. This has been measured by:

a. His performance on the GCE Examination

b. His performance on the English Proficiency Test ${ }^{3}$

c. Language classroom assessment

d. Discussions with Deans and department heads to ascertain the language used in classes, tutorials and seminars, in texts, outside reading, and in writing.

\subsubsection{Observed Future Needs}

What level of competence will the individual need when he leaves university? This will be determined by:

a. His personal goals, ie further study, employment, etc.

b. The socio-economic environment and requirements.

By keeping abreast of government policy (eg bilingualism), socioeconomic developments, and by discussions with Deans and heads of departments, by reference to reports on graduate employment and assessment of Nanyang graduates ${ }^{4}$ we have tried to be aware and informed of future needs.

\subsubsection{Felt Present Needs}

What does the student himself feel that he lacks in language profi- 
ciency? What does he want to get out of his language courses? Answers to these questions we have sought to discover through student surveys, one conducted in 1971-72 and another in 1975. Results of this later survey showed that at that time students did not consider English for study purposes, although in ranking of skills first year students ranked reading most important, but conversation as their main need. (It was in the 1975-1976 academic year that English was made the medium of instruction for all first year lectures.)

Continuing assessment is made through personal dialogue between students and teachers.

\subsubsection{Felt Future Needs}

The 1975 survey made it very clear that English study was considered important for future employment and social needs.

Recent reports of employment rates and difficulties Nanyang University graduates face as they move out in to the job market have highlighted the need for graduates to be able to function in English as well as Mandarin.

\subsection{Operational Rationale}

The operational rationale which the Language Centre has applied begins with an assessment of the needs of the student, the objectives to be met, an assessment of existing courses, and the determination of courses needed. The conceptual framework is then decided upon, based on the language needs and principles of language learning.

Goals, content, format, skills to be developed, and methodology are then specified. Periodic evaluation during the writing of the materials is carried on, and the materials are then put into classroom use. This reveals areas that need modification, revision or deletion, and omissions that need to be filled. The materials are then used in the classroom again, following which there should be a thorough evaluation and comparison with student needs and interest.

\subsection{Broad Objectives}

In working out broad objectives for the English language courses offered at the Language Centre the following general principles are borne in mind.

Firstly, as the Government, the University and the students themselves view the use of English mainly as a tool for effective communication, it is important that we give top priority to the consideration of intelligibility (comprehensibility) of communication by paying particular attention to problems of pronunciation, intonation, vocabulary and structure which interfere most severely with effective communication.

Secondly, English is not a new language to the students. Our task is remedial language teaching. Hence, what has been badly learnt in the past 12 years (approximately 720 hours of instruction in English plus exposure to English through the teaching of science and mathematics) can only be unlearnt with great difficulty in 
the one year compulsory English they get at the Centre (approximately 120 hours). In teaching, therefore, the teacher should aim primarily at correcting those mistakes which not only interfere with communication but which one can reasonably expect to be corrected within the time available.

Thirdly, in view of the limited hours of instruction available, bilingualism if defined as 'native-like competence' is impracticable and unattainable for most of our students.

Our aim, then, is to produce students who can use English with reasonable fluency and accuracy but who would rarely be mistaken for native speakers.

\subsection{Learning and Language}

The primary need of students entering the University is to develop those skills which are required for successful study on the tertiary level, where English is the language of lectures and textbooks.

Important for our consideration is the problem of cognition, or concept formation and, through language learning, the naming of these concepts in the mother tongue, followed by renaming them in the school language and a further development of concepts in the learning experience, which form the scholastic background of our students. Upon entering the University the student is expected to build upon this foundation, to develop new concepts, restructure earlier concepts, reorganize his experience so that he is able to reach new levels of generalization and apply what he has learned to new problem-solving activities, all in a second (or third, or fourth!) language which he has not really internalized and which he is unable to use with competence and confidence.

Carroll (1964, pp. 178-190) describes the task of educationists and textbook writers as the teaching of words, and the meanings and concepts they convey:

'Students must be taught the meanings of unfamiliar words and idioms; they must be helped in recognizing unfamiliar ways in which familiar words may be used; and they must be made generally aware of the possibility of ambiguity in meaning and the role of context in solving it. Often the task of the teacher is not merely to explain a new word in familiar terms, but to shape an entirely new concept in the mind of the student.'

For us it means trying to explain a new word in a difficult language in terms that may be equally unfamiliar, or to shape an entirely new concept in the mind of the student by using a partially understood language which may be describing a totally unfamiliar situation, far removed from his own experience, and for which he has no background in his own language or in the language of lecture or text.

The child learning in his mother tongue learns the concepts of classes of things, qualities and events, categories which correspond to nouns, adjectives and verbs in English. By the time he begins formal schooling he already has a good store of vocabulary items, and has learned the basic features of syntax in his mother tongue, and perhaps another dialect or two. In school he is exposed to new learning experiences, he adds new concepts, reorders, or adjusts his previously learned concepts, and brings the totality of his experience to bear upon new experiences. 
If his linguistic environment during this early learning period is different from that of his home there is the possibility of inadequately formed concepts and faulty linguistic expression, so that the child finds difficulty in internalizing the learning process, both in his mother tongue and in the school language. Faced with the task of learning new materials he may do it simply by rote memory, with the result that no actual learning takes place, and he is unable to apply what is taught to new experiences.

There is a great need in Singapore for psycholinguistic research into the learning process and its relation to language. Such research on early childhood language acquisition can contribute to our understanding and provide firm theoretical models which can be utilized in teaching. We need studies of the development of child thought and language, the nature of adult reinforcement and expansion of child language, and the effects of dual and plural language exposure.

With the increase in second language teaching and use in the primary and secondary schools our students come to us with more extensive exposure to English. One would like to believe that competence is directly proportional to teaching and exposure. However, this has not been proven true as yet, and there are many variables that hinder the acquisition of the second language.

\subsection{Motivation for Language Learning}

Motivation for learning another language may come from many sources. The attitudes and provisions of government, the economic needs of the individual, his social environment, and his own personal goals and desires.

We are very fortunate indeed to have in Singapore a government which is both realistic and efficient in dealing with the needs of its people. Realizing the role of language in building social cohesion and in providing economic and social mobility the government has stressed the need for language acquisition and is seeking to provide within the educational system equal and effective opportunities for language learning.

With the development of Singapore into an industrialized and urbanized centre for the exportation of goods and technological expertise, a regional centre for banking and commercial interests, has come increasing exposure to cultures, ideas and life-styles from the West. The influence of permissive societies, radically different philosophies of life, and all that is pictured in the cinema and on TV brings also the danger, especially to our youth, of producing bilingual citizens who are neither Asian nor Western, individuals who are without the stabilizing controls of a national culture.

Ours is a very pragmatic society and the motivation for language learning has emphasized the value of language as a tool of communication, a means of producing social cohesion, an instrument for effecting social and economic mobility. The job seeker faces the need of being able to use more than one language; parents send their children to English schools so that their future employment and social prospects will be brighter. 
Lambert and his colleagues report (Lambert etal. 1968, pp. 473-474) that the learner's 'motivation to learn is thought to be determined by his attitudes and by his orientation toward learning a second language. The orientation is "instrumental" in form if the purposes of language study reflect the more utilitarian value of linguistic achievement, such as getting ahead in ones occupation, and is "integrative" if the student is oriented to learn more about the other cultural community as if he desired to become a potential member of the other group ... In the Montreal setting it was clear that students with an integrative orientation were the more successful in language learning in contrast to those instrumentally orientated.'

The dilemma therefore is : Should we settle for less effective instrumental motivation and resist the adoption of Western culture, or press for the more effective integrative motivation with its inherent dangers?

However, the status of English as a world language removes it from being the language of a particular nation or ethnic group, be it England, Australia or America. It is true that Western modes of thought, social organization, value systems, and life styles are reflected in the language coming from the West. But language is a living, changing thing, and when transplanted it adapts itself, adopts features of the new environment and broadens its conceptual base. It is time for realignment, transferring our association of English language usage from the West to those of our countries who represent the successful bilingual or multilingual citizen. Our own Prime Minister and others in places of government responsibility, those in the professions: doctors, lawyers, architects, engineers, educators, those in industry and business, should be looked upon as members of a bilingual or multilingual community, membership in which should be a highly desired goal. If the learner seeks not to learn a language for its instrumental utilitarian value, but to become a member of that social group whose linguistic capabilities mark them as successful in their careers, broad in their cultural appreciations, and sympathetic to the needs of all our people, the learner's personal motivation will be manifested in lively interest and achievements extending beyond the goals of school requirements.

\section{Conclusion}

I have tried to put the role of the Nanyang University Language Centre within the context of the bilingual educational policy of the Singapore Government and the pressures of an industrialized, urbanized society. I have also sought to show something of the difficulties our students face and the inadequate motivational force for second language acquisition.

I would end with a plea for in-depth research in psycholinguistics, the role of language in learning and the way language is learned. We need more specific definitions of bilingualism and multilingualism. We need sociolinguistic studies of the roles of the different languages in our society. How much language do our people need? What do they need it for? Where will they use it?

Such studies would enable educators to better understand the needs and problems of our students, to set objectives, develop programmes, and produce materials that would make attainment of the objectives possible. The results will been in young people who are members of a linguistic community and who are able to steceed in their careers and at the same time contribute to the unity and progress of their nation. 
Notes

1. In a stated:" . . because of the structure of our society, for a long while, those who want to be effective in supervisory positions must be bilingual, preferably trilingual ... In order that you can do your job and discharge your debt to the community you must have a second and third language capacity.' (Straits Times, 29 December 1977).

2. Students of the Chinese stream rarely have Mandarin as their mother tongue. They are usually able to speak two or more Chinese dialects, and Mandarin is their 'school language', English their school 'second language'. See Murray, pp. 231-236.

Mr. Lee Kuan Yew has noted: 'When a Singapore child goes to school he is exposed to bilingualism, in 75 per cent and maybe 72 per cent of the cases - to two new alien languages.' (Straits Times, 29 December 1977).

3. The English Proficiency Test is constructed and administered to all entering students by the Language Centre, and is scored and analysed by computer.

4. For example : A Report on the 1975 Employment Survey of Nanyang University Graduates, prepared by Pang Eng Fong and Leong Lee Voon, Economic Research Centre, University of Singapore, 1976. 


\title{
CONTRASTIVE APPROACH IN BILINGUAL EDUCATION
}

\author{
Tang Ting-chi
}

\begin{abstract}
Second language learning, hence contrastive analysis and error analysis, could play an important role in bilingual education, especially in those situations where balanced bilinguals are not the realistic end-product of the educational process. The article below represents a translated extract from Professor Tang's original paper entitled" 對比分 析 與 雙語 教 逳.'The complete version begins with a general discussion of differences between Mandarin Chinese and English which make language learning problematic and engender interference in the leamer's performance. In isolating some of the linguistic dissimilarities that enable one to predict areas of difficulty in each language Professor Tang deals with 'parts of speech' (articles, modal auxiliaries, and prepositions), morphology (inflection) and word order. He also points out that, whereas much is made of negative transfer or interference, the notion of positive transfer or equivalence between languages can be effectively exploited in the classroom. Finally, in the section which immediately precedes the extract as it is presented below the author explors the relevance of Transformational Generative theory to contrastive analysis. It is only in surface realizations, he writes, that English grammar differs from Chinese. The deep structures of the languages, before transformational rules are applied, are identical (SVO construction). According to the author it is the analysis of transformational rules in English and Mandarin which has most relevance to a contrastive study of these two languages.
\end{abstract}

\section{Contrastive Analysis and Cognitive Approach}

In the past, structural linguists advocated an oral approach to the teaching of languages. They believed that learning a language, like the learning of other kinds of behaviour, is a matter of habit formation which depends on a stimulus and response procedure with incessant practice and reinforcement until the behaviour becomes instinctive. The cognitive approach, developed under the influence of the Transformational Generative theory, which posited that language learning is a natural cognitive activity. To learn a language is not to memorize individual sentences by imitating and repeating them and then reproducing them intact. It is, rather, a process of discovering grammatical rules through one's natural intellectual processes and using these rules to create sentences which suitably express one's meanings and feelings. Therefore, in language teaching, teachers should explain clearly the rules of the grammar (including pronunciation and choice of words) so that the students not only know What, but also Why. The cognitive approach does not deny the importance of practice, but it advocates 'conscious' learning in the acquisition of a language, followed by continuous practice, and finally the 'unconscious' application of what has been learned. This procedure is similar to learning to knot a tie or drive a car. In the beginning, every movement is a 'conscious' intellectual exercise, but after a certain period the operation becomes

Professor Tang read Law for his first degree at the National Taiwan University and obtained his $P h . D$. in Linguistics from the University of Texas at Austin. His research interest is primarily in Chinese Linguistics and Applied Linguistics, and he is currently Professor in the Graduate English Language Institute at the National Taiwan Normal University. 


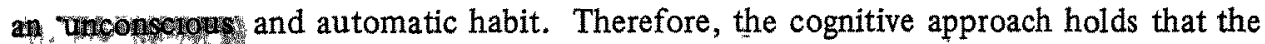
object of language learning should be internal linguistic competence rather than external linguistic performance. In the learning of a foreign language such linguistic competence includes both the grammatical understanding of one's native language ${ }^{1}$ as well as the learning of grammatical rules and features of the foreign language which are unlike those in the native language. This kind of linguistic competence and performance not only includes a passive receptive skill, it also includes an active expressive skill.

For example, with regard to the modal auxiliaries in English discussed earlier, since their meanings and usages lack clarity and are difficult to master, an average student would find them a hindrance in the development of 'linguistic competence; let alone 'linguistic performance.' In grammar books published in Taiwan nowadays, the meanings and usages of each modal auxiliary are not distinguished. Neither are they listed together with their Chinese equivalents. As a result, these books cannot help students to understand such meanings or usages. Actually, every modal auxiliary in English has a root meaning and an epistemic meaning:

\section{ROOT MEANING}

1. will (willingness, insistence)

I will go with you. (willingness)

You will come with me. (insistence)

2. should (obligation) We should love our parents.

3. may (permission) You may come with us.

4. can

\section{(ability, permission)}

I can speak three languages. (ability)

You can come with me. (permission)

$\begin{array}{ll}\text { 5. must } & \text { (compulsion) } \\ & \text { Man must eat to live. }\end{array}$

\section{EPISTEMIC MEANING}

(future prediction)

He will be here this afternoon.

(prediction)

Boys will be boys.

(future expectation)

I should get a letter today.

(possibility)

The road may be blocked.

He may not be there.

(theoretical (im)possibility)

The road can be blocked.

It can't be him.

(logical necessity)

He must be there.

The meanings of the modal auxiliaries may be determined by the context. For instance, if may, must, or can't occur in the context of It be (the case) that, the modal takes on an epistemic meaning (possibility/logical necessity) rather than a root meaning (permission/compulsion). Similarly, if these auxiliaries occur before a stative verb eg He may/must/can't resemble his mother, the epistemic meaning prevails. If the modal auxiliary is in the past tense, however, both the root meaning and the epistemic meaning are possible:

$$
I \quad\left\{\begin{array}{l}
\text { might (permission, possibility) } \\
\text { could (permission, possibility) } \\
\text { would (willingness, future prediction) }
\end{array}\right\} \quad \text { do it tomorrow. }
$$


Nevertheless, it is the epistemic meaning in these examples which would be most commonly understood. Another example of the possibility of double (root/epistemic) meaning is found in sentences employing verbs in the perfect, progressive, or perfect progressive tenses:

$$
\text { He must } \quad\left\{\begin{array}{l}
\text { have studied } \\
\text { be studying } \\
\text { have been studying }
\end{array}\right\} \quad \text { English. }
$$

It is possible in these examples to conceive of a situation in which the root meaning for must (compulsion) would be indicated. However, in most cases, it is the epistemic meaning of must (logical necessity) which would predominate. In sentences where the modal auxiliary occurs within an if-clause (If he can/will/must do it...) the epistemic meaning would be impossible, and the root meaning always understood.

The traditional method of teaching tense in English is to divide it into three time categories (present, past, future), each of which is further divided into four subcategories (simple, continuous, perfect, perfect continuous), resulting in 12 tenses. A new method of teaching tense in English is to assign to each component of the English tense expression (including tense, mode, aspect, phase and voice) a concrete semantic content. Students have only to choose from these semantic components according to the meaning they wish to express and to string them into a tense expression.

\begin{tabular}{|c|c|c|c|c|c|}
\hline Tense & Mode & Aspect & Phase & Voice & Verb \\
\hline$\left\{\begin{array}{l}-(s) \\
-e d\end{array}\right\}$ & $\left\{\begin{array}{l}\text { will } \\
\text { shall } \\
\text { may } \\
\text { can } \\
\text { must }\end{array}\right.$ & (have-en) & (be-ing) & (be-en) & V \\
\hline
\end{tabular}

In the table above, 'Tense' is divided into past ('-ed") and non-past (ie $-(s)$, which includes present, future and generic tense). The braces $\{$ mean that one, and only one, of the two items enclosed must be chosen. Mode' refers to the mood of the speaker as expressed by modal auxiliaries (will, shall, may, can, must). The parentheses ( ) indicate that the items enclosed are optional, and the braces indicate that, if a modal auxiliary is used, only one can be chosen. 'Aspect' refers to the presence or. absence of the perfect, which shows the relevant anteriority or priority of the event or situation, and 'Phase' to the presence or absence of the progressive, which shows the currency or simultaneity of the action. 'Voice', referring to the active or the passive voice, indicates whether the subject is the actor or the recipient. The hyphen in $-(s)$ $-e d$, -ed and -ing shows that these are suffixes and have to be moved to the end of theimmediately following element. By following the rules formalized above, it should be possible for students to correctly produce all the possible tense expressions in English. For example: 


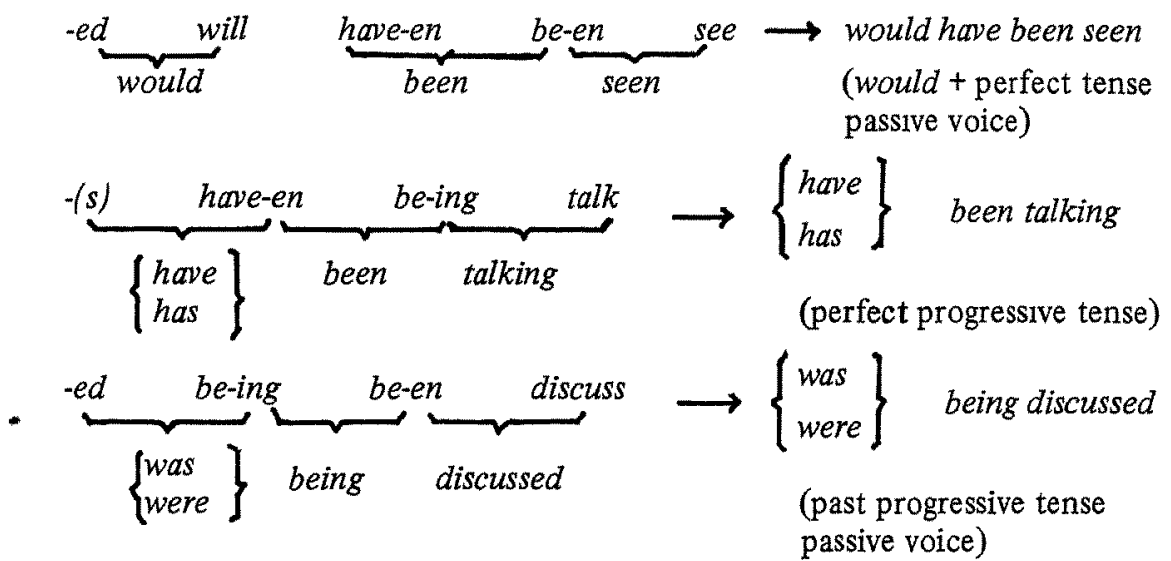

When this formalized rule is used to produce English tense expressions, students can see automatically that the 'perfect tense' must be expressed with the verb have plus a past participle (have-en); 'the progressive tense' with the verb to be plus a present participle (be-ing); the 'passive voice' with the verb to be plus a past participle (be-en); and that the tense-markers $-(s)$ and -ed must be added to the first tense component. More importantly, as each tense component has a fixed meaning, it is easy for students to make a choice to express what they wish to express, and then apply the rules to produce the tense expression they need. For instance, if what you want to express something factual but also something that happened in the past, then past tense $(-e d)$ has to be selected. But if it is something that happened in a non-past time (ie present, future, or generic time) then a non-past tense $(-(s))$ has to be used. If you wish to express something that is nonfactual, like a supposition contrary to fact, or a wish that is impossible or unlikely to come true, and if, further, this is connected with past time, then past tense or perfect tense is used. If this is connected with non-past time, then the simple past tense should be used. According to the content of what is expressed, if it is connected with 'modality', then a suitable modal auxiliary should be used. If it is connected with 'anteriority', then the perfect tense (have-en) has to be used. If it is connected with 'continuity' or 'simultaneity', then the progressive tense (be-ing) has to be used. Finally, if it is related to the notion of 'actor' and 'recipient', then the passive voice (be-en) has to be used. Here are two examples showing how this works:

$$
\begin{aligned}
& \left\{\begin{array}{l}
\text { 他告訴我他整個上午都在圆畫館讀畫。 } \\
-e d+\text { tell } \\
\text { He told me that he had been studying in the library all morning. }
\end{array}\right. \\
& \left\{\begin{array}{l}
\text { 假若他開車子沟有開得太快的話, 他就不會給計程車撞上了。 } \\
-e d+(\text { have-en })+(\text { be-ing })+\text { drive -ed will }+ \text { (have-en })+(\text { be-en })+\text { had } \\
\text { If he had not been driving too fast he would not have been hit by a taxi. }
\end{array}\right.
\end{aligned}
$$

\section{The Application of Contrastive Analysis in Teaching Materials and Methods}

At present, there are few scholars in Taiwan concerned with the contrastive analysis of Chinese; still less, teachers capable of applying results of contrastive analyses in language classes. As a matter of fact, apart from contributing to the discovery of the student's difficulties and the analysis of his errors, contrastive analysis is also helpful in the design of teaching materials and in teaching method. 
For example, it is often said that the arrangement and design of teaching materials should proceed from the easy to the difficult and from the simple to the complicated. But how are we to determine the degree of difficulty, especially of syntactical difficulty? Contrastive analysis tell us that one of the criteria is the amount of syntactic correspondence between equivalents in the two languages. In other words, patterns which differ less from their native-language equivalents are easier to learn than those with greater difference. Of course, apart from factors of quantity, factors of quality should also be taken into consideration; for some difficulties are inherent or internal. For example, rolled $/ \mathrm{r} /$ is inherently more difficult to produce than the labial sounds $/ \mathrm{p}, \mathrm{b}, \mathrm{m} /$, and the verb tenses in English are inherently more difficult to memorize than the inflections of English nouns or adjectives. The job of the teacher is to discover a simple and explicit rule to explain to students why some of the expressions are grammatical and why others are ungrammatical, preferably with the aid of corresponding structures or rules in Chinese. For example:

\begin{tabular}{|c|c|}
\hline $\begin{array}{l}\text { [such [(adjective) noun] } \\
\text { 這樣的 (好) 孩子 } \\
\text { 這樣的 (貴重的) 娟物 }\end{array}$ & the type of noun is not restricted \\
\hline $\begin{array}{l}{[[\text { so adjective }] a(n) \text { noun }]} \\
\text { 這麼好的孩子 } \\
\text { 䢣麼貴重的禮物 }\end{array}$ & $\begin{array}{l}\text { the noun is restricted to singular } \\
\text { countable }\end{array}$ \\
\hline $\begin{array}{l}\text { [such quantifier (adjective) noun] } \\
\text { 這麼多/少的好孩子 } \\
\text { 還麼多 /少的貴重禮物 }\end{array}$ & $\begin{array}{l}\text { the noun is restricted to plural } \\
\text { countable or singular uncountable }\end{array}$ \\
\hline $\begin{array}{l}\text { [quantifier [such (adjective) noun]] } \\
\text { 很多/少這樣的禮物 } \\
\text { 很多 /小狺栚的孩子 }\end{array}$ & the type of noun is not restricted \\
\hline
\end{tabular}

The examples above show that such is a noun modifier or a limiter of a noun phrase. The adjective after such is optional, and the type of noun is not limited. So is an adjective modifier or an intensifier of manner adverb and it must be followed by an adjective, which must be placed before the article $a(a n)$. At the same time the noun must be a singular countable noun. Therefore, neither plural nouns (eg gift) nor uncountable nouns (eg food or news) can be used after so. Also, quantifiers (eg many, much, few, little) appear after so but before such. A comparison between English and Chinese shows that such and 這樣的 are similar in meaning and usage, as are so and 递麼 With such generalization and systematization students will find it easier to understand the difference between such and so without having to grope in the dark. The difference between such and so can also help students to understand the behaviour of the intensifiers as and too and of the exclamatory how, all of which behave like so (eg as good a gift, too good a gift, how good a gift), as well as the behaviour of the exclamatory what, which behaves like such (eg what wonderful gifts, what a wonderful gift, what wonderful news, what wonderful food).

Well-handled discussion of contrastive analyses between Chinese and English before students in the classroom can help students realize the difficulties they might come across in learning either English or Chinese. Teachers can even design suitable exercises to help students overcome these difficulties. 
CONTRASTIVE APPROACH IN BILINGUAL EDUCATION

Notes

1. The 'grammar' here includes syntax, phonology and semantics.

2. For further discussion of English tenses refer to my book $A$ Cognitive Approach to English Grammar and Rhetoric. 


\title{
SOME OBSERVATIONS ON HONG KONG SECONDARY SCHOOLS
}

\author{
Arthur Hinton \\ The following is based on Mr. Hinton's remarks as discussant for the \\ Panel: Bilingual Education and Curricular Development in Secondary Education.
}

I do not propose to discuss the various points which the panel speakers have presented so clearly in their papers. I would like rather to comment on their general topic in the light of my experience of supervising student teachers over the last nine years and; in particular, during the past four weeks.

Those I have seen at work in the classroom in the past four weeks are all graduates with a degree in their major teaching subject. Most of them are experienced teachers who have been teaching for two, three, four, or more years but who are only now getting their professional training in a two-year part-time course. A few of them, however, are fresh graduates without previous teaching experience. Nearly all the lessons were given in Anglo-Chinese schools, though a few were held in Chinese middle schools, and the subjects were usually History or English.

We have heard about English schools, Anglo-Chinese schools and Chinese schools, but Miss-Leung pointed out in many of the Anglo-Chinese schools Chinese is used quite extensively as the medium of instruction. This obviously blurs the distinction between the different types of school. I would now like to mention four types of instruction, as far as the language medium is concerned, which $\mathrm{I}$ have seen.

In the first typk, lessons were given in the medium of English and English language tex tbooks were used. The standard of English of both teachers and pupils varied very much from school to school. The questions asked by the teachers tended to be purely factual. Thus in the History lessons the kind of question which predominated was: 'When did this happen?' 'Who did that?' 'How do you spell the name of this man or this city?' The response to these questions varied from very good to very poor but, even where the response was good, there was seldom any discussion. In some cases this was due to the failure of the teacher to stimulate any discussion, but to a farge extent it was, I believe, due to the language diffetty.

In some other schools, also Anglo-Chinese schools, the textbook was in English but both English and Chinese were used for instruction. When the teacher gave information it was usually in English and blackboard notes were in English, but questions were usually asked in Chinese and the replies came in Chinese. The teacher would sometimes put a question in English and receive no response. He would then ask it in Cantonese and get a good response as well as sometimes a good deal of discussion.

Mr. Hinton received his $B . A$. in History and a Certificate of Education from the University of Bristol. He has written on the history of Hong Kong and on topics in education in Hong Kong. He is currently Lecturer in the School of Education at the Chinese University of Hong Kong. 
In the third type, also Anglo-Chinese schools, the language of instruction was Chinese but the textbook was in English. In this type the lesson consisted almost entirely of the teacher ranslating the text into Cantonese so that the pupils could understand it. Questions asked were basically concerned with understanding the text or rather, in a more limited capacity, with knowing the Chinese equivalents of the words in the text and not with understanding the ideas and issues involved.

The fourth type, mainly in Chinese middle schools, or in Chinese History lessons in Anglo-Chinese schools, saw teaching in Chinese using Chinese textbooks. The interaction between teacher and pupils varied very much, depending on the atmosphere in the school. In some lessons there was a good deal of very good discussion and lively participation from the students. In others the approach was more old-fashioned, the teacher giving information and the pupils apparently listening to it and possibly understanding it.

The point I wish to make is that we are oversimplifying the situation when we talk about English-medium schools and Chinese-medium schools. I was interested to hear that in Singapore some of the lessons in Chinese midde schools are taught in English. Here in Hong Kong in many of our Anglo-Chinese schools-someessons are being taught in Chinese or in a combination of both languages,

In the English lessons that I saw; the standard of the teaching in English and the response of the pupils in English varied tremendously. But this variation depended not so much on the level of the pupils as on the ability of the teacher. I saw pupils in 'good' schools (ie schools from which many students succeed in entering university) who did not respond at all well; saw pupils in 'bad' schools (ie with a poor record as far as university entrance is concerned) who responded enthusiastically. This depended not so much on the standard of English of the teacher (assuming a certain minimum ability to use the language) as on the atmosphere of the class which the teacher created, . en the abitity of the teacher to encourage and persuade the pupils to respond, to speak, to participate actively in the lesson.

This class atmosphere - and often a school atmosphere - is hard to define, but one can detect it very quickly. And the same teacher can create a different atmosphere, a different impression, with different classes. Let me give a vivid example which I saw about ten days ago. Through force of circumstances I observed a teacher in two successive lessons. She was expecting me for the second of these lessons but not for the first. However, I arrived early at the school and asked her if she would mind my seeing both lessons. I suppose she did not dare say 'no', but, in fact, she welcomed me warmly. That lesson was with a Form 1 class. The teacher was encouraging, smiling, and she had the pupils speaking. She had a most lively response from them. It was an excellent lesson, far superior to anything I had seen her achieve on previous visits.

The next lesson was with Form 5 and we all know how serious this task is. Form 5 pupils are preparing for The Examination. The teacher lost her smile. Her voice response from the class was completely different, not only because they were older, more adolescent and more self-conscious, but because of the attitude of the teacher. The same teacher; one personality with the younger pupus, another with the older ones. With the Form 1 pupils she could say: 'It is fun teaching them! They don't have to worry about an examination, about learning. We can just talk and enjoy ourselves.' And they did talk and did enjoy themselves and learnt a tremendous amount. 'But Form 5 involves serious 
education. You must teach them, and they must learn.' And the result was that they were bored, uninvolved, and learnt very little. So, the standard of language teaching depends not only on the level of the teacher's knowledge of the language, but on his or her personality and teaching ability. And I am certain that I would much rather have someorre-making mistakes in English, but with the ability to teach and impart the knowledge (even an imperfect knowledge) of the language that he or she possesses, than some. one who speaks flawlessly but without communicating and without getting a esponse.

I would like to make one or two further points before you have your turn to comment or ask questions. The first concerns the question of motivation. I belive, as someone pointed out earlier, that motivation comes mainly from the teacher. Examinations do not provide a very positive motivation. Some of the duttest English lessons I have seen, with least responise from the pupils and most unwillingness on their part to learn, have been in Form 6 when they have been preparing for the Use of English Examination of Hong Kong University. Many of these pupils are not interested and refuse to make an effort. Somehow they feel that it is not relevant and yet, from the examination point of view, from the career point of view, the motivation should be there. The teacher feels that, because of the examination, the motivation is in-built. She can say to herself: 'I don't have to make it interesting. I don't have to make it exciting. They have the examination to look forward to and this will make them work.' In fact, the motivation for real study comes mainly from the teacher. Can the teacher make the lessons interesting and exciting? Can the teacher make the pupils eager to communicate, to speak, to write, to express ideas, thoughts and feelings? Some teachers do this very very well; some fail completely.

I would like to mention also that I have seen English lessons in Chinese middle schools where the response from the pupils was much better than in many AngloChinese schools, even though pupils in this latter group of schools are exposed to far more English. The reason, once again, was the quality of the teacher. Yet it is probably true to say that, by and large, the best teachers of English obtain posts in theAngloChinese schools, and so, the pupils in the middle schools often find themselves with teachers who have failed to secure jobs in Anglo-Chinese schools. I know there are many exceptions to this but it does mean that the pupils who are exposed to less English tend to get the weaker teachers.

My last point is a plea for imaginative teaching, whatever the subject or the language. I recently saw one teacher, whose command of English was not particularly good, using pop songs to teach grammatical structures. He had the class singing. They enjoyed it and learnt the constructions he was illustrating far more effectively than if they had recited the relevant rules and observed their application in irrelevant sentences. 


\title{
E. The Chinese Curriculum in the Bilingual Context
}

\section{THE TEACHING OF CHINESE IN THAILAND}

\author{
Prapin Manomaivibool
}

This paper will be divided into two parts. The first part will give an account of the teaching of Chinese in schools below university level; the second part will concentrate on Chinese taught at university level.

\section{Pre-university Level}

Chinese is taught as a subject in primary schools from the first grade up to the fourth grade. From the fifth grade up to the end of secondary school no Chinese is offered. ${ }^{1}$ Chinese is then offered again as a subject in some vocational schools, especially in the commercial schools. The commercial students learn either Mandarin or the Ch'aochou (Swatow) dialect, but mainly the latter, since a large part of business in Thailand falls in to the hands of the Ch'aochou people.

Let us first focus on the teaching of Chinese in primary schools. ${ }^{2}$ The Compulsory Education Act in Thailand ${ }^{3}$ was issued in 1918 , but it was not until after 1932 that the act was enforced throughout the country. Officers from the Ministry of Education were then sent out to inspect the primary schools, including the private schools where Chinese was taught as a subject. ${ }^{4}$ Before the act was enforced the Chinese schools mainly taught Chinese, and only a few hours were given to Thai as a subject. After 1932 it was required that more hours be given to Thai than Chinese; that Chinese be offered only up to the fourth grade (compulsory education was only for the first four grades); and that the Chinese teachers who taught Chinese in those schools be required by law to obtain a teaching certificate from the Ministry of Education. The Chinese teachers then had to learn Thai, and were expected to pass the fourth grade placement test within a year of their first day of teaching, in order to be qualified for a teaching certificate. ${ }^{5}$

The requirements set up for the Chinese schools were obediently fulfilled, and although the directors of those schools complained about the new regulations, it turned out that new Chinese schools were established every year. Most of the Chinese schools were under the auspices of different associations, and the language the school taught was usually the dialect of the sponsoring association. There were five different dialects being taught in Chinese schools, namely: Ch'aochou, Hakka, Cantonese, Fukien and Hainanese (Skinner. 1962, p. 169). Before the Second World War, there were 294 Chinese schools in Thailand (Wisamansuksa. 1957). But, when China was defeated by Japan during the Second World War and subsequent agreements were made between the Thai and Japanese governments, most of the Chinese schools were closed. A few of the Chinese schools that were not closed at that time simply stopped teaching Chinese. ${ }^{6}$ By 1941 there was only one Chinese school left, ie the Chunwitthayakorn School, which later was named Kosol-witthaya School, a school under the patronage of the Ch'aochou Association of Thailand (Wisamansuksa, 1957, p. 13).

Professor Manomaivibool obtained her B.A. from Chulalongkorn University in Bangkok, and her Ph.D. in Linguistics from the University of Washington in Seattle. Her primary research interest focuses upon Chinese and That and she is currently Assistant Professor in the Department of Oriental Linguistics at Chulalongkorn University. 
In 1946, after the Second World War, the Chinese in Thailand, considering themselves among the victors, started setting up Chinese schools again. Many Chinese schools were established throughout the country and were not under the control of the Thai government. For political reasons the Thai government did not really control them and even allowed the Chinese who did not know Thai at all to continue teaching in these schools. The result was that Chinese schools became exempt from control by the Thai government. Some schools taught only Chinese to the exclusion of Thai; and some did not even fly the Thai flag, flying the Chinese flag in its place.

Later, in 1949, after agreement was reached between the Thai and Chinese governments, the Chinese schools came under the control of the Thai Ministry of Education again. They were permitted to teach 10 hours of Chinese per week (out of a total of 30 ), and it was required that those who taught Chinese had to pass the fourth grade placement test for Thai language in order to obtain a teaching certificate.

In 1948 the Thai Ministry of Education issued a directive to control the number of Chinese schools in Thailand. The directive permitted only eight Chinese schools in Bangkok and two in each of the provinces. ${ }^{7}$ Those schools that had already been set up before this directive were allowed to continue. In 1954 an anti-communist act was passed and many leftist Chinese schools closed of their own accord.

At present there is a total of 139 private primary schools all over the country where Chinese is taught as a subject. Of these schools, 41 are in Bangkok and 98 in other provinces. As for the private evening schools, there are 14 schools where Chinese is taught, of which eight are in Bangkok and six in other provinces: 8

The Chinese language taught in most schools is Mandarin. In some of the Chinese schools, the language taught is the Chinese dialect of the school management, which can be Ch'aochou, Cantonese, Hakka, or Fukien. Of these dialects Ch'aochou is the most popular. If the dialect is not directly taught as a subject, then it is used as the medium for teaching Mandarin. From the first grade up to the fourth grade the pupils learn both writing and speaking, utilizing Chinese textbooks edited by the Thai Ministry of Education. After four years of ten hours per week studying Chinese in a Chinese school the pupils have to transfer to a Thai school where no Chinese is offered. Consequently, most pupils simply forget their Chinese, especially the characters, unless their parents can afford to hire private tutors to give them lessons at home.

The private schools where Chinese is taught are known to the Chinese in Thailand as Chiao-shou Hua-wen min-hsiao (教授文民校). These schools are supported by the Thai government, as are many other private schools in the country. The only difference between Chinese schools and other schools is that the former offer Chinese as a second language, instead of English, Malay, Japanese, or any other foreign language.

\section{University Level}

Before 1970, Chinese was taught as a subject in Chinese primary schools and in some vocational schools, but not at university level. The first Thai university which planned to offer Chinese as a subject was Chulalongkorn University.

In 1965 the Faculty of Arts at Chulalongkorn University set up a Japanese programme. The Faculty then thought of introducing Chinese as a subject, but it 
lacked teaching staff for Chinese. Later, in 1967, the Gowen Fellowship was offered to Chulalongkorn University by the University of Washington. This fellowship was to be granted to a Thai student for the pursuit of Chinese studies at the University of Washington. The author was selected for the fellowship. Upon completion of her studies at the University of Washington the author returned to Thailand and started the Chinese programme at the Faculty of Arts, in June 1973. Chinese has been offered as a minor language in the Department of Oriental Languages since June 1977. The courses offered are: Mandarin I, II, III, and IV; the Structure of Mandarin I and II; Reading of Selected Texts from the Mainland; Reading of Newspapers I and II; Composition I and II; Chinese Tales and Sayings; Introduction to Chinese Literature I and II; Introduction to Chinese Phonology; and Selected Chinese Short Stories and Novels.

Courses offered at other universities, eg Thammasat University and Ramkamhaeng University, are more or less the same as the above-mentioned courses offered at Chulalongkorn University. The other universities that are planning to start Chinese programmes in the very near future are Songklanakharin University and Sinlapakorn University.

The Chinese language courses offered by the Department of Oriental Languages emphasize the skills of speaking and listening, especially during the first year of learning Chinese (Mandarin I and II). Towards this end, the traditional method of teaching a language through grammar and translation is not used. Instead, the audio-lingual method is applied. Pattern drills have proven to be very effective in getting students to speak Mandarin. Since classes are limited to not more than 40 students, students are expected and given opportunities to participate in the class, especially in the conversation classes which take place twice a week. Besides three lecture hours a week and two hours of conversation there are additional tutorial periods. Each student is assigned a period of fifteen minutes per week during which the student's pronunciation is corrected individually as the student converses in Mandarin with the tutor. Also, there is a master tape to accompany each lesson. This is assigned as homework. In other words, the students must listen to and repeat after the taped speaker either in the language lab or at home. At the end of the semester the students have to take both oral and written examinations for first year Chinese.

Once the students have mastered the sounds of Mandarin and the basic structures of the language the aim from the second year onward is to provide students with skills in reading, comprehension and writing. During the course they are taught how to use a Chinese dictionary, to enable them to read Chinese sources.

In all the Chinese courses traditional Chinese characters are used. Students are not taught the simplified characters, because they would have great difficulty in reading shop signs, local Chinese language newspapers, classical Chinese texts, or any materials printed in China before 1955 (when simplified characters were first introduced on the Mairlland).

Students interested in taking Chinese can be divided roughly into two groups:

(1.) Those who want to widen their opportunities for employment in business firms. Business in Thailand is run mostly by the Chinese. If one speaks Chinese, then one has a better chance of getting a good job. 
(2.) Those who want to learn Chinese as a tool for academic purposes, such as students in area studies. Right now the Department of Oriental Languages, owing to shortage of teaching staff, cannot offer courses for students with such an interest. The Faculty of Political Sciences, making use of a part-time instructor, has to offer Chinese courses for its own students.

Shortage of staff is one of the problems in the teaching of Mandarin. It is difficult to find trained teachers for Mandarin. Chulalongkorn University is the only place where there is a trained teacher on the permanent staff. Other universities make use of part-time instructors who are native speakers, but who are not trained especially for the teaching of Mandarin. Thammasat University is currently waiting for one of its teachers to complete a Ph.D. degree in Chinese Language and Literature at the University of Washington. The hope is that,eventually, a Chinese language centre can be organised by bringing together the lecturers and instructors from the four institutes which offer Chinese courses. This Chinese language centre will then be able to service those universities that want to offer Chinese as a subject.

Besides the shortage of trained teachers, textbooks present a problem in the teaching of Mandarin. There is a lack of suitable written material. In Thailand, Chinese textbooks are not easy to find, and imported books are usually too expensive for students to buy. Thus, instructors at each university have to try to produce their own teaching materials. On top of that, they have to be careful not to touch on politics. One instructor mentioned that he could not simply select passages from Mainland textbooks when studying simplified characters, but only those sentences that said nothing about politics on the Mainland. The result is that the students have to read fragmented passages or unconnected sentences instead of coherent passages or short articles.

Another problem that instructors of Chinese in Thai universities have to overcome is the differing background of the students. Some of the students have already studied Chinese as a second language in primary schools for a period of four years, whereas some of them have had no Chinese at all. Language placement tests cannot be used in this case because most of the former have already forgotten the Chinese language they learned as children. However, once they come to learn Chinese again, the forgotten language gradually comes back and they can learn much faster than the beginners. Some attempts are made to overcome this problem. For example, different topics are used for different groups in the tutorial periods, and the examination papers are marked differently.

One other problem in teaching Mandarin is that of pronunciation. It is generally assumed that it is not difficult for a Thai to learn Mandarin since both Thai and Mandarin are tonal languages. This is not true. It turns out to be a major problem for some Thai students to master the four tones of Mandarin because they tend to identify the tones in Mandarin with those in Standard Thai. For example, there is a tendency to identify the first tone in Mandarin with the first tone in Thai (Mandarin's is high-level whereas in Thai it is a mid-level tone). The initials and finals in Mandarin also pose a problem. For instance, Mandarin has the finals -ua and -uo, whereas Thai has only one such diphthong: $-u a$ which is neither the Mandarin -ua nor $-u o$, but something in between. The students do not differentiate between Mandarin - $u a$, and $-u o$, and pronounce them as Thai final -ua. Problems of pronunciation are many and would have to be studied in detail in a separate paper. The suggestion here is that a language teacher should have linguistic training. It would be an advantage if the teacher also knew the native language of the students. He would then be able to explain why certain mistakes are made, and he 
would also know how to correct these mistakes by pointing out the differences and similarities between the two languages.

1. Primary schools which are privately owned are allowed to teach five hours per week of one foreign language as a subject. The most popular and most common language is English. Unlike Chinese, English is offered again in all secondary schools. As for the government-run schools, no other language besides the national language, Thai, is taught. The teaching of English as a subject starts only from the secondaryschool level. According to an interview given to the daily newspaper Prachathipatai on the 12 January 1968 by Mr. Griang Iamsakul, Director of the Elementary Education Department at that time, the Ministry of Education tried to have all primary schools throughout the country teach Thai only. The teaching of any other foreign language would begin in secondary schools. However, the policy did not work. The Ministry finally had to give all privately owned schools permission to teach one foreign language, with the condition that, if the school asked to teach Chinese, it could be oftered only up to the fourth grade. Therefore, the main difference between the government-run and the privately owned schools is that the latter offer the opportunity to learn a foreign language. Most parents prefer to have their children start learning a foreign language as early as possible. They usually send their children to private schools if they can afford it.

2. The information on the teaching of Chinese in primary schools in Thailand was kindly given to the author by Mr. Sunthorn Wanitchasathien, chief inspector (Ministry of Education) of the private schools where Chinese is taught.

3. The Compulsory Education Act of 1918 was the first document issued concerning compulsory education in Thailand. The Act specifies that all children from seven to fourteen must go to a primary school, either public or private, which adheres to the curriculum endorsed by the Ministry of Education. The Act also dictates that all courses must be offered in Thai, with the exception of one foreign language course approved by the Ministry, such as English, French, Chinese, etc.

4. Private schools where Chinese was taught existed long before the passage of the Compulsory Education Act in 1918. The Ministry of Education recorded that the first 'Chinese' school was set up in 1918 by the Chung-hua Association in Bangkok (Wisamansuksa. 1957, pp. 2-3).

5. Details about those private schools teaching Chinese and the qualifications of their teachers are given in Ratchakitjanubeksa, No. 31 (Ratchabandittayasathan. 1918).

6. According to statistics gathered by the Ministry of Education, 242 Chinese schools were closed by the Ministry between 1938 and 1940; and 51 simply closed down on their own initiative (Wisamansuksa. 1957).

7. The directive was issued on the 11 May 1948 and was named Controlling the Number of Private Schools for Teaching Chinese. Only four other provinces, besides Bangkok, were allowed to have more than two Chinese schools. They are the 
STUDIES IN BILINGUAL EDUCATION

provinces of Thonburi, Chiangmai, Nakorn-srithammarat, and Ubol-ratchathani. Each was allowed to have three schools instead of two.

8. All of the six evening schools are in southern Thailand: one in Petchaburi, one in Chumporn, one in Phuget, and three in Trang province. 


\title{
日本的中文敎學及其環境
}

\author{
大河內康憲
}

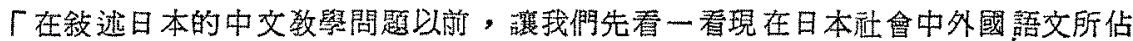
的地位是很有必要的。作䨖外國語文的一種一中文, 多少也反映所有的外國語文在日 本所受的限制。

厂在目前的日本社會中，外國語文所佔的地位和亞洲其他很多國家的情形比较起来 似乎有很大的區別。外國語文中具有代表性的當然是英文, 而英交在一般人的日常生活 中並不能在任何情况下起決定性的作用。能在社會生活中起作用的語言只有日文, 除此 以外, 再也找不到別的語文了。就䗪播和電䤐來說, 不管那一個電台沒有不用日文播䢪

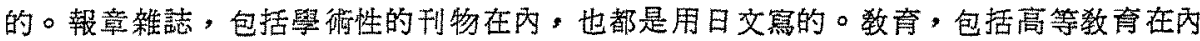
, 學校的課堂裡都是用日文講授, 絕沒有只用英文檴授的課程。因此, 學生們自小學至 大學，除了英文課以外，都用日文課本，所聽到的也是用日文的解釋和說明。在高 度水本的技術和知識上所要求的語言也不例外，例如䈣生談醫學、科學家談火箭、詞句 裡面踓加上一些外來語（根據外文的發至，用日本標至字「假名」竄出的），而都是用 日文交談, 不使用英交。總而言之, 現在的日本是一個單一語言的社會, 不像香港、新 加坡等地使用雙重語言, 也不像 亞洲其他渚國那樣, 在高等教育的階段上急不了依靠英 文的現家。

$\Gamma$ 日本的逼種現賽情况, 本來對社會的發展是很有利的, 但是, 另一方面卻反映出 日本人的外國語文能力低, 尤其是在會涪方面。逼對促進國際文化, 技術的交流便造成 了一定的障礙。一般日本人, 其中包括接受高等教育的知識份子在內, 除非有機會去外 國留學或到外國去工作, 幾乎都不能使用外文對話, 郎使能講一點, 也不能啺迌自己的 意見。日本向來不是不重視外國語文教育的; 近一百年以來, 教育的普及是國家主要政 策之一, 中等學校, 高等學校都是以英文呚育篇外國语文教育的重點。就現在的學制而 諭, 學生自初中一年級開始學英文, 直到大學果業, 一共學習十年之久, 每週的数授時 間不下四小時, 成霨主要學科之一。然而他們在口頭上運用英文的能力卻差得很。關於 镸個問题，最近有個特輯雜誌作了逼樣的心理分析：

厂他們影然是怕說錯了而會王面子，所以對於說一句正確無錯的英文太過分地去費 心考虑。心裡踓然知道英文不過是交際的工具, 錯一點也沒有什麼關係, 但是要把它說 出來時, 就克服不了這種心理上的障礙, 成爲『還是不說的好吧』而閉口不言了。偶而 遇到英文說得較流利的人, 口裡雖說『他裝腔作勢』, 但心裡卻以篇『多麼好! 恨不得 學他那樣子』」

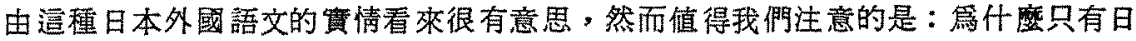
本出現逜種情况? 我以爲造明顯地是和近一百年以來的日本近代化有關係。所謂近代化 不過是西歐化, 乾脆一點說, 是把自己的文化, 特別是在物質文明上作有限度的西歐化 。大致當時所用的弶革方法略有兩種：一種是以自己的整體投入歐洲文化中，直接地從 中學習對自己有佥的東西。在語言上也不願將外國語文譯成自己的語文, 而是把歐洲的 東西連名帶物的搬過來使用。培養學生學習新事物時也是直接把學生派到歐洲諸國去學

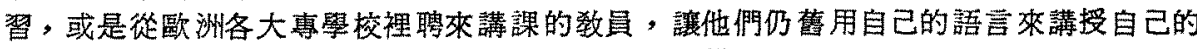
東西。這和現在部多亞洲國家所探用的方法似乎一樣。

Professor Ohkochi received his B.A. from Osaka University and his M.A. from Osaka City University, both in Chinese Studies. He also studied at Princeton University and in Peking. He is currently with the Department of Foreign Languages at Osaka University of Foreign Studies. 
另一種方法是間接的，那就是先器找歐洲文化中有用的東西，把它變鸱自己能充分 消化的東西再去吸收利用。外國語言上的困難也自然能第自己的語言所克服, 也就是說 把它當作好像自己本來的東西一樣, 夾雜在自己的文化裡去使用。因此, 在教育上也不 必依靠着外國語文, 是好是多, 反正是自己的, 根㹉目己的理解力去教育學生, 䈏然這 就和歐洲人斷絕了直接的關係, 歐化初期, 來到日本任教的外國教師也在逼種狀態中早 就離開了直接教學法, 除了特殊的情形以外, 本國的先進敉師便代替了外國人。日本和 中國, 雖在形式上有種種的不同, 但在基本上卻都採用了道種方法。

明治維新以後的日本所需要的是：先吸收歐洲文化, 再推䍌知識。先進的知識分子 如有機會便到歐洲去留學, 沒有機會便留在日本學漗英、法、德等諸阈語文。對他們來

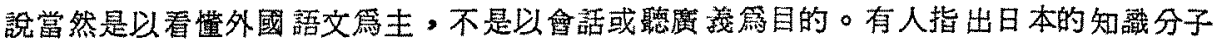
缺乏創造性，熱心於外國文化的介紹，逼種傾向也或與上述的事璸有關。日本的傳統英

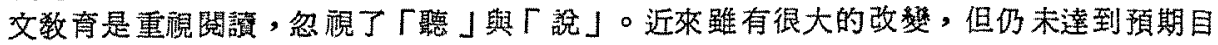
標。

$$
\text { (二) }
$$

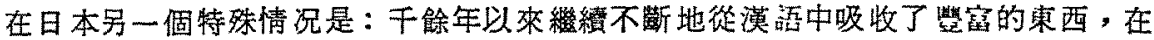
西歐交化傳來的前夕，已經有了較高的文化水平，在近代化的過程中，探取了上述的第 二種方式。關於造一事需，現在宜就語言方面作一检討。

據傳說, 把中國書籍最早傳入日本的是四五世紀之交, 經過朝鮮来到日本的殓化人 王仁。他應邀來日本時帶來論語十卷, 干字文一卷, 献給當時日本朝廷。自那時起, 日 本受到一千五百餘年的漢語恩惠, 直到十九世紀後牛期, 歐洲文化大距地傳入第止, 貫擺脫不了中國文化的深刻影响。

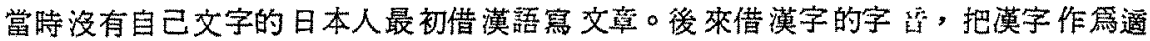
合於自己語言的標昔文字使用。去掉字義, 只取字至或部份字吾, 通梯只用漢字寫出結 構不同的日文, 在八世紀最爲流行, 那時以道種文字記錄的歌謡書籍是「萬葉集」, 我

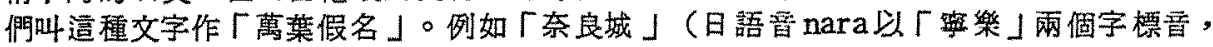
「山」(日語音yama以「也麻」標音。標至方法本來有幾種。漢字凨來日本時只有中

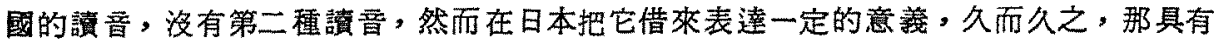
一定意義的日語音便固定了那個漢字, 結果就發生一個字有雨種讀点。一個是所谓漢字

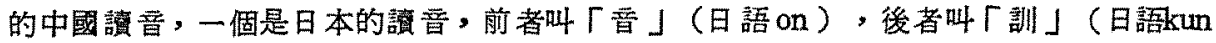
）。例如：「天地能」是日文「 ame tuti no」的漢字寫法。ame 是「天」字的「訓 」, tuti 是「地」的「訓」, no 是借「能」字的「畐」來萃達日文裡的助菏（相當於 結構助詞的「的」字）。逜三個字合起來就意味着「天地之間」的意思。逼樣，用厂畐 」和「訓」雨種讀音㳒合在一起來記錄自己的語言是日文的一個特徽。

「到了十世紀借用漢字至來表記日語至的方法更第發達, 於是就形成了現在日文所

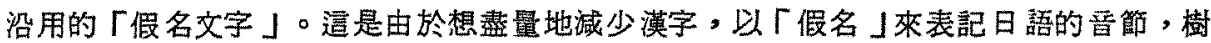
立日文的體系。

檢討中文教學的歷史沿革時, 特別値得我們过意的是當㭙日本人怎摩樣地去哈中圆 書籍, 又怎麼㥞地去了解它的內容。中國書籍傳入日本的初期，日本人是用中國字音去 唸, 吟了以後再翻成日文。在這段特期中, 他們當然以 新奇的眼光去看待中文, 學習方 法大概和現在没有什磨差別。可是，日本人在學習那些不標晋的漢字時，好像引起了不

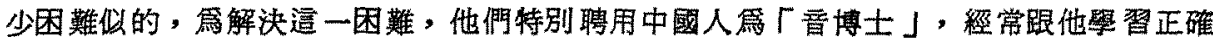
的讀至。然而到了九世紀末以後, 由於日本和中國（唐朝）的來往斷絕, 同㭙學㕷字音

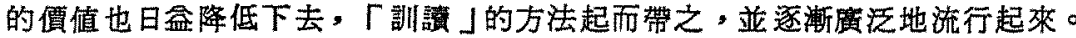

「初期的「訓謓」法是，一個一個的漢字用厂訓」唸出的同時, 並在漢字的左右上 下加上黑點或特別的符踇（叫「訓點」）以補助解讀。對日本人來說，中文不外是一種

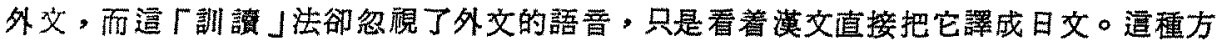

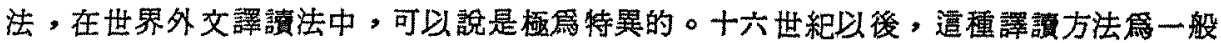
讀書人所採用, 把古時博士們所習用的神秘難懂的「訓點」改鳥通俗易孉的「剖點」, 
促進了日本近代的中國語學的發展。現在的日本人看漢文時, 還仍篦用着跟逼差不多的 方法去解颉，白話文是決不會合他們的口味的。現在通用的厂訓櫵」有選樣的一個例子 :

有明自裳方來，不亦樂乎。

「訓㵝」法包含兩個性質不同的階段：第一個階段是把這些漢字唸成日文中逼當的厂音 」或者「訓」, 第二個階段是爲了克服語法上的差異，有時把詞句中的漢字從下向上倒 過來唸。在各個漢字右下邊加上「假名文字」，表示各個字的詞尾或格助詞，以助「晋 」讀和「訓」颉的區別。一般叫作「遥假名」（okuri gana）。例如, 上揭「論語」 的詞句, 「有」字唸 ari ( $y$ 相當於 ri ), 「朋」吟 tomo, 「自」唸 yori, 「遠方 」唸 empoo（狺是「音」, ) 「来」唸 kitaru（夕幾相當於 taru, 如果唸「音」, 「 来」是 lai , 日語 lai 決不能和 taru 這個詞尾結合, 因此附有「夕幾」就表明它應該唸 「訓」kitaru）。這樣, 除「遠方」也可唸爲 enpoo, 不能唸爲 yuanfang, 這說明了 它雖是古時借來的詞, 而現在已和日文的詞魚融化起來, 成了賔賽在在的日文。在這個 階段上, 我們可以把全句喻篇：

ari tomo yori enpoo kitaru, zu ya mata tanosi

然而通和正確的日文比较還是有一點不順口。要調整詞序上的差別, 就得在原文漢字左 下邊加上符號以調整其詞序。這種符號一般叫做「返點」（kaeriten）。厂二二」等數 字是表示唸的次序, 「 $\mathrm{v}$ 」是表示兩個漢字倒過來唸。如果是這樣的話, 那桵上述的唸 法應該按照「返點」的指示改雼逼㥞:

tomo ari enpoo yori kitaru , mata tanosikara zu ya

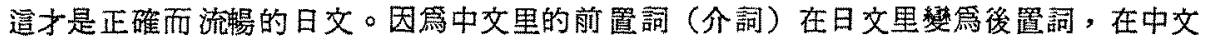
裡放在動詞後燠的橮語, 在日文裡則應該放在動詞的前邊, 否定詞也應讋放在相反的位 置上, 因此, 加上了「返點」。此外, 又因篇中文的詞裡沒有詞的屈折, 而在日文的詞 裡卻不可缺少它（日文裡叫「活用」）, 在中文裡基本上不用助詞表示「格」關係, 在 日文裡加上了厂透假名」, 用逼樣的方法就可把中文直接地翻成地地道道的日文而吟。

在實行明治維新而步入近代化的前夕，一般日本的知識分子就以這種方法去了解漢 文, 吸取中國文化, 雖有一部份人對荷蘭的學問表示關心, 在接受西洋文化的過程中起 了重要的作用, 但他們對西洋語文的了解邆不如了解漢文的明磪。當西洋文化源源傳入 到日本封, 他們把它已深深渗透到日語裡的「漢語」來翻譯, 並且配合漢字創造新詞( 最近把西洋的新事物用厂畐」譯的外來語表現, 無疑是暗示着漢語基礎的降低)。因此 , 離開中國文化的基礎, 我們就難以設想日本近代化能順利進行。

在日本的中文教學中, 另外應當重視的就是一貫缺少對當代中國的關心, 特別是十 九世紀末以後最䉆顯著。

十七世紀沟，日本封建政府採取閉關自守政策，郎是所謂「鎮國」，於是便和中國 的來往冷淡起來, 通商口岸只限於長崎一港。當時呼究或學相中國語交的人只有在長崎 當翻譯的「唐通事」, 大部份人都以「訓訟」的方法看漢文, 對語言上的影响是很有限 的。

十九世紀㣪牛, 歐洲文化陸續地轉入日本, 人們對文化的關心都集中到歐洲文化上 去, 反之, 對中國文化的關心都集中到䟜洲文化上去，反之，對中國文化的閣心卻降低 了, 尤其是一八九二年甲午戰爭以後, 由於中國的國際地位急速地下降, 對近代中國的

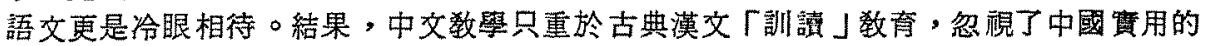
白話文教育。他們把白話文看做通商貿易等業務上的言語, 和專爲吸收先進文化的語言 （就是歐洲諸國的語文, 中國的漢文也包括在內）分開爽教學, 在日本的傳統文化中, 語言的主要功能是吸收先進文化, 使自己的文化豐富。教育上雖然失掉了對話交談的能 力, 但日本近代化過程中能起作用的, 是古典漢文知識或從古典漢文中吸取中國文化的 精粹, 不是近代中國的文化。中國的白話文只列於少數外國語學校, 商業學校等的科目 以內, 在一般中學和大學裡卻不能立足。

$$
\text { (三) }
$$

第二次世界大戰結束以後, 隨着日本社會狀况的改蕊，外國語文的数學情形也改變 
了面貌。學習外國語文的主要目標設定在作霑國際文化交流的工具上, 加深學生們的國 際認識與理解, 因此, 創出許多具體的制度和方法。結果, 一貫被人們忽視的中國白話 文教學也被列在一般高等教育的科目中。除了外國語大學之外, 一般大學也把它與英、 德、法等外文科目同栐地看待, 使許多學生有學皙現代中國語文的機會。當然, 關於逼 一點, 我們絕不能忽期一九四九年新中國的誕生。

隨着現代中國語文敉學的普及, 對現代白話文的研究也急速發展。一九四七年, 當 時任教於京都大學的数授倉石武四郎先生創辦了一個「中國語學研究會」(Chinese

Language Society of Japan ), 聚集京都、大阪、神户等地担任中文数學的教授以及 研究者們在一起, 開始逼應逼種新情况的研究工作。後來会石先生轉任東京大學, 辞會 又在東京組織一個分會。這様, 「中國語學䂧究會」便逐漸發展成震一個全國性的學會 , 現在雜有會員四百餘名, 會誌「中國語學」的刊出已達到二二三號。我們從通事賽可 以看到這三十年來日本中國語文教學的發展和現在的研究水本。

關於現在日本各大學的中國語文敉學, 由於数學方法和內容的不同, 大致可分感三 種。茹將其概况略述於下:

第一是在一般四年制的大學的前雨年中，作曘一般外國語課程，人文科學系和社會 科學系的學生幾平全部選修中文。按照日本一般大學的規定, 學生要學兩種外文, 就是 所謂第一外文和第二外文。第一外交是英文, 選修的學生人數居首位。第二外文是德文 或法文, 選修的學生人數僅次於英交。此外繁有不少的學生選修作篇第二外文的中文, 俄文和西班牙文以代替德文, 法文。選修中文的學生數目究竟有多少? 現在台末紶計出 來, 不過我相信有百分之五以上的學生選修中文。中文授課時間每星期雨次, 計 $3 、 4$

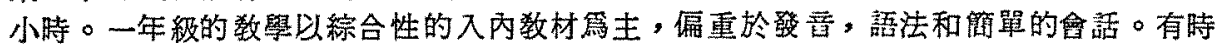
也請中國教師担任一牛時間指導學生發曋和會話。到了二年級時, 教學的重點便以閱俩

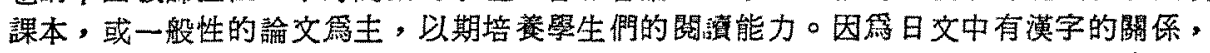
學生比较容易從字面上了解文章的內容，所發生困蜼的地方倒在於把远些漢字怎黁去吟 的問題上。因此, 他們學習了兩年中文以後, 會舕或朗讀文章的能力的水本都不很高, 只有閱讀方面可以略獲一點成績。

第二是外國語大學的中交教學。現在日本有五個大學（其中包括兩個國立大學）。 逜些外國語大學里有中文系。每年培養一定數目的學生以供應社會上的需要。外园語大 學和一般大學一梯, 都是四年制大學。四年中學生專門學習中文, 而且, 以中文雼中心 的有閣於中國的其他問題也在必修科之內, 因此, 中文水本比一般其他大祭要高。畢業 以後，大多就業於與中文有關的工作機構。外國語大學的學生每星期有中文祼五至六堂 (8-9 小時) , 大學一、二年級時, 注重掌握中文的基本能力, 就是锐發琵, 會話和

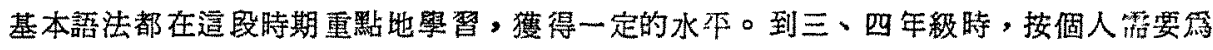

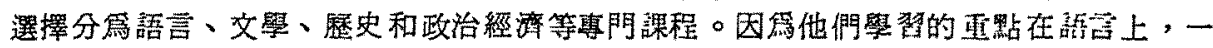
般專門課程也只限於現代或近代的中國。遍一點是和一般大學的中文系略有不同的地方 。

第三是一般大學中文系的中文数學。其方法是，按上述的一、二年級的學，學生 到了三年級時, 再開始講授中文專門橦程。由於教材內容較深, 加之日本人始終對漢文 古典有傳統的愛好, 因此專心學習古典者较多, 學柏現代部文者较少。但日本的傳統中

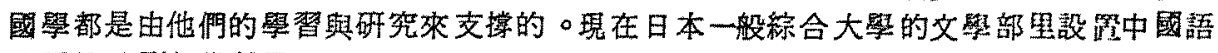
文系的達到相當數目。

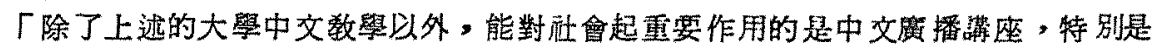
電視。造是差不多每天晚上一般人容易看到的播沿節目, 十分引人注意, 而且也使一般 人容易去學習, 於是學晳中文的人便日盒增加起來, 數年前, 田中首相訪問北京, 中日

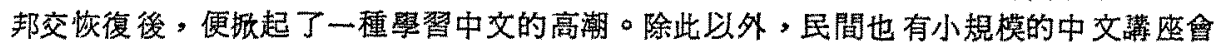
, 使一般人有學習中文的機會。因此, 在今日的日本國丙, 只要有人願意學梖中文, 噰 都可以有機會學好中文。

「日本和中國在地理、歷史、交化上有極第泌切的閣倸，從日本人的心情上看來， 中國不一定是所謂厂外國」。我們能肯定地說, 将來兩國的關係将會更接近、更親䖝, 隨之學習中文的人也會更䉆增加, 中文呚學也將要更進一步地發展起來。 


\title{
漢語書面語所受奥方言和英語之干擾及對干擾之容限
}

\author{
張日昇
}

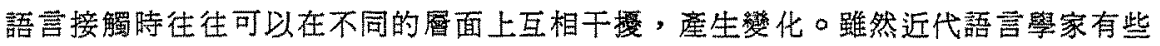

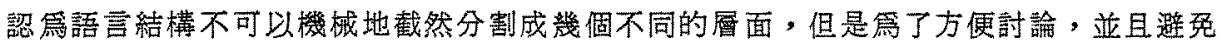

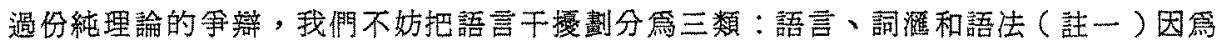

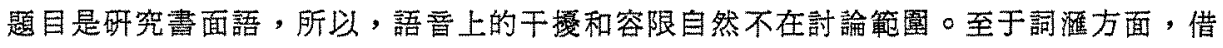
詞行變的規律和文化傳播的閣係, 都是檤得我們深入探研的問題。但是在語文教學上, 詞滩干婹所產生的問題, 比較容易處理, 所以我們希望集中語法部份的討論。

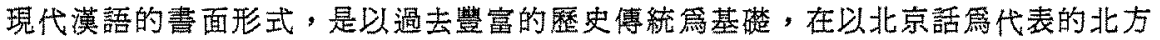
話之外, 吸收了古漢語, 外來語及其它方害發展而形成。在語吾融合的過程中, 出現了

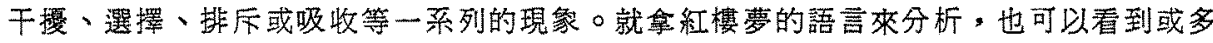
或少帶有些方票色柇和與口語不完全相雔的文言成份。五四運動以㣪，典範的現代白話 交 (噇二)，已經把許多不必要的方言或外語成份去掉。同時國務院閣于推廣普通話的 指示指出（註三），普通話的語法規範，是以這些典範著作作篇根據的。語言不管是口 頭形式澴是畫面形式，在發展過程中，必定要逶守內部規律的一致性（註四），因此對

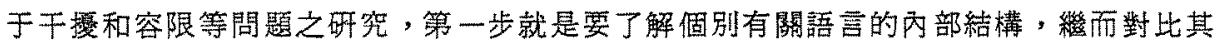
中異同，制断受干櫌之語急對外來成份的空限。

香港大部份人都講奥語。在某些交際、工作或學畾環境中，也有使用英語之需要。

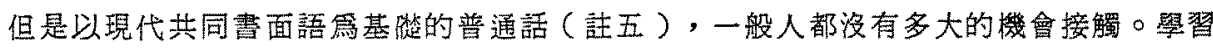
漢語書面語的方法因此圭要是通過閱譏。由于缺之對普通話的認識和長期與外語接觸,

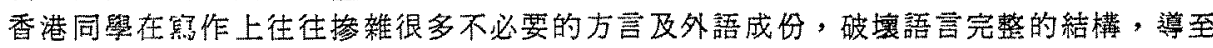
句子几鳌, 莧至引起語意混淆。本來, 語言因接䪅而產生干攃是一種很正常的現象( 六）, 但是，作孚一種全民的共同畫面語言，我們不能容許隨便把一些未經選擇洗煉的

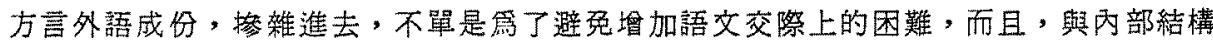
不一致, 或者遠反内部發展規律的外來成份, 往往構成別抂的句型, 很自然地受到排指 。另一方面, 外來成㘬如果與語言文部結楧不衝突, 符合其發展規律, 或满足在表達上

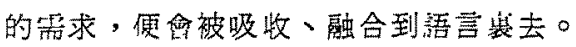

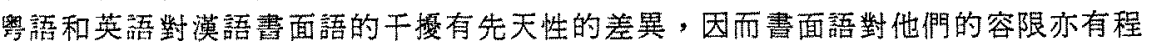

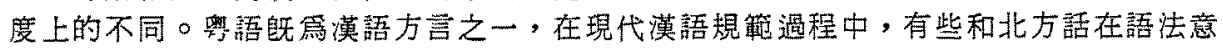

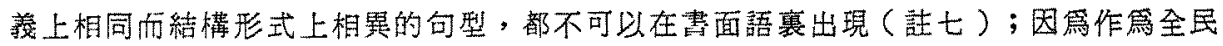
共同使用的活文, 並不需要兩種不同的形式同時並存, 來反映同一語法意䣡的結構, 在

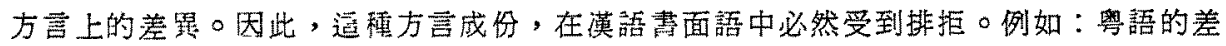
比結構中, 相比之甲乙雨項, 分別置於句首和句末, 被結啭助詞「過」和形容詞或副詞

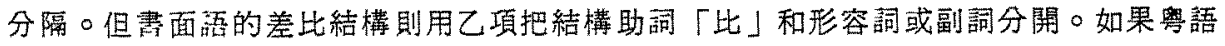
话 :

1.「甲雺過乙」

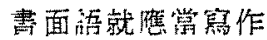

Dr. Cheung received his $B . A$. and an M.A. in Chinese Linguistics from the Chinese University of Hong Kong. He then received an M.A. and a Ph.D. in Linguistics from the University of California, San Diego. He was previously Lecturer at San Diego State University, and is currently Lecturer at the Chinese University of Hong Kong. His research interest focuses upon Chinese linguistics. 
2.「甲比乙高」

其中的差異, 不毠是結構助詞之不同, 同時亦有詞序上的問題。還沒有掌握普通話語法 的香港同學, 往往寫出像「幾乎睹場多過園書館, 俱樂部多過運動場」(註八)這一類 的句子。在教學上處理這類問题, 其賽並不太過複雜。我們只要把粵語和普通話語法對

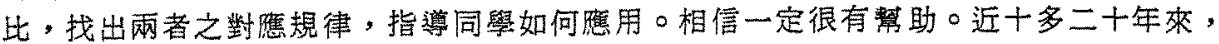
中國語言學學者, 篇推行普通話而舁了很多各種方言和普通話對比的害, 可借在香港, 對比語言學還末普遍地雪人所注意。

英語對漢語畫面語的干摄比方言來得複雑, 而書面語對其干猡的容限亦不如對方言 般來得明確。同學的寫作中有一望而知是暴做英語結構的洋式句子, 有湿入外語成份而 變成圥贅, 但又不能說完全不合漢語語法的句子, 也有源于英語句法而其句型已被漢語 吸收的句子。我們無意說明語言對外來干模的容限只可以作三級都分, 也暫時沟有用數 子表達衡量容限的方法, 不過, 這種噁直學的觀察, 是可以從铻官結構分析中得到解釋 和支持。現在我們就以上三種容限分別舉例, 粗略地說明一下。

首先, 生硬套用英語語法的中文句子, 是絕對不可以接受的。中英文都有差比結構 , 在詞序上英語比較接近罣語, 只要掌握了奥福和紫通話的對比規律, 英語的差比結構 是不會產生對畫面語的干摄的。但是現代漢語及各方言的差比結構有一項語法限制, 就 是句子中的甲乙丽項，一定是平行結構。例如舆方言俗語說：

3.「我食監多過你食米」

其中甲項「我食監」和乙項「你食米」都是兩個平行䍃構。英語則不受這條規別的限制 , 我們可以說：

4. "Dortt cough more than you can help"(噇九)

其中甲項 “Dorit cough”和乙項 “you can help” 並没有本行的關係。換言之, 甲項不能和 乙項相比。如果在現代白話文中出現菜做英語差比結構的句式, 像

5 . 「不要比你能忍受的咳得更多」

6. 一个不要咳得比你能忍受的更多」

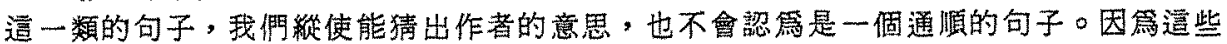
句子違反了漢語法規律的限制。在第 5 . 句中, 甲項是「不要」, 乙项是「你能忍受的咳 」, 兩者不能相比, 在第 6 . 句襄, 甲項是「不要咳得」, 乙项是「你能怨受的」兩者也 不能相比（註十）。其蕒, 英語和漢語差比結構的對䈍關係, 不是一比一。㓮少的例句 , 可以和另一種漢語句型對應：

7. 「能不咳, 就不咳」( 詳十一)

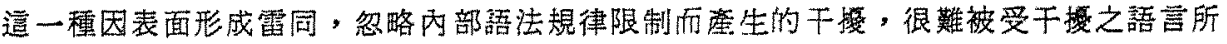
接受。

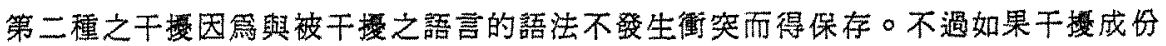

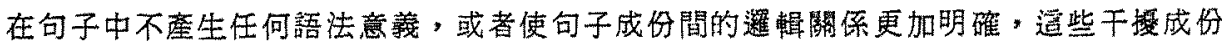

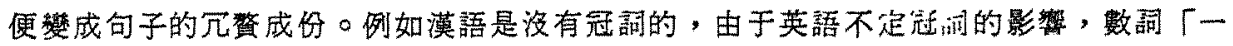
」加單位詞的結構如：「一個」、「一種」等等便潢泛地加在名部前頭, 有如英語不定 冠詞一樣, 例如 :

8. 「一個軍人䍜當忠於他的國家」(註十二)

造個句子中, 「一個」和「他的」都是几餘成份, 一方面没有握任任何語法職務, 另一

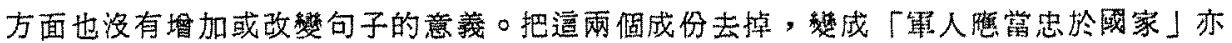

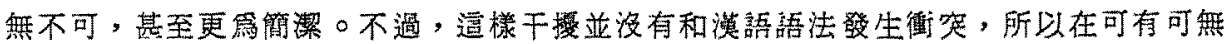

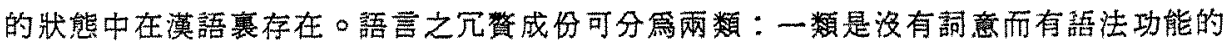
○英語中一個詞的複數概念可能需要三個詞素同時分擔, 例如：

9. "These books are mine"

一語中, 除了“book” 要加上複數的 $s$ 外, 指示形容呞和動詞都要用複數“these”和

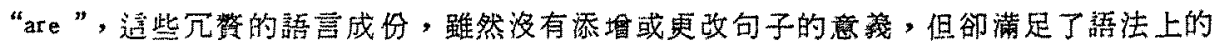
要求。 
10. "A soldier should be loyal to his country"

一句中, “a”和“his”都是不可缺少的成份。反過來說，漢語例子中的「一個」和「他的」

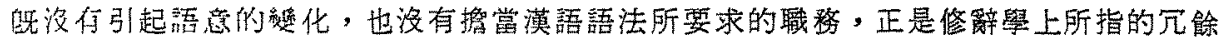

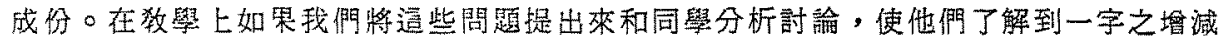

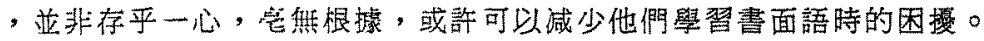

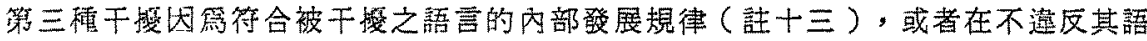

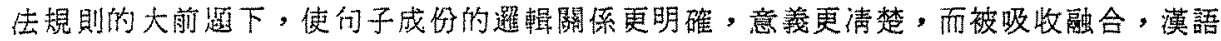
寒由雨倜以上的平行結構組成的句子，相同的主語可以省略，但相同的竇語一般不能省 略，如句11. 可以寒成向 12 ：

11. 「我看報紙, 我看襍镱」

12 「找看報紙和襍誌」

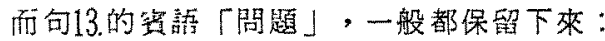

13. 「大家學會觀察問超、提出問題、分析問題和解決問題」。

但是現在流行一種把前頭幾個子句的相同賨語都省略掉, 只保留最後一個竇語的句型, 我們可以治：

14.「大家學會觀察、提出、分析和解決問題」。

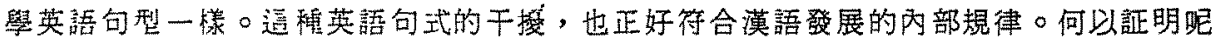
? 數十年前的漢語教材裹, 選擇問句的形式是 :

15. 「你吃钣不吃」?

這個問句的底厤結構, 原是由16.和17.

16. 「你吃飯

17. 「你不吃飯」

爾個子句結合而成在表面結構上第二子句的主語「你」和懢語「飯」都被前向删略律 ( For ward Del etion) 省略掉（註十四）。但是近年来的句式都變成

18. 「你吃不吃钣」?

如果我們比較15.和18.句，便可以發現唯一不同的地方就是句16.的「飯」被省略掉，而句 17.的「飯」反而保留下來。漢語從句15.行變到句18的歴史過程中, 我們應當如何去理解 呢? 根據變形學派 (Transf or mational ist) 的理論。在現代漢語的語法系統中，多了一條逆 向删略律（Backward Del etion）（註十五）。首先, 前向删略律把17的主語「你」省略, 但賓語「飯」卻保留下來; 然後逆向删略律把 16 的賓語「飯」删去, 便造成句 18 。䅉條 逆向删略律是漢語語法内部的自然發展, 沟有受其它語言的影響, 起初只是適當於疑問 句中, 但卻有發展到別種句式的可能, 剛才提到句 14 的賓語省略, 是受到英語的影整, 但其中從句13.推行到句 14的過程, 必然要使用莎向删略律, 把「觀察」和「分析」的察 語「問題」溯除，而使用造條變形規律又正好和漢語疑問句的麼史發展不謀而合，因此 , 像句14的漢語句型, 㯖起來不感到洋腔, 而且會慢慢的被漢語吸收, 成爲稳定的基本 旬㤠。

上述的三種干掫，經常在一個三三十字的句子中同時出現，除非教師在教學上對學

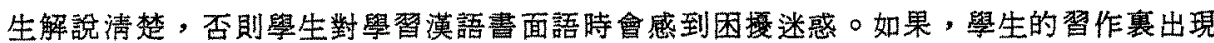
如19.的句子，我們應鲎如何處理呢?

19.「已經享受過良好的教育的人們應該在他們的行霹語言上表現它」。 薑個句子中, 我們不能接受的干擾成你是無生命代詞「它」, 即指「教育」, 因雼反語 代詞並没有英語那麼發達，通常只用人稱代詞「我」、「你」、和「他」。副蔀「已經 」、物主代詞「他們的」和代表複數的「們」都是可有可無的成份。漢語的名詞, 單數 複數原來就沒有形式上的區別，只有在人稱代名詞中甫用「們」字來區分單數和複數, 但近年來卻有少數的名詞，特別是作呼唤語時，可以用複數，例如「同志們」等。漢語 物主代詞的應用，也不如英語腐泛，因爲英語名詞差不多不用冠詞便一定要用物主代詞 或其他不定詞, 副詞「已經」和體貌詞尾「過」在意義上重複, 是受英語時態結構形式 的影響。英語 “have enjoyed” 共有三個成份, 助動詞 “have”, 動詞 “enjoy”和渦去式詞 
尾“-ed”。本來漢語用「享受過」（動詞十體貌詞尾）便已足范，加上「已經」兩字，

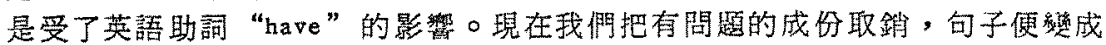

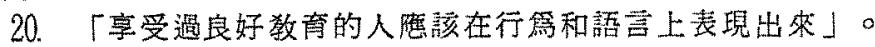

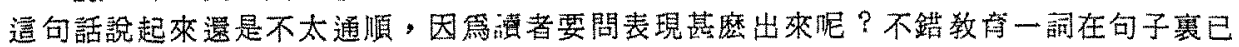

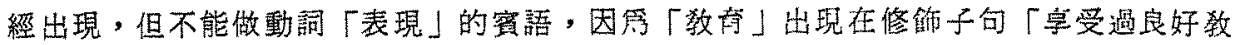

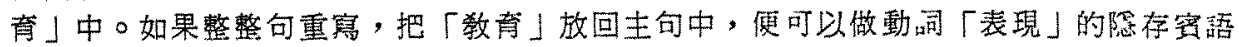
了。

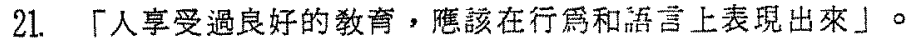

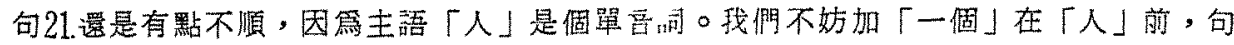
子便没有甚麼問題了。

22. 一一個人享受過良好的呚育，應咳在行号和语言上表現出來」。 在談及第二種干嗄的時候, 我們曾經提出句 8 中「一個軍人」的「一個」是几餘城份,

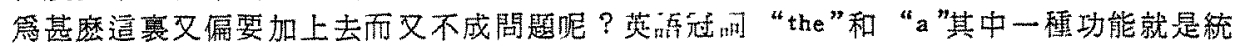
指。

23. "The dog is a faithful animal"

24. “A dog is a faithful animal"

上面兩句英語句子的 “dog”是統指狗類, 不是指某一隻狗。本來漢語的統揩是不用加任

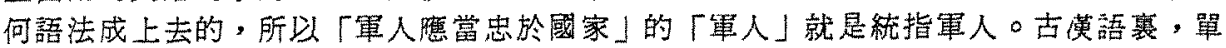
吾詞顔多, 但現代漢語卻以複畐詞佔優势。句21. 裹的「人」是統指, 把和英語冠詞對雄 的「一個」加在前頭, 既不發生語法意䅗上的衙突, 更能補足單晋節上的缺憾, 所以, 具有統指作用的 [一個」，便在漢語裹有限度地應用起来。

假如以上的觀察與分析是正確的話，我們便連帶地想起一個問題來。在漢語語文教

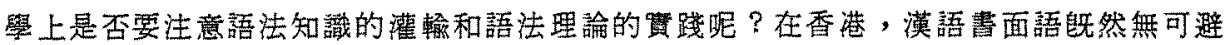

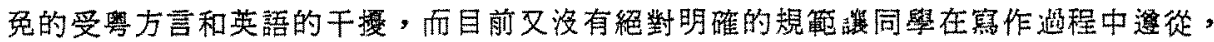
因此, 我們看來只有通過䦣釋語言內部結構, 和其歷史發展的可能性, 智助同學決定外 來千摄的容限，來提高他們使用漢語書面語的能力。

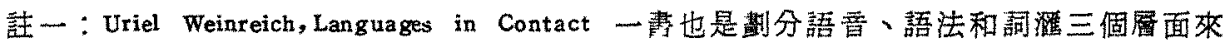
討論語言接觸時难生的干嗄。J.R.Rayfield, The Language of a Bilingual Community 則

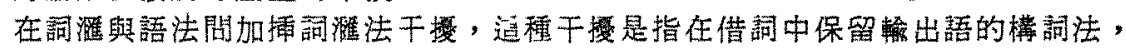
例如㑈地語的英語借詞中保留英珸的名詞複數 -s: 英語 meetings 在㑈地語中除了 作 Mitinge / Mitingen 外, 還可以作 Mitings 。其次他又在語兽與語法間加挿語法語

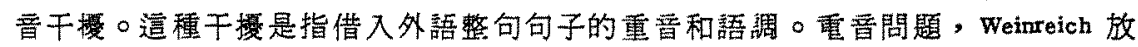

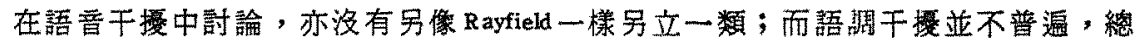

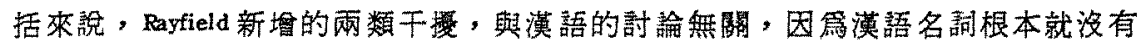
數, 而重普語調的問題, 到本前還没有發現。

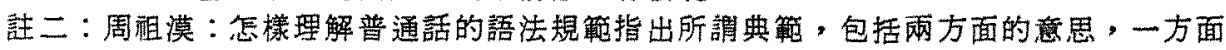
是符合全民語害的規範，不用特殊的方言士語; 一方面是經過文學的加工，不但

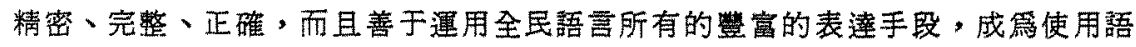
言的規籍。

註三：見一九五六年二月六日间務院關于推罊普通話的指示。

註四：漠語語法的規範, 歷史發展因素佔了紦對重要的地位, 造一點恐伯不會有誰提出

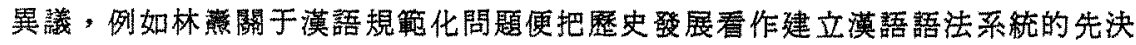
因素；「直到現在篇止，我們還沒有建立起一套完整的、意見一致的現代漢語語 法系統, 謰就給語法的規範化带來了一定的困難。目前首要的任務就是根據歷史

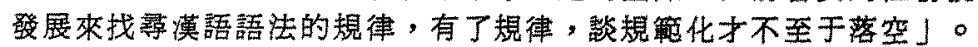

註五：見一九五六年二月六日國務院關于推展普通話的指示。 
註六：見 Weinreich 及Rayfield, 前引書。

註七：北方話分佈的區域極盧，包括大北方、西南各省和長江中部及下江沿江一帶，末

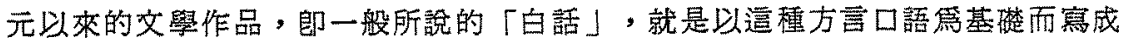
，現代漢語書面語又是建基於「白話」，所以，息語中和北方話相異的句型，也 被書面話排斥。

註八：引自香港中文大學大一國文某同學習作。

註九：引自余光中「篎通的蓺術」聽聽那冷雨。

註十：也産有人會問爲甚麽我們可以說「他跑得比我快」呢? 句子中的甲項是「他跑得 」，乙項是「我快」，按道理雨者都不是平行結構，跟第五和第六句相同，霨甚 㦄這裏又沒有問題呢? 其實造個句子的底層結構是由「他跑得快」和「我跑得快 」兩個子句結合而成。

$\begin{array}{ccc}\dot{\mathrm{v}} & \dot{\mathrm{s}} & \\ & \dot{\mathrm{s}} & \dot{\mathrm{s}} 2 \\ \text { 比 } & \text { 他跑得仭 } & \text { 我跑得快 }\end{array}$

$\mathrm{S} 1$ 的「快」和 $\mathrm{S} 2$ 的「跑得」, 在表面結構中省略掉。

註十一：見余光中前引文。

註十二：引自余光中前引文。

註十三: 王力中國語法理論下頁259說「其一族語之受外族語言的影䇾, 亦自有其限度 , 尤其是語法一方面, 必須這族語本來有某種可能性, 然後能容許某種變化」。 註十四：見拙作 “Negative Question in Chinese” Journal of Chinese Linguistics 2:325$339(1974)$ 。

註十五: 這個問題首先提出討諭的是郎嘉彥, 見制氏博士論文 Studies in The Phylogenesis of Questions and Diachonic Syntax (1971)。 


\title{
PROBLEMS OF PSYCHOLOGICAL TESTING IN TWO LANGUAGES IN HONG KONG
}

\author{
Jimmy Chan
}

\section{Introduction}

As a research worker I tend to approach the problem of bilingualism empirically, or experimentally, as I lack actual personal experience in language teaching. In a 'bilingual' society such as Hong Kong we are often confronted with the language problem when we construct a new test, particularly a psychological test. We often wonder whether we are testing a different thing altogether or tapping a different underlying attribute when we employ an overseas test or when we construct a test using English in the instructions and/or items for a psychological test. Wemay in fact be measuring such things as intelligence, attitude, interest, personality, etc. In Hong Kong,even if English is much used in academic and commercial circles, it is-not often used in the majority of Chinese families. Hence, children are not really truly bilingual though they may speak or understand some English. The native Chinese tongue or dialect, whether it be Cantonese (88\%), Hoklo (4.2\%), Hakka (2.7\%), Swatowese (Chiu Chau), Mandarin, etc, is still often ùsed in the thinking process, and a translation process might take place if English is used. It seems appropriate therefore to use Chinese as the medium in psychological tests as far as possible, rather than English, as it is more related to the real-life situations of the subjects. Moreover, psychological test items or scales are generally more subtle, delicate and sensitive, and the points may be missed if the instructions or the actual question items are in English.

\section{The Problem}

Two psychological tests, one on verbal reasoning ability (use of language for reasoning) and the other an numerical ability (use of mathematics for reasoning) were constructed and standardized with a view to testing the two basic academic abilities for success in school at the Primary 6 level. The child at this stage is in his last year of primary education, or about 12 years old. The question is whether these two tests should be in English or in Chinese, for instructions as well as for the test items. That is to say, would there be any difference in children's scores between the two parallel tests in the two languages?

\section{The Investigation}

Two tests were constructed with items equivalent in both languages. The meanings were, as far as possible, the same in both Chinese and English. It was believed that the correct response for each item should require the same reasoning process, irrespective of the language used. The words used in both languages are within the vocabularies of the children under consideration.

Dr. Chan obtained his B.Sc, in Science and an M.A. in Education from the University of Hong Kong. He also received a B.Sc. in Science, an M.Phil. in Psychology, and a Ph.D. in Educational Psychology, all from the University of London. He is currently the Senior Education Officer with the Educational Research Establishment, Education Department, Hong Kong. 
A group of 141 Primary 6 pupils ( 75 boys and 66 girls) aged between 9.11 and 14.9 (mean age $=12.3$ ) from 4 schools was selected for the purpose. They were of average standard according to their overall performances on the attainment tests of English, Chinese and Mathematics constructed by the Research, Testing and Guidance Centre. Half of the group did the Chinese version before doing the English version of the two papers, and the other half did the reverse, so that a cross-over or change-over design with replication was used.

\section{Results}

The following data was obtained:

Verbal Test

\begin{tabular}{cc}
\multicolumn{1}{c}{$\underline{\text { Replication I }}$} \\
Order 1 & Order 2 \\
Class 1: Chinese & English \\
$\overline{\mathrm{x}}=87.64$ & $\overline{\mathrm{x}}=67.68$ \\
s.d. $=10.45$ & s.d. $=7.54$ \\
Class 2: English & Chinese \\
$\overline{\mathrm{x}}=70.11$ & $\overline{\mathrm{x}}=100.25$ \\
s.d. $=9.67$ & s.d. $=16.72$
\end{tabular}

\begin{tabular}{|c|c|}
\hline \multicolumn{2}{|c|}{ Replication II } \\
\hline Order 1 & Order 2 \\
\hline $\begin{aligned} \text { Class 1: Chinese } \\
\overline{\mathrm{x}}=88.07 \\
\text { s.d. }=8.08\end{aligned}$ & $\begin{array}{c}\text { English } \\
\overline{\mathrm{x}}=69.73 \\
\text { s.d. }=7.11\end{array}$ \\
\hline $\begin{aligned} \text { Class2: English } \\
\overline{\mathrm{x}}=67.28 \\
\text { s.d. }=7.5\end{aligned}$ & $\begin{array}{l}\mathrm{Ch} \\
\overline{\mathrm{x}}= \\
\text { s.d. }=\end{array}$ \\
\hline
\end{tabular}

Numerical Test

$\begin{array}{cc}\stackrel{2}{\text { Replication I }} & \\ \text { Order } 1 & \text { Order 2 } \\ \text { Class 1: Chinese } & \text { English } \\ \overline{\mathrm{x}}=79.64 & \overline{\mathrm{x}}=82.20 \\ \text { s.d. }=8.24 & \text { s.d. }=10.32\end{array}$

\section{Replication II} Order $1 \quad$ Order 2

Class 1: Chinese

$$
\overline{\mathrm{x}}=82.34
$$

English

$\overline{\mathrm{x}}=87.90$ s.d. $=5.35$

Chinese

Class 2: English

s.d. $=7.51$

Class 2: English

$$
\begin{array}{rr}
\bar{x}=95.00 & \bar{x}=99.78 \\
\text { s.d. }=10.64 & \text { s.d. }=13.48
\end{array}
$$

Chinese

\begin{tabular}{|c|c|c|c|c|}
\hline Source of Variation & s.s. & d.f. & m.s. & $\mathrm{F}$ \\
\hline Between Verbal and Numerical & 493.73 & 1 & 493.73 & 0.59 \\
\hline $\begin{array}{l}\text { Within Verbal: } \\
\text { Between Chinese and English }\end{array}$ & 695.56 & 2 & 347.78 & $4.17^{*}$ \\
\hline $\begin{array}{l}\text { Within Numerical: } \\
\quad \text { Between Chinese and English }\end{array}$ & 9.33 & 2 & 4.67 & 0.06 \\
\hline Error & 831.38 & 10 & 83.14 & - \\
\hline Total & $2,030.00$ & 15 & - & - \\
\hline \multicolumn{5}{|c|}{$\begin{array}{l}\text { Notes: * denotes significance at } 5 \% \text { level. } \\
\text { s.s. }: \text { sum of squares } \\
\text { F } \quad \text { F ratial } \\
\text { d.f. : degree of freedom } \\
\text { m.s.: mean sum of squares. }\end{array}$} \\
\hline
\end{tabular}

$$
\overline{\mathrm{x}}=84.83
$$$$
\overline{\mathbf{x}}=96.08
$$

s.d. $=8.64$

Analysis of variants 


\section{Discussion and Conclusions}

From the results obtained from this research it seems obvious that the average pupils did significantly better in verbal reasoning if the paper was in Chinese. In numerical reasoning, though, there was, no difference in the scores of the two versions (English or Chinese). It is of great interest to note that significantly better scores were obtained in the Chinese paper for items which were given under long rubric or instruction, and particularly for items which were problematic, or which required an understanding of the language. These research findings are certainly empirical evidence in support of the general belief that Chinese (the mother tongue) should be used wherever possible in testing.

This confirms what research workers and test experts throughout the world have generally found. For instance, Anastasi (1968) pointed out that, al though a bilingual person may have a sufficient mastery of English to communicate on ordinary matters and even to attend an English-speaking school, he may be handicapped when taking a verbal test in English, as he may lack the monolingual's vocabulary range, verbal fluency, or facility in handling verbal relations in English. She went on to say that in testing any bilingual groups, the possible influence of a tanguage handicap on test performance must be given serious consideration. It cannot generally be assumed that such bilingual individuals can be adequately tested in verbal tests, despite their apparent mastery of English. Studies on American-born school children of foreign parentage who perform poorly on verbal tests are further evidence of this. This is of particular relevance in the Hong Kong situation where most children are native Chinesespeakers learning English in school.

Cronbach (1961) compared children who speak only English with bilinguals who speak a second language at home. Both groups were tested on the StanfordBinet and the Atkins Object-Fitting Test, a performance test which does not demand facility in English. It was evident that the bilingual group, which was superior on the nonverbal test, would be inferior on the Stanford-Binet.

\begin{tabular}{lcc} 
Test & Mean IQ for Monoliguals & Mean IQ for Bilingualism \\
\hline Stanford-Binet & 98.7 & 90.9 \\
Atkins Object-Fitting & 89.0 & 97.5
\end{tabular}

(Note: Both differences are significant.)

On the other hand, though many of the earlier investigations found lower IQ and lower verbal abilities in bilingual children, Butcher (1970) maintained that, if brought up from infancy as bilingual speakers, children would appear to suffer no measurable handicap. In the Hong Kong context, however, our children can hardly be called true bilingual speakers, and hence it might be safe to conclude that, in testing, English should not be used, either in the instructions or the items, as far as possible. This particularly applies to primary school children taught in Chinese.

Finally, the effect of bilingualism on intelligence is very complex and far from clear, and hence a great deal of further research is required to understand the problem more clearly. In Hong Kong the problems are further complicated by the fact that the Chinese written language is 'ideographic' whereas the English written language is 


\section{PROBLEMS OF PSYCHOLOGICAL TESTING IN TWO LANGUAGES}

'phonetic', and that spoken and written Chinese are quite different. Very often, too, the Chinese characters give away the answer to an item, eg 鐵 'iron' ( 金 means 'metal'), 河 'river' ( F means 'water'); 鯨魯、露帒、墨魚 (魚 means 'fish') 'whale', crocodile', and 'octopus' are very distinct in English, but in Chinese they tend to suggest the same kind of animal. 


\title{
PUBLIC EXAMINATIONS GO BILINGUAL FOR HONG KONG PRIMARY AND SECONDARY SCHOOLS
}

\author{
Lee Lai-min
}

.- Two languages, English and Chinese, are commonly used in teaching in Hong Kong primary and secondary schools. The testing and assessment of learning is usually given in the same language medium as the teaching. This paper reports on the language media used for instruction, the use of bilingual papers in public examinations, and some results of these examinations in Hong Kong primary and secondary schools.

\section{Medium of Instruction}

Most of the primary schools in Hong Kong are Chinese schools except for those catering to minority communities. In a number of Anglo-Chinese primary schools English is the language of instruction. The ratio of student enrolment in these two types of primary schools was approximately 1:11 in 1976:

Table I

Student Enrolment in Primary and Secondary Courses by Type of School (September 1976)

\begin{tabular}{|c|c|c|c|c|}
\hline $\begin{array}{l}\text { Type of School } \\
\text { (Day Schools) }\end{array}$ & English & $\begin{array}{l}\text { Anglo- } \\
\text { Chinese }\end{array}$ & Chinese & Total \\
\hline A. Primary & & & & \\
\hline Government & 2145 & - & 33764 & 35909 \\
\hline Subsidized & 882 & 15818 & 467867 & 484567 \\
\hline Private & 587 & 33046 & 53881 & 87514 \\
\hline Total & 3614 & 48864 & 555512 & 607990 \\
\hline
\end{tabular}

B. Secondary: Other than Certificate of Education Courses

\begin{tabular}{lcrrr} 
Government & 885 & 15753 & 2276 & 18884 \\
Grant & - & 18847 & 263 & 19110 \\
Subsidized & 1011 & 52268 & 8439 & 61718 \\
Private & 512 & 209918 & 52539 & 262969 \\
\hline Total & 2408 & 296786 & 63517 & 362681
\end{tabular}

C. Secondary: Certificate of Education Courses

\begin{tabular}{lrrrr} 
Subsidized & - & 4277 & 4471 & 8748 \\
Private & - & 1614 & 879 & 2493 \\
\hline Total & - & 5891 & 5350 & 11241
\end{tabular}

Dr. Lee received his B.A. in Psychology from the University of Hong Kong. He also received an M.A. in Mathematics from the University of London. Subsequently he received an M.A. and a Ph.D. in Education from the University of Iowa. He is currently Subject Officer with the Hong Kong Examinations Authority. 
Secondary schools, Anglo-Chinese grammar schools and secondary technical schools use English as the medium of instruction and offer courses leading to the Hong Kong Certificate of Education Examination. Chinese middle schools offer courses in the medium of Chinese. Secondary modern schools and prevocational schools offer threeyear courses in the medium of both English and Chinese. The ratio of secondary school students taught in English to those taught in Chinese was approximately $4: 1$ in 1976 (see also Table I). Thus, the medium of instruction in primary schools is largely Chinese. In secondary schools both English and Chinese are used. However, English predominates.

\section{Public Examinations in Hong Kong}

There are two public examinations conducted for schools by the Examinations Division of the Education Department:

\subsection{The Secondary School Entrance Examination}

The Secondary School Entrance Examination (SSEE) is a competitive test to select pupils for places in Government and Government-aided secondary schools and in private secondary schools in which the Government provides aided places. The examination is open to all Primary 6 pupils of registered primary schools. All candidates (97,930 in 1976), except a small group of non-Chinese speakers, must take three examination papers: Chinese, English and Mathematics (the latter in either Chinese or English). Non-Chinese-speaking candidates (118 in 1976) take Alternative English I and II instead of Chinese and English respectively. Allocation is based on a candidate's attainment in the examination and the parents' choice of schools. Where necessary, account will be taken of such factors as personal preference for types of schools and the district in which the candidate lives. Table II gives an analysis of types of secondary school places available in the last six years. Most places are in Anglo-Chinese schools.

The SSEE is to be conducted for the last time in 1977. In 1978 a new procedure for allocation will be adopted, using schools' internal assessment, to be scaled by an Academic Aptitude Test which consists of two parts - verbal reasoning and numerical reasoning. Every Primary 6 school leaver will be allocated an aided secondary school place by 1978 .

\subsection{The Hong Kong Certificate of Education Examination}

The Hong Kong Certificate of Education Examination (HKCEE) is primarily intended to be a test of general education for students who have completed a recognised secondary school course of five years' duration. A Certificate of Education is awarded to each candidate sitting the examination, and results of individual subjects are graded from $A$ to $\mathrm{H}$. The examination is also open to suitably qualified private candidates.

The original Hong Kong School Certificate Examination was conducted in English for Anglo-Chinese secondary school students. In 1952 the Hong Kong Chinese School Certificate Examination was launched for Chinese middle school students. This examination was conducted in Chinese, except for the subject of English Language. For more than twenty years, these two distinctive school leaving 
STUDIES IN BILINGUAL EDUCATION

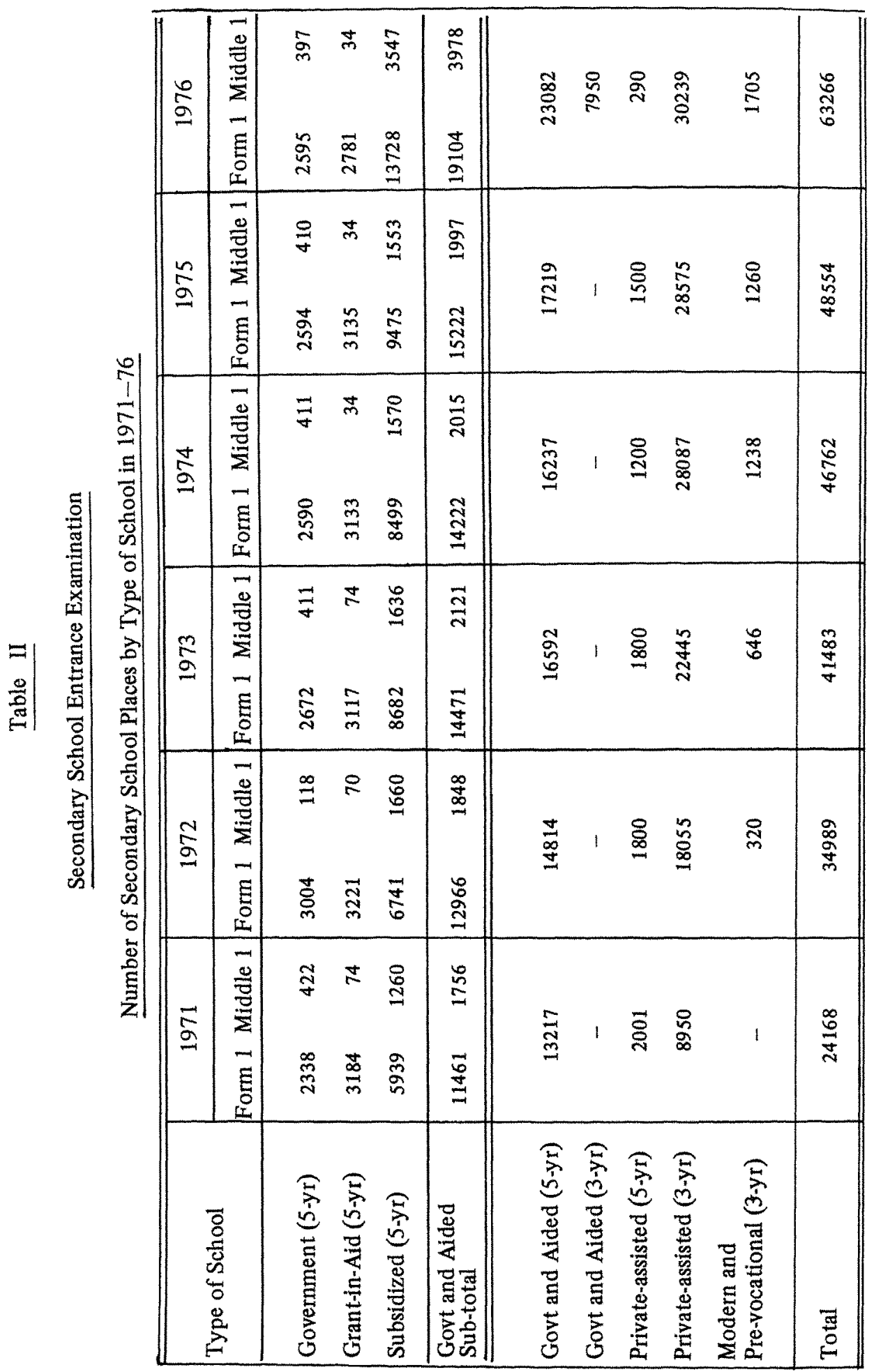


examinations existed side by side. In the course of time, the curricula of the two types of school-Anglo-Chinese secondary schools and Chinese middle schoolshave been drawing closer together. In 1974 these two examinations were combined to form the $H K C E E$. By stages, identical examination papers were set on identical syllabuses, and scripts were marked and results graded with identical standards, the only difference being the language medium used, English or Chinese. The amalgamation was fully completed in 1976.

In the HKCEE, Grade $\mathrm{C}$ or above in most subjects is recognised as being equivalent to an ' $O$ ' Level pass in the United Kingdom's General Certificate of Education Examination. Since the amalgamation the same recognition is extended to subject examinations taken in the Chinese version in the HKCEE.

\section{Examining in Bilingual Versions}

In the SSEE bilingual versions of the Mathematics paper are offered. By 1976, except for language subjects and subjects such as typing and shorthand, all subject examinations in the $H K C E E$ were offered in bilingual versions. It should be noted that, in any subject with syllabuses to be examined in either English or Chinese, only one language version of the examination is allowed to be offered.

In setting the questions for bilingual versions the general practice is to devise questions first in one language. After the content of the paper is agreed it is translated into the other version. However, during the process of translation, it is common to go back to the original version for amendments and necessary clarification in wording. This is to ensure that the questions in the two versions are as far as possible identical. The marking schemes are prepared in a similar manner. Therefore, no matter which version candidates attempt in the examination they will be marked according to the same standard. Technical terms in English are often included together with the Chinese translation. Similarly, certain Chinese terms are included in the English version where appropriate. In general, the setting of 'identical' questions in the two versions is quite satisfactory. More difficulty is encountered in setting the multiplechoice items. Due care is taken to ensure that options plausible in one version are not 'giveaways' in the other version because of the language medium used. Generally, the same patterns of response are often observed in both versions.

It may be of interest to compare results obtained by candidates taking the English and Chinese versions of the same subject examination. Table III gives the 1976 HKCEE results of some of the amalgamated subjects with large entries. It is observed that, without exception, candidates taking the English version of a subject are better at the Grade $A$ and Grade $C$ levels than their counterparts taking the Chinese version. At the Grade $\mathrm{E}$ level the distinction between the performance of these two types of candidates is not so clear.

The following two explanations, among others, are being offered for the above observation of the difference in performance for candidates taking the English and the Chinese versions : (i) The difference may be due to the academic standards of Primary 6 students allocated to the different types of secondary schools based on the SSEE results. Table $I V$ gives the mean and standard deviations of blocks of representative samples by school type and of the total allocated in the 1970 SSEE. It is observed that 
Table III

Hong Kong Certificate of Education Examination 1976

Analysis of Results of School Candidates

\begin{tabular}{|c|c|c|c|c|c|c|c|c|}
\hline \multirow{2}{*}{ Subject } & \multirow{2}{*}{ Version } & \multirow{2}{*}{ Numbers } & \multicolumn{2}{|c|}{ Grade A } & \multicolumn{2}{|c|}{$A-C$} & \multicolumn{2}{|c|}{$A-E$} \\
\hline & & & No. & $\%$ & No. & $\%$ & No. & $\%$ \\
\hline \multirow{2}{*}{$\begin{array}{l}\text { Additional } \\
\text { Mathematics }(1,2)\end{array}$} & English & 6988 & 116 & $1.66 \%$ & 1433 & $20.51 \%$ & 4799 & $68.67 \%$ \\
\hline & Chinese & 1774 & 11 & $0.62 \%$ & 168 & $9.47 \%$ & 977 & $55.07 \%$ \\
\hline \multirow[t]{2}{*}{ Biology } & English & 26591 & 416 & $1.56 \%$ & 3908 & $14.70 \%$ & 14705 & $55.30 \%$ \\
\hline & Chinese & 4675 & 2 & $0.03 \%$ & 308 & $4.76 \%$ & 3055 & $47.18 \%$ \\
\hline \multirow[t]{2}{*}{ Chemistry } & English & 17828 & 218 & $1.22 \%$ & 3002 & $16.84 \%$ & 10506 & $58.93 \%$ \\
\hline & Chinese & 2863 & 12 & $0.42 \%$ & 253 & $8.84 \%$ & 1531 & $53.48 \%$ \\
\hline \multirow{2}{*}{$\begin{array}{l}\text { Economic and } \\
\text { Public Affairs }\end{array}$} & English & 17691 & 119 & $0.67 \%$ & 1347 & $7.61 \%$ & 7125 & $40.27 \%$ \\
\hline & Chinese & 3593 & 5 & $0.14 \%$ & 197 & $5.48 \%$ & 1711 & $47.62 \%$ \\
\hline \multirow[t]{2}{*}{ Geography } & English & 17734 & 268 & $1.51 \%$ & 2752 & $15.52 \%$ & 9984 & $56.30 \%$ \\
\hline & Chinese & 4693 & 2 & $0.04 \%$ & 234 & $4.99 \%$ & 2342 & $49.90 \%$ \\
\hline \multirow[t]{2}{*}{ History } & English & 15198 & 204 & $134 \%$ & 2215 & $14.57 \%$ & 8120 & $53.43 \%$ \\
\hline & Chinese & 4022 & 4 & $0.10 \%$ & 180 & $4.48 \%$ & 1961 & $48.76 \%$ \\
\hline \multirow[t]{2}{*}{ Mathematics } & English & 22656 & 774 & $3.42 \%$ & 6287 & $27.75 \%$ & 17533 & $77.39 \%$ \\
\hline & Chinese & 2026 & 13 & $0.64 \%$ & 402 & $19.84 \%$ & 1606 & $79.27 \%$ \\
\hline \multirow{2}{*}{$\begin{array}{l}\text { Mathematics } \\
\text { (Alternative } \\
\text { Syllabus) }\end{array}$} & English & 13902 & 445 & $3.20 \%$ & 3116 & $22.41 \%$ & 10068 & $72.42 \%$ \\
\hline & Chinese & 4102 & 56 & $1.37 \%$ & 699 & $17.04 \%$ & 2989 & $72.87 \%$ \\
\hline \multirow[t]{2}{*}{ Physics } & Eng & 17641 & 205 & $1.16 \%$ & 2797 & $15.86 \%$ & 10332 & $58.57 \%$ \\
\hline & Chinese & 2365 & 2 & $0.08 \%$ & 208 & $8.79 \%$ & 1332 & $56.32 \%$ \\
\hline \multirow{2}{*}{$\begin{array}{l}\text { Principles of } \\
\text { Accounts }\end{array}$} & & 1319 & 68 & $5.16 \%$ & 191 & $14.48 \%$ & 838 & $63.53 \%$ \\
\hline & Chinese & 247 & 6 & $2.43 \%$ & 16 & $6.48 \%$ & 114 & $46.15 \%$ \\
\hline
\end{tabular}

Table IV

Mean and Standard Deviation of Blocks ${ }^{1}$ of Representative Samples by School Type and of Total Allocated in the 1970 SSEE

\begin{tabular}{lcccc}
\hline Type of School & $\begin{array}{c}\text { Sampling } \\
\text { Ratio }\end{array}$ & $\begin{array}{c}\text { Sample } \\
\text { Size }\end{array}$ & Mean & S.D. \\
\hline Government and Aided: & & & & \\
Anglo-Chinese Grammar & $1: 10$ & 537 & 4.99 & 1.62 \\
Anglo-Chinese Technical & $1: 3$ & 302 & 5.52 & 1.18 \\
Chinese Middle & $1: 4$ & 201 & 6.00 & 1.16 \\
Private Schools & $1: 10$ & 196 & 6.2 & 1.08 \\
\hline Total Allocated & - & 15164 & 5.78 & 1.54
\end{tabular}


Government and Government-aided Anglo-Chinese secondary schools are more popular and hence have attracted more able pupils. (ii) The observed difference may also be due to the differences in school facilities, and the avallability of suitable textbooks for the two types of secondary school. In the HKCEE 1976 Annual Report the chief examiner of Principles of Accounts wrote : 'It appeared that those candidates taking the English version paper had done much better than those taking the Chinese version. This might be due to the fact that few textbooks written in Chinese which can cover the syllabus adequately are available on sale...'

\section{Examining English and Three Chinese Subjects}

It is of interest to compare the performance of Anglo-Chinese school candidates and Chinese middle school candidates in the examinations of English Language and three Chinese subjects - Chinese Language, Chinese Literature and Chinese History. In the HKCEE two syllabuses are offered in English Language : Syllabus A and Syllabus B. Certain multiple-choice items are common to the multiple-choice papers of the two syllabuses. In general the Chinese middle school candidates taking Syllabus A perform less well on these common items than Anglo-Chinese school candidates taking Syllabus B. Some examples of these multiple-choice items are given in Table $V$.

\section{Table V}

Examples of English Multiple-Choice Items Common to Syllabuses A and B

1. Whenever I go on a picnic, I always take a radio with me.

Percentage choosing the option

\begin{tabular}{lrr} 
& Syll. A & Syll. B \\
\cline { 2 - 2 } A. bearable & $6.98 \%$ & $10.51 \%$ \\
B. movable & $26.79 \%$ & $13.64 \%$ \\
C. portable & $20.50 \%$ & $47.06 \%$ \\
D. transportable & $21.05 \%$ & $13.75 \%$ \\
E. transferable & $24.55 \%$ & $14.96 \%$
\end{tabular}

(Synonyms)

2. The Chief Justice said this was a very serious offence and sentence to next Monday, pending a probationary report.

Percentage choosing the option
A. deferred
B. referred
C. conferred
D. preferred
E. transferred

Syll. A

$16.57 \%$

$23.93 \%$

$18.37 \%$

Syll. B

$19.46 \%$

$40.74 \%$

$21.45 \%$

$12.03 \%$

$21.81 \%$

$9.99 \%$

$15.28 \%$

(Words similar in form) 
3. I want five tickets____ for my family.

Percentage choosing the option

$\begin{array}{lrr} & \text { Syll. A } & \text { Syll. B } \\ \text { A. reserve } & 12.48 \% & 14.17 \% \\ \text { B. reserved } & 12.38 \% & 29.05 \% \\ \text { C. reserving } & 15.97 \% & 15.38 \% \\ \text { D. to reserve } & 49.47 \% & 31.77 \% \\ \text { E. to be reserving } & 9.61 \% & 9.58 \%\end{array}$

(Verb forms - parts of spech performing different functions)

4. The Indians greatly increased the area of their home and by the Eskimo tribes on their borders and their lands.

Percentage choosing the option

Syll. A Syll. B
A. discovering, giving up
$20.28 \%$
$7.73 \%$
B. observing, admiring
$9.16 \%$
$4.52 \%$
C. approaching, travelling through
$12.03 \%$
$6.89 \%$
D. leaving, selling
$2.81 \%$
E. defeating,
settling on
$48.98 \%$
$77.78 \%$

(Comprehension ability)

The medium of instruction is mainly Chinese in primary schools in Chinese school and Chinese middle school candidates. Table VI, for Chinese Language in 1976 , shows that the performance of the two types of candidates was quite similar. The Chinese middle school candidates were slightly better. The majority of Chinese middle school candidates took Chinese Literature, and they performed much better than AngloChinese school candidates taking the same subject. In Chinese History both types of candidates performed about equally well.

\section{Summary}

The medium of instruction is mainly Chinese in primary schools in Hong Kong. Anglo-Chinese secondary schools are much more popular than Chinese middle schools. Hence, the majority of secondary schools use English as the medium of instruction. Public examinations conducted by the Examinations Division of the Education Department are given in bilingual versions where appropriate. Both versions are 'identical' and are marked according to the same standard, and the same recognition is 
given to the standard achieved in both versions. In the HKCEE candidates taking the English versions generally perform better, most probably because Anglo-Chinese secondary schools have attracted better students through the SSEE. Anglo-Chinese school candidates perform better in English Language, but are inferior in Chinese Literature. In Chinese Language and Chinese History both types of candidate perform similarly.

Table Vl

Hong Kong Certificate of Education 1976

Results for School Candidates in Three Chinese Subjects

\begin{tabular}{|c|c|c|c|c|c|c|c|c|}
\hline \multirow[b]{2}{*}{ Subject } & \multirow[b]{2}{*}{$\begin{array}{l}\text { Type of } \\
\text { School }\end{array}$} & \multirow[b]{2}{*}{ Numbers } & \multicolumn{2}{|c|}{ Grade $\mathrm{A}$} & \multicolumn{2}{|c|}{$A-C$} & \multicolumn{2}{|c|}{$A-E$} \\
\hline & & & No. & $\%$ & No. & $\%$ & No. & $\%$ \\
\hline \multirow[t]{3}{*}{$\begin{array}{l}\text { Chinese } \\
\text { Language }\end{array}$} & $\begin{array}{l}\text { Anglo- } \\
\text { Chinese }\end{array}$ & 40790 & 442 & $1.08 \%$ & 6054 & $14.84 \%$ & 29461 & $72.23 \%$ \\
\hline & $\begin{array}{l}\text { Chinese } \\
\text { middle }\end{array}$ & 8239 & 104 & $1.26 \%$ & 1452 & $17.62 \%$ & 5904 & $71.66 \%$ \\
\hline & Total & 49029 & 546 & $1.11 \%$ & 7506 & $15.31 \%$ & 35365 & $72.13 \%$ \\
\hline \multirow[t]{3}{*}{$\begin{array}{l}\text { Chinese } \\
\text { Literature }\end{array}$} & $\begin{array}{l}\text { Anglo- } \\
\text { Chinese }\end{array}$ & 14241 & 112 & $0.79 \%$ & 1965 & $13.80 \%$ & 8129 & $57.08 \%$ \\
\hline & $\begin{array}{l}\text { Chinese } \\
\text { middle }\end{array}$ & 6419 & 100 & $1.56 \%$ & 1500 & $23.37 \%$ & 4468 & $69.61 \%$ \\
\hline & Total & 20660 & 212 & $1.03 \%$ & 3465 & $16.77 \%$ & 12597 & $60.97 \%$ \\
\hline \multirow[t]{3}{*}{$\begin{array}{l}\text { Chinese } \\
\text { History }\end{array}$} & $\begin{array}{l}\text { Anglo- } \\
\text { Chinese }\end{array}$ & 26517 & 220 & $0.83 \%$ & 3460 & $13.05 \%$ & 13900 & $52.42 \%$ \\
\hline & $\begin{array}{l}\text { Chinese } \\
\text { middle }\end{array}$ & 5500 & 64 & $1.16 \%$ & 758 & $13.78 \%$ & 2898 & $52.69 \%$ \\
\hline & Total & 32017 & 284 & $0.89 \%$ & 4218 & $13.17 \%$ & 16798 & $52.47 \%$ \\
\hline
\end{tabular}

Notes

1. In 1970 results of SSEE were given in Blocks 1 to 18. Secondary school places were allocated to candidates in Blocks 1 to 7 , and to some candidates in the upper Block 8. 


\title{
G. Closing Remarks
}

\section{BILINGUAL EDUCATION AND PRACTICAL NECESSITY}

\author{
Robert Lord
}

My closing remarks might appear sombre, but they are not so intended. It is simply that this is the first time a symposium of this kind has been held in Hong Kong; and, to my knowledge, it is the first of its kind in South East Asia. Even if we take an optimistic long-term view we are not going to be able to bring participants together more than once every two years. But, at least, the bandwagon is now rolling, the scope of bilingual education, as it stands at present, has been partially reviewed, and there is a reasonable chance that the concept will begin to influence educational thinking and practice in areas where it should and where previously it has not.

The reason why this Symposium is being held at all is not mainly because it provides a convenient excuse to bring together a wide variety of specialists, or even because we need to know more about the functions of language, its relation to the individual or society, about learning mechanisms or teaching methods - though all of these rank high in our pnorities - but mainly because there is something amiss in the expectations we and other members of the community have of our children, in our perceptions of the ways in which we expect them to learn and develop, and in what we expect them to achieve; and more particularly because we believe that we, as teachers, educators, researchers, and planners, hope to learn from each other. The problem varies, both in degree and kind, from one country to another; but I do not believe any participant would claim that anything approaching perfection has, or ever will be, achieved in any country.

It is only if we take bilingual education in its very narrow sense that it will seem to have only minor relevance to the problem I have just outlined. But if we take a larger view we will see that bilingual education is not only an important aspect of education in general, but merges with it imperceptibly in every kind of way. I may be born into an (officially) monolingual society, but then I go to school. I have to learn to communicate in ways I have never encountered before. I not only have to leam to read and write, but have literally to find new ways of talking. When I get older I move to a different kind of school perhaps. Here I may have to learn the language of a different social class. I will have to master the different registers of the "language,' which in fact is the language of the 'establishment' or most prestigious class. I cannot avoid mastering this many-faceted instrument; otherwise' I will fail to get into university, and will not, in the case of the more sought-after professions, find the requisite doors open. I will not become a person reasonably well in control of my own destiny unless I have acquired a sophisticated mastery of the language or 'languages' I am expected to have mastered by the time I reach my late teens. Between the situation of the monolingual and the bilingual there is no difference of kind, but only of degree.

The acquisition of a second language increases not only the learning load, but exerts complex cultural pressures on the learner. However great the efforts of the educational planner in making the second language culturally neutral, the total context will usually be very much more complicated and demanding for someone who acquires and uses, at the levels demanded by 'society,' two systems than for a person who uses only one; especially if the latter is not a world language or a culturally highly evolved system. 
Bilingual education is not, to my way of thinking, something ideal, not the noble achievement we read about sometimes; in Lambert's Montreal experiment, for example. It is a practical necessity. And it is a practical necessity only in certain countries and regtons of the world (though these are very numerous) and only for certain minorities within them. Furthermore, bilingualism is sometimes determined more by supra-national than by national considerations. A sophisticated monolingual speaker of English in England has no need to learn any other language, unless he wants to, or unless he places himself in a particular situation. Wherever he goes in the world, the sort of people he meets will speak enough English to make it unnecessary for him to learn their language. Indeed, his attempts to learn a foreign language may be frustrated by the desire on the part of the people he meets to practise their English. It is only if he becomes an anthropologist, a missionary, a social worker, a developmentalist, or the like, that he will find it really necessary to learn the language of a foreign country in which he lives. "By contrast, a Hakka speaker in Hong Kong who wants to achieve any kind of social and professional currency will need to learn to speak Cantonese (as this would be the first language he would learn to write), and of course eventually to acquire English. If he aspires to become a lawyer, or an English language journalist or broadcaster, or a high-grade government servant, he will need to know English in its wide range of registers. Not only that, but he will be required to surpass the monoglot Britisher or American, insofar as he will have to learn the delicate borderline between knowing when to suppress his near-native English, in order to speak comfortably in the different ranges of English acceptable in different social milieus in Hong Kong. I mention all this, even if it is tediously familiar to members of this audience, simply to emphasise the harsh necessity, as opposed to any idealistic wish, for bilingual education in many parts of the world.

Bilingual education has least of all to do with linguistics or with language structure, hand has most of all to do with the individual and the context of the society in which he lives! If we put language first, or éven if we put language teaching method or the language curriculum first, we will get things all wrong. If we do not keep the whole, healthy development of the individual person, and the welfare of that person, firmly within our sights we shall end up by placing a greater burden on him than that which exists already through necessity.

We need to educate the individual so that he can perceive the next stage he may need to reach in his 'bilingual' ( $\mathrm{am}$ using the term in the widest possible sense) development, and to place the means to attaining this within his reach. We should guide him but not pressurize him. And this entails, to use a familiar slogan, equal opportunity for everyone. There is no need for everyone to attain the same standard, even less the same range of competence in his first or second (or third) language. It is because we create syllabuses that artificial, catch-all standards are set for students whose expectations (more usually, initially, his parents', teachers' or employers' expectations) vary. If we manage to develop a system which is sufficiently well-articulated to enable the individual to find his own level and to satisfy his own needs, and to develop his own sense of identity and well-being, most things will come out right in the end. The most important thing to get right is education at the outset. If the parent is 'educated' in the way his children learn, if kindergarten and primary education are right, the rest can take care of itself, provided we build the appropriate degree of flexibility and articulation into our 'educational system.' 
This means we have to learn more about educational 'routes' for the individual, and spend less time polishing syllabuses. The teacher is not always the best person to decide how much language a learner needs, or for what purposes. The learner must be trained to perceive for himself. A Japanese violinist who goes to America to join a symphony orchestra may not, the educationalist could argue, need much English to see him through. But who knows what degree of sophistication in the second language might be necessary before the violinist could even begin to think of pursuing his profession in America? What is more to the point: we should be able to rely on the individual to discern his owns needs for himself, and assist him to our utmost to satisfy them, within the limits of national and supra-national resources available. Language is a part of human ecology. As educators, we should do all we can to assist the integral development of the individual, and frustrate him as little as possible with artificial objectives, like public examinations, and meaninglessly (as opposed to usefully) competitive exercises.

All those who have been taking part in this Symposium have surely learnt a great deal from each other. There has in the past few days come into being at least a basis for the exchange of information and experience, and for more systematic comparisons within the wide field of bilingual education, especially within East and South East Asia.

I would like to conclude with a closing 'closing remark'. And it has to do with Hong Kong, where this first Symposium on Bilingual Education is being held.

Anyone familiar with Hong Kong will know (and if they are not, they will be able to guess) that the one language problem which dominates the minds of most policy-makers, administrations, educationatists, tertiary teachers, parents, school principals, employers, and so forth, is English. While not wishing to deny the importance or urgency of this problem, I would say that there is an even greater problem - Chinese. It may be that standards of English at several different levels are declining; but there exists a likelihood that, unless an educational policy for Chinese is formulated and implemented (something far exceeding existing measures, that is) the future of Chinese, as a sophisticated, 'elaborated' language of social intercourse, spoken as well as written, will be at risk in Hong Kong. I am aware of at least some of the complexities of the problems including the difficulty of locating an acceptable standare, the convoluted diglossia, the existence of a Cantonese 'language loyalty," and so on. But $I$ am equally aware of the inroads that have for long been made by English, and more recently by Japanese. Unless Chinese, spoken and written, is not to degenerate into some new form of Hong Kong Pidgin, or creolized Chinese, one generation from now, our policy-determiners and educators will have to sit down together and do some very hard thinking, inquiring and planning, before it is too late. 


\title{
AN END TO A BEGINNING
}

\author{
Benjamin K. T'sou
}

When we set out to organize this symposium, we had four aims in mind. I shall briefly reiterate them here:

(1) To focus on those communities of Sorth East Asis where $\int$ English plays an important role along with indigenous languages, and to examine the educational and other language problems that are significant in these communities.

(2) To bring together specialists in various fields from this region and beyond to share experience and to exchange views on bilingual education as a means to solving some of the problems raised under (1).

(3) To explore the situation in Hong Kong specifically.

(4) To bring the proceedings of this conference into some publishable form.

By and large, in terms of the first three aims we have basically succeeded. Regarding the third aim, we did not intend to resolve the language problems in Hong Kong, but to bring them out in an international forum.

Let me briefly speak about this. The Hong Kong situation is special in many ways. Some of the problems are not reflected in other countries, but certainly individual issues are very important and relevant for other parts of Asia., For example, 98 percent of the Hong Kong population is of Chinese background and the English language is spoken by less than I percent of the population as the home language. And yet English has become, over a long period of time, the most inportant language from the point of view of economics and education. At the same time the have seen a corresponding decline in the position of the Chinese language, which is of concern to the population. It has brought about many problems in education, and ofther fundamental questions have also surfaced, including (as my Co-chairinan has mentioned) the position and future of Pưtōnghua, on which written Chinese is based.

We find that even though Hokkien is the most commonly spoken dialect among the Chinese in Singapore, Mandarin has become the most important Chinese language there in education and at the official level. This is significant because, in Singapore, Mandarin has few or no native speakers. What are the reasons? What can be shared between Singapore and Hong Kong, which maintains Cantonese but not Mandarin? The implications of the language policy in Singapore and (the lack of it) in Hong Kong could provide valuable information for the other nations in this region.

Lastly, I think there is yet a third very important area: the question of standard and norm. It has come out again and again in the discussions about Hong Kong and it has relevance to all of the other areas.

Another point I would like to focus our attention on briefly is that in the course of this conference we have explored various sociological, psychological, cultural and educational aspects of bilingual communities and bilingual education. However, at 
tumes we have been encumbered by the traditional notions and limitations of second language teaching and learning (including English as a Second Language and Chinese as a Second Language). There were times when we were free from such encumbrances and concentrated our attention on the totality of bilingual education. The ideas and discussions that have come out in these few days have benefitted me greatly and I hope they have benefitted all the participants.

Bilingual education is a very powerful concept whose time has come. If properly exploited and implemented, it can enrich people in the society that practises it, even if $1 t$ cannot be a panacea for all of the serious problems in that society. On the other hand, if it is exploited incorrectly, it can compound the ills of society.

As far as we know, this is the first international conference on bilingual education held in Asia and as such it marks the beginning of serious interest in this area. Let us hope that the intial phase of exploration will soon come to an end and that sound bilingual education programmes will be implemented in increasing number in many Asian countries. Perhaps at the next conference on blingual education in Asia we shall be able to hear about the progress that will surely have emerged. 
SELECT BIBLIOGRAPHY 


\section{SELECT BIBLIOGRAPHY}

Ahmad, S. 1971. 'Singapore Malays: Education and national development.' In Malay Participation in the National Development of Singapore. Government Printing Office, Singapore.

Alatis, J. E. (ed.) 1970. Bilingualism and Language Contact. Georgetown University Press, Washington D.C.

Alatis, J. and Twaddell, K. (eds.) 1976. English as a Second Language in Bilingual Education: Selected TESOL Papers. Teachers of English to Speakers of Other Languages, Washington D.C.

Anastasi, A. 1968. Psychological Testing. Macmillan, New York.

Anderson, M., Lord, R. and Sherman, A. 1976. 'Creative writing across two cultures,' Topics in Culture Learning 4 66-76 (East-West Center, Hawaii).

Anderson, T. and Boyer, M. 1970. Bilingual Schooling in the United States. 2 vols., U.S. Government Printing Office, Washington D.C.

Angle, J. 1976. 'Mainland control of manufacturing and reward for bilingualism in Puerto Rico,' American Sociological Review 41 289-307.

Barthes, R. 1972. Mythologies. Trans. A. Lavers, Penguin, London.

Bernstein, B. 1971. Class, Codes and Control. Routledge and Kegan Paul, London. Bilingual/Bicultural Education. 1975. Inequality in Education 19 (Center for Law and Education, Harvard University, Cambridge, Mass.)

A Better Chance to Leam: Bilingual Bicultural Education. 1975. U.S. Commission on Civil Rights Clearinghouse Publication 51 (Washington D.C.)

Butcher, H.J. 1970. Human Intelligence: Its Nature and Assessment. Methuen, London.

Carroll, J.B. 1964. 'Words, meanings, and concepts,' Harvard Educational Review 34 $178-90$.

_-___ 1968. 'Contrastive linguistics and interference theory,' Monograph Series on Language and Linguistics 19 113-22.

Catford, J.C. 1968. 'Contrastive analysis and language teaching,' Monograph Series on Language and Linguistics 19 160-73.

Chastain, K. 1975. 'Affective and ability factors in second language acquisition,' Language Learning 25 153-61.

Chelliah, D.D. 1947. A History of the Educational Policy of the Straits Settlements. Government Printers, Kuala Lumpur.

Chinese Schools: Bilingual Education and Increased Aid. 1953. Government Printing Office, Singapore.

Chinese Schools and the Education of Chinese Malayans (Fenn-Wu Report). 1951. Government Printers, Kuala Lumpur.

Church, J. 1961. Language and the Discovery of Reality. Random House, New York.

Cohen, A. 1975. A Sociolinguistic Approach to Bilingual Education: Experiments in the American Southwest. Newbury House, Rowley, Mass.

Commission of Inquiry into Education in Singapore (Lim Tay Boh Report). 1964. Government Printing Office, Singapore.

Commission of Inquiry into Education in Singapore (Interim Report on the s1x-Uay Week). 1962. Government Printing Office, Singapore.

Commission of Inquiry into Vocational and Technical Education in Singapore (Chan Chieu Kiat Report). 1961. Government Printing Office, Singapore.

Coughlin, R. 1960. Double Identity: The Chinese in Modern Thailand. Hong Kong University Press, Hong Kong. 
Cronbach, L.F. 1961. Essentials of Psychological Testing. Harper and Row, New York. DeCecco, J.P. 1967. The Psychology of Language, Thought, and Instruction. Holt, Rinehart and Winston, New York.

Department of Education (Hong Kong). 1976. Annual Summary 1975-76. Hong Kong Government Printer, Hong Kong.

Department of Education Annual Report 1946-1952. 1952. Government Printing Office, Singapore.

Deutsch, K.W. 1953. Nationalism and Social Communication. MIT Press, Cambridge, Mass.

__- 1966. Nationalism and Social Communication. Second Edition, MIT Press, Cambridge, Mass.

Dictionary of Usual Chinese 1973. Hangzhou.

Doraisamy, T.R. (ed.) 1969. 150 Years of Education in Singapore. Teachers' Training College Publications Board, Singapore.

Dutton, T.E. and Brown, H.A. 1976. 'Hiri Motu: The language itself.' In S.A. Wurm (ed.) New Guinea Area Languages and Language Study. Vol. 3: Language, Culture, Society, and the Modern World (Pacific Linguistics, Series C.40.) Australian National University Press, Canberra.

Education Act, Malaya, No. 43. 1961. Government Printers, Kuala Lumpur.

Education in Malaysia. 1970. Educational Planning and Research Division, Ministry of Education, Dewan Bahasa dan Pustaka, Kuala Lumpur.

Education in Singapore. 1969. Ministry of Education, Educational Publications Bureau, Singapore.

Education in Singapore. 1972. Second Edition, Ministry of Education, Educational Publications Bureau, Singapore.

Education Ordinance (Singapore). 1957. Government Printing Office, Singapore.

Education Development in Singapore. 1971. The Joint Singapore-UNESCO Study Mission, Singapore.

Educational Statistics of Malaysia 1938-1967. 1967. Ministry of Education, Malaysia.

Etherton, A.R.B. 1975. 'English and the Chinese University note.' In The First Ten Years of the Chinese University. Students" Union, Chinese University of Hong Kong, Hong Kong.

Fishman, J.A. et al. 1966. Language Loyalty in the United States. Mouton, The Hague.

Fishman, J.A. 1970. Language and Nationalism: Two Integrated Essays. Newbury House, Rowley, Mass.

_-_ 1972a. (ed.) Advances in the Sociology of Language. 2 vols., Mouton, The Hague.

- 1972b,c. 'Problems and prospects of the sociology of language,' and 'The impact of nationalism on language planning.' In J.A. Fishman (ed.) Language in Sociocultural Change. Stanford University Press, Stanford, Calif, pp. 22443 and $268-85$.

- 1973. 'Bilingual education: What and why?' Florida FL Reporter $11(1,2)$ $13-15 ; 42-43$.

Franke, W. 1965. 'The problem of Chinese education in Singapore and Malaysia,' Malaysian Journal of Education 11 (2) (page numbers not available).

Efies, C.C. 1945. Teaching and Leaming English as a Foreign Language. University of Michigan Press, Ann Arbor, Mich.

EC, G.S. 1976. 'Readings in bilingualism: A Hong Kong perspective.' The English Bulletin 6 (5) $49-57$.

Geffert, H., Harper, R., Sarmiento, S., and Schneid, D. 1975. The Current Status of United States Bilingual Education Legislation. Papers in Applied Linguistics (Bilingual Education Series 4.) Center for Applied Linguistics, Arlington, Va.

Gopinathan, S. 1974. Towards, a National System of Education in Singapore: 19451973. Oxford University Press, Singapore.

The Government Grant-in-Aid Regulations. 1957. Government Printing Office, Singa129 pore. 
Hall, R.A. Jr. 1955. Hands Off Pidgin English. Pacific Publications, Sydney.

Harré, R. and Secord, P.F. 1972. The Explanation of Social Behaviour. Oxford University Press, London.

Haugen, E. 1950. 'Problems of bilingualism,' Lingua 2 271-90.

_-__. 1956. Bilingualism in the Americas: A Bibliography and Research Guide. University of Alabama Press, Birmingham, Ala.

_-__. 1965. 'Bilingualism as a goal of foreign language teaching.' In V.F. Allen (ed.) Conference of Teaching English to Speakers of Other Languages. National Council of Teachers of English, Champaign, I11.

_-___. 1966a. 'Bilingualism and bidialectism.' In R.W. Shuy (ed.) Social Dialects and Language Learning. National Council of Teachers of English, Champaign, I11., pp. 124-6.

_-___. 1966b. Language Conflict and Language Planning. Harvard University Press, Cambridge, Mass.

_-_ 1970. 'On the meaning of bilingual competence.' In R. Jakobson (ed.) Studies in General and Oriental Linguistics. TEC Corporation for Language and Educational Research, Tokyo, pp. 221-9.

____ 1972. 'The stigmata of bilingualism?' In A.S. Dil (ed.) The Ecology of Language: Essays by Einar Haugen. Stanford University Press, Stanford, Calif., pp. 307-24.

-___- 1973. 'Bilingualism, language contact, and immigrant languages in the United States: A research report 1956-70.' In T.A. Sebeok (ed.) Current Trends in Linguistics. Vol. 10, Mouton, The Hague, pp. 505-91.

Ho, D.Y.F. 1978. 'English language skills and academic performance.' In R. Lord, (ed.) Hong Kong Language Papers. Hong Kong University Press, Hong Kong.

Ho Seng Ong. 1952. Education for Unity in Malaya. Ganesh Printing Works, Penang.

Hsu, R.S.W. 1978. 'What is Standard Chinese?' In R. Lord (ed.) Hong Kong Language Papers. Hong Kong University Press, Hong Kong.

Hull, B. 1968. 'The use of Pidgin in the House of Assembly,' Joumal of the Papua New Guinea Society 22-5 (Port Moresby).

Hunter, D. 1975. Bilingualism: Problems of Description and Measurement. Unpublished M.Phil. Dissertation. University of Hong Kong, Hong Kong.

-_. 1978. 'The measurement of bilingualism.' In R. Lord (ed.) Hong Kong Language Papers. Hong Kong University Press, Hong Kong.

Hymes, D. (ed.) 1964. Language in Culture and Society. Harper and Row, New York.

Irvine, S.H. 1966. 'Towards a rationale for testing attainments and abilities in Africa,' British Joumal of Educational Psychology 36 24--32.

Jernudd, B. and Das Gupta. 1971. 'Towards a theory of language planning.' In J. Rubin and B.H. Jernudd (eds.) Can Language Be Planned? University Press of Hawaii; Honolulu, pp. 16-20.

Johns, V. and Horner, V. 1971. Early Childhood Bilingual Education. Modern Language Association, New York.

Kelly, L. (ed.) 1969. Description and Measurement of Bilingualism. University of Toronto Press, Toronto.

Kelman, H.C. 1971. 'Language as an aid and barrier to involvement in the national system.' In J. Rubin and B.H. Jernudd (eds.) Can Language be Planned? University Press of Hawaii, Honolulu, pp. 21-51.

Kloss, H. 1969. Research Possibilities on Group Bilingualism: A Report. National Center on Research on Bilingualism, Quebec, Canada.

Kokugo Gakkai (The Society of Japanese Linguistics) (ed.) 1955. Kokugogaku Jiten (Dictionary of Japanese Linguistics). Tokyo Do, Tokyo. 
Krom Wisamansuksa. 1957. 'Rongrien-rat phua Sorn Phasa Chin' (Private Schools for Teaching Chinese), Ekkassan-kansuksa, Wisamansuksa 7. Bangkok.

Kuo, E.C.Y. 1976a. 'A sociolinguistic profile.' In R. Hassan (ed.) Singapore: $A$ Society in Transition. Oxford University Press, Singapore, pp. 134-48.

___ 1976b. 'Language, nationhood and communication planning: The case of a multilingual society,' Southeast Asian Joumal of Social Science 4 (2) $31-42$

-__ 1977. 'The status of English in Singapore: A sociolinguistic analysis.' In W. Crew (ed.) The English Language in Singapore. Eastern Universities Press, Singapore, pp. 10-33.

Kran, E. 1969. 'Problems of bilingual milieu in Hong Kong: Strain of the two-language system.' In I. Jarvie and J. Agassi (eds.) Hong Kong: A Society in Transition. Routledge and Kegan Paul, London, pp. 327-44.

Lado, R. 1957. Linguistics across Cultures. University of Michigan Press, Ann Arbor, Mich.

Lambert, W.E., Gardner, R.C., Olton, R. and Tunstall, K. 1968. 'A study of the roles of attitudes and motivation in second-language learning.' In J.A. Fishman (ed.) Readings in the Sociology of Language. Mouton, The Hague, pp. 473-91.

Laycock, D.C. 1969. 'Pidgin's progress,' New Guinea Quarterly 4 (2) 8-16 (Sydney).

-1976. 'Creative writing in New Guinea Pidgin.' In S.A. Wurm (ed.) New Guinea Area Languages and Language Study. Vol. 3: Language, Culture, Society, and the Modern World (Pacific Linguistics, Series C.40.) Australian National University Press, Canberra.

Lee Kuan Yew. 1966. New Bearings in our Education System. Government Printing Office, Singapore.

Lehmann, W.P. (ed.) 1975. Language and Linguistics in the People's Republic of China. University of Texas Press, Austin and London.

Lieberson, S. 1970. Language and Ethnic Relations in Canada. Wiley, New York.

Lieberson, S. and Hanson, L.K. 1974. 'Nation development, mother-tongue diversity, and the comparative study of nations,' American Sociological Review 39 $523-41$.

List of Schools, Singapore (1969-1977). 1977. Ministry of Education, Singapore.

Lo Hsian-lin. 1963. Hong Kong and Western Cultures. The Centre for East Asian Cultural Studies, Tokyo.

Loo Shaw-chang. 1976. Typology of Bilingualism. Monograph No. 20, Chinese Language Centre, Nanyang University, Singapore.

Lord, R. 1976. 'Language and laissez-faire,' Interflow, January 1976,pp. 4-6 (University of Hong Kong, Hong Kong).

-_-_- (ed.) 1978. Hong Kong Language Papers. Hong Kong University Press, Hong Kong.

Lyczak, R., Fu, G. and Ho, A. 1978. 'Language attitudes among university students in Hong Kong.' In R. Lord (ed.) Hong Kong Language Papers. Hong Kong University Press, Hong Kong.

Mackey, W.F. 1962. 'The description of bilingualism,' Canadian Joumal of Linguistics $751-85$.

1967. Bilingualism as a World Problem. Harvest House, Montreal.

. 1970. 'A typology of bilingual education,' The Foreign Language Annals 3 $596-608$.

-_- 1972. Bilingual Education in a Binational School: A Study of Equal Language Maintenance Through Free Alternation. Newbury House, Rowley, Mass.

Mason, F. 1959. The Schools of Malaya. Donald Moore, Singapore. 
McElhanon, K.A. (ed.) 1975. Tok Pisin i Go We? (Proceedings of a Conference held at the University of Papua New Guinea, Port Moresby, Papua New Guinea, 1821 September 1973.) Kivung Special Publication No. 1, Port Moresby.

Miller, R.A. 1967. The Japanese Language. University of Chicago Press, Chicago.

Milsky, C. 1973. 'New developments in language reform,' The China Quarterly 15 98-133.

Ministry of Education, Annual Report 1953-1956. 1956. Government Printing Office, Singapore.

Ministry of Education, Annual Report 1958-1967. 1967. Government Printing Office, Singapore.

Ministry of Education, First Education Triennial Survey 1955-1957. 1959. Government Printing Office Singapore.

Muihlhauisler, P. 1975a. Samoan Plantation Pidgin and the Origin of New Guinea Pidgin (paper presented at the Annual Meeting of the Linguistic Society of Australia, Sydney, 1975.) Australian National University, Canberra. - 1975b,c. 'Sociolects in New Guinea Pidgin' and 'Reduplication and Repetition in New Guinea Pidgin.' In K.A. McElhanon (ed.) Tok Pisin i Go We? Kivung Special Publication No. 1, Port Moresby.

-_. 1975d. Functional Possibilities of Lexical Bases in New Guinea Pidgin (Paper presented at the International Conference on Pidgins and Creoles, Honolulu, Hawaii, January. 1975.) Mimeographed.

-_. 1976a,b. 'History of New Guinea Pidgin: The external history' and 'Variation in New Guinea Pidgin.' in S.A. Wurm et al (eds.) Handbook of New Guinea Pidgin (Pacific Linguistics, Series C. 48.) Australian National University Press, Canberra.

_____- 1976c,d. NNew Guinea Pidgin and society: Sociolects in New Guinea Pidgin' and 'New Guinea Pidgin and society: The Social Role of Pidgin in New Guinea Today.' In S.A. Wurm (ed.) New Guinea Area Languages and Language Study. Vol. 3: Language, Culture, Society, and the Modern World (Pacific Linguistics, Series C. 40.) Australian National University Press, Canberra.

-_. 1976e. Growth and Structure of the Vocabulary of New Guinea Pidgin. Unpublished Doctoral Dissertation, Australian National University, Canberra.

Murray, D.P. 1971. Multilanguage Education and Bilingualism: The Formation of Social Brokers in Singapore. Unpublished Doctoral Dissertation, Stanford University, Stanford, Calif.

Musa, B. and Harun, S. 1970. Situation of Children and Youth in West Malaysia. Prime Minister's Department, Kuala Lumpur.

Naipaul, V.S. 1969. A Flag on the Island. Penguin, London.

Ong Pang Boon. 1964. 'Towards a national education system.' In People's Action Party: 10th Anniversary Souvenir. Government Printing Office, Singapore.

Overbeke, M.V. 1972. Introduction au Problème du Bilinguisme. Fernand Nathan, Paris.

Pang Eng Fong and Leong Lee Voon. 1976. A Report on the 1975 Employment Survey of Nanyang University Graduates. Economic Research Centre, University of Singapore, Singapore.

Policy on Services to Limited-English-Speaking Students. 1976. Department of Education, California State Government, California.

A Preliminary Report of the Royal Commission on Bilingualism and Biculturalism. 1965. Queen's Printer and Controller of Stationary, Ottawa, Canada.

Purcell, V. 1967. The Chinese in Malaya. Oxford University Press, Kuala Lumpur. 
Quirk, R. et al. 1970. Contemporary Grammar of the English Language. Longman, London.

Progress in Education, 1959-1965. 1966. Government Printing Office, Singapore. Registration of Schools Ordinance (No. 16 of 1950). 1950. Government Printing Office, Singapore.

Report of the All-Party Committee of the Singapore Legislative Assembly on Chinese Education. 1956. Government Printing Office, Singapore.

Report of the Royal Commission on Bilingualism and Biculturalism (Book II: Education). 1968. Queen's Printer and Controller of Stationary, Ottawa, Canada.

Rivers, W.M. 1968. 'Contrastive linguistics in textbook and classroom,' Monograph Series on Language and Linguistics 19 151-8.

Robinson, K. 1957. 'Recent developments in Chinese education,' Overseas Education 29 (Singapore) (page numbers not available).

Rowe, E. 1966. Failure in School. Hong Kong University Press, Hong Kong.

Rubin, J. 1968a. 'Bilingual usage in Paraguay.' In J.A. Fishman (ed.) Readings in the Sociology of Language. Mouton, The Hague, pp.512-30.

_- 1968b. National Bilingualism: Paraguay. Mouton, The Hague.

Schachter, P. 1967. 'Transformational grammar and contrastive analysis,' Workpapers in English as a Second Language, 1-7. Department of English as a Second Language, University of California, Los Angeles.

Searle, C. 1972. The Forsaken Lovers: White Words and Black People. Routledge and Kegan Paul, London.

Secondary Education in Hong Kong During the Next Decade (White Paper). 1974. Hong Kong Government Printer, Hong Kong.

Selinker, L. 1972. 'Interlanguage,' IRAL 10 (3) 209-31.

Colony of Singapore, Annual Report (1946-58). 1958. Government Printing Office, Singapore.

State of Singapore, Annual Report (1959-63). 1963. Government Printing Office, Singapore.

Singapore Yearbook (1964-76). 1976. Government Printing Office, Singapore.

Skinner, W. 1962. Chinese Society in Thailand: An Analytical History. Cornell University Press, Ithaca, N.Y.

'Smith, L.E. 1975. 'Teaching English in Asia: An overview,' Topics in Culture Learning 3 133-7 (East-West Center, Hawaii).

Spate, O.H.K. 1966. 'Education and its problems.' In E.K. Fisk (ed.) New Guinea on the Threshold. Australian National University Press, Canberra, pp. 117-34.

Spolsky, B. 1969. 'Attitudinal aspects of second language learning,' Language Learning 19 271-83.

Stern, H.H. (ed.) 1963. Foreign Languages in Primary Education: The Teaching of Foreign or Second Languages to Younger Children: Report on the International Meeting of Experts. 9-14 April 1962. UNESCO Institute for Education, Hamburg.

Stewart, W.A. 1968. 'A Sociolinguistic typology for describing national multilingualism.' In J.A. Fishman (ed.) Readings in the Sociology of Language. Mouton, The Hague, pp. 531-45.

Stockwell, P.P., Bowen, J.D. and Martin, J.W. 1965. The Grammatical Structures of English and Spanish. Contrastive Structure Series, University of Chicago Press, Chicago.

Suzuki, T. 1969. 'Hyoki to shite no kanji' (Chinese characters as a notation), Gengo Seikatsu 214 7-25 (Tokyo). 
1975. 'On the twofold phonetic realization of basic concepts: In defence of Chinese characters in Japanese.' In C.C. Peng (ed.) Language in Japanese Society. Tokyo University Press, Tokyo.

ran Peng Boo. 1970. Education in Singapore. Educational Publications Bureau, Singapore.

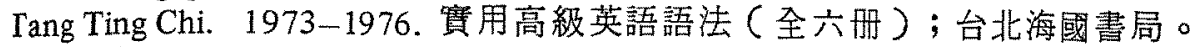
(Practical Advanced English Grammar.) Haiguo, Taipei.

- - - (In press ). 國語變形語法研究第一集：移位變形; 台北學生 書局。(Studies in Chinese Transformational Grammar. Vol. 1: Movement Transformations.) Shyue-sheng, Taipei.

Todo, A. 1961. Dan-go to Nihon-go (Chinese Loanwords and the Japanese Language). Shuey Shuttan, Tokyo.

Troike, M. 1973. Bilingual Children: A Resource Document. Papers in Applied Linguistics (Bilingual Education, Series 12.) Center for Applied Linguistics, Arlington, Va.

Troike, R. and Modiano, N. 1975. Proceedings of the First Inter-American Conference on Bilingual Education. Center for Applied Linguistics, Arlington, Va.

T'sou, B.K. 1974. 'Asymmetric bilingualism: A sociolinguistic study of Cantonese emigrants,' Joumal of Chinese Language Teachers' Association of America 8 (3) $134-44$.

-_-_. 1975a. 'Bilingualism, cultural pluralism, and bilingual education.' Paper given at the Southwestern Areal Language and Linguistics Workshop, San Diego, Calif.

- - $1975 \mathrm{~b}$. 'On the linguistic covariants of cultural assimilation,' Anthropological Linguistics $17445-65$.

-_._. 1978. 'Language Loyalty among minority groups in Hong Kong.' In B.K. T'sou (ed.) Proceedings of the Asian Round Table Conference on Chinese Language and Linguistics, Hong Kong, 22-23 December 1976. In preparation.

The Use of Vernacular Languages in Education. 1953. Monographs in Fundamental Education, No. 8, UNESCO, Paris.

Weinreich, U. 1963. Languages in Contact. Mouton, The Hague.

Wong, R. 1977. Educational Innovation in Singapore 1960-1972. Ministry of Education, Singapore.

Wu Yuzhang. 1958. 'Report on the current tasks of reforming the written language and the draft scheme for a Chinese phonetic alphabet.' In Reform of the Chinese Written Language. Peking.

Wurm, S.A. 1964. 'Motu and Police Motu: A study in typological contrasts.' In S.A. Wurm (ed.) Papers in New Guinea Linguistics. No.2 (Pacific Linguistics, Series A.4.) Australian National University Press, Canberra.

_____- 1966a. 'Papua New Guinea nationhood: The problem of a national language,' Journal of the Papua New Guinea Society 1 (1) 7-19.

-_. 1966b. 'Language and literacy.' In E.K. Fisk (ed.) New Guinea on the Threshold. Australian National University Press, Canberra, pp. 135-48.

____. 1971. 'Language policy, language engineering: New Guinea and Australia.' In T. Sebeok (ed.) Current Trends in Linguistics. Vol. 8; Linguistics in Oceania. Mouton, The Hague, pp. 1025-38.

_-__ 1976a,b. 'Criticisms and attitudes towards Pidgin', and 'Future outlooks and standardization of Pidgin.' In S.A. Wurm (ed.) New Guinea Area Languages and Language Study. Vol. 3: Language, Culture, Society, and the Modern World (Pacific Linguistics, Series C.40.) Australian National University Press, Canberra. 
1976. (ed.) New Guinea Area Languages and Language Study. Vol. 3: Language, Culture, Society, and the Modern World (Pacific Linguistics, Series C.40) Australian National University Press, Canberra.

- - et al. 1976. Handbook of New Guinea Pidgin (Pacific Linguistics, Series C.48) Australian National University Press, Canberra.

Wurm, S.A., Muihlhausler, P. and Laycock, D.C. 1976. 'Language planning and engineering.' In S.A. Wurm et al (eds.) Handbook of New Guinea Pidgin (Pacific Linguistics, Series C.48) Australian National University Press, Canberra. 
APPENDICES 


\title{
APPENDIX I \\ A CHRONOLOGY OF DEVELOPMENTS IN BILINGUAL EDUCATION \\ IN SINGAPORE SCHOOLS 1951 - 1977
}

\author{
Loo Shaw-chang
}

\begin{abstract}
Bibliographical references on which the author has based his chronology may be found in the Select Bibliography.
\end{abstract}

1951 Full-time teachers of languages, other than those used as the medium of instruction, made their first appearance.

1956 Report of the All-Party Committee of the Singapore Legislative Assembly on Chinese Education recommended that at least two of the following languages: English, Malay, Mandarin, and Tamil, should be the medium of instruction in their respective schools, and that language teaching should be of the best possible standard, so that the future educational system of Singapore could produce students equally conversant in two, if not in three, of those languages.

The same report recommended that, without sacrificing efficiency, there should be free transfer from English to Chinese schools of teachers best qualified to teach English, and those best qualified to teach Mandarin in Chinese schools should be encouraged to teach in English schools, to improve the standard of language teaching in both. The same principle would apply to Malay and Tamil. Subsequently, the preceding points were embodied in the White Paper on Education Policy and become known as the scheme for the introduction of bilingual education into primary schools and trilingual education into secondary schools.

1957 The New Education Ordinance stated that common syllabuses should be planned for all schools, and that the learning of a second language should be made compulsory.

1959 Integrated secondary schools were planned and implemented the following year. These schools were to use two different language media within a common curriculum. They were housed in a single building, under a single principal. There was to be a joint programme in all extra-mural activities. It was hoped that, in these schools, the barriers between pupils of different streams would be broken down. (Ministry of Education Annual Report. 1959; Education in Singapore. 1969, 1972.)

1962 Second languages were introduced as optional subjects in the Primary School Leaving Examination. (This is mentioned in an official circular of the Ministry of Education.)

There were 5 papers for PSLE:
Subject
Weighting
1. First Language
2. Mathematics
3. History \& Geography
4. Science
5. Second Language (optional)
2 units
1 unit
1 unit
1 unit
1 unit

Integrated Primary Schools (English/Chinese; English/Malay) were established.

Mr. Loo received his $B$.A. from Nanyang University, and his $M$.A. in Chinese Studies from the University of Singapore. He is currently. Acting Director of the Chinese Language Centre at Nanyang University, Singapore. 
1963 There were 24 integrated schools in 1963 as against 9 in 1962. It was intended that the sharp increase in this type of school would break down the language barriers between the pupils in the different language streams.

The scheme set out below shows the number and type of integrated schools: (Ministry of Education, Annual Report. 1962, 1963)

\begin{tabular}{lcc} 
& 1962 & 1963 \\
Chinese/English & 7 & 17 \\
Malay/English & 2 & 6 \\
Tamil/English & 0 & 1 \\
& -9 & 24 \\
\hline
\end{tabular}

1964 Steps were taken to implement a recommendation made in the Final Report of the Lim Tay Boh Commission that emphasis should be given to the teaching of Chinese phonetic symbols (注符號) and that all pupils should be taught to read and use these symbols from Primary 2.

The syllabus for Chinese in Chinese-medium pre-University classes was thoroughly revised to provide for two papers: Chinese $I$, containing selected passages from prescribed texts for comprehension and appreciation, was to be a compulsory paper for the Arts stream; and Chinese II, testing the candidates' preparation, was to be compulsory for the Science stream. Two new syllabuses were also produced:

(1) Chinese Literature for the School Certificate (English) Classes; and

(2) Malay as a Third Language, which was intended for non-Malay-medium schools.

1965 The following two syllabuses underwent revision:

(1) The syllabus for Chinese as a Second Language for Non-Chinese Primary Schools; and

(2) The syllabus for Chinese as a Second Language for Non-Chinese Secondary Schools.

1966 Second languages became compulsory subjects in the Primary School Leaving Examination.

The compulsory study of a second language was extended to secondary schools. Teachers of English in non-English medium schools were required to undergo a course of in-service training at the Teachers' Training College on the teaching of English as a second language.

The following syllabuses were revised:

(1) Malay for Chinese Pre-University Classes;

(2) Chinese I and II for Chinese Pre-University Classes;

(3) Chinese Literature for Chinese Pre-University Classes;

(4) Chinese Literature for the Government Secondary Four (Chinese Examination);

(5) Chinese for Chinese Primary, Secondary, Vocational and Non-Chinese Vocational Schools. 
1967 The First National Junior College was established as a two-year, pre-university, whole-day institution in three language streams : Chinese, English and Malay.

1968 The mother tongue became the medium of instruction for the Civics Course in English schools.

1969 The school certificate examination offered a second language. 502 simplified Chinese characters were adopted.

1970 Science and Mathematics were to be taught in English in non-English schools where facilities were available.

1972 The policy of bilingual education for primary schools set a target of minimum second language exposure time for the following four years:

$\begin{array}{ll}1972 & 18.0 \% \\ 1973 & 25.0 \% \\ 1974 & 33.3 \% \\ 1975 & 40.0 \%\end{array}$

1973 The Pin-yin system became adopted.

Although there was no requirement in a second language for promotion to secondary schools after 1973, the weighting in the PSLE of first and second languages became the same. History and Geography were dropped (Refer to item 1962).

$\begin{array}{ll}\text { First Language } & 2 \text { units } \\ \text { Second Language } & 2 \text { units } \\ \text { Mathematics } & 1 \text { unit } \\ \text { Science } & 1 \text { unit }\end{array}$

19742248 simplified Chinese characters were adopted (and revised in 1976). Education for Living was introduced in all primary schools and it was taught in the mother tongue.

1977 The Basic Course was introduced. There is now diversification in primary school education. Pupils who do not do well can be retained only for a maximum of 2 years. If they do not fail, they can complete their primary education in 8 years instead of 6 . Those who fail a third time at any stage of their primary school career are given an additional opportunity to continue their schooling in the Basic Course. 
Table I

The Primary School Curriculum (Standard Course)

(Students who are able to cope with at least two languages)

\begin{tabular}{|c|c|c|c|c|}
\hline \multirow{2}{*}{ Subjects } & \multicolumn{4}{|c|}{ No. of minutes spent per week ${ }^{1}$} \\
\hline & $\operatorname{Pr} 1 \& 2$ & $\operatorname{Pr} 3$ & $\operatorname{Pr} 4$ & $\operatorname{Pr} 5 \& 6$ \\
\hline First Language & 395 & 390 & 335 & 340 \\
\hline National Language & - & 30 & 35 & 35 \\
\hline Second Language & 180 & 210 & 210 & 220 \\
\hline $\begin{array}{l}\text { History } \\
\text { Geography } \\
\text { Civics }\end{array}$ & 90 & 170 & 385 & 250 \\
\hline Science & 90 & 105 & 165 & 140 \\
\hline Mathematics & 180 & 210 & 210 & 270 \\
\hline $\begin{array}{c}\text { Art, Handwork \& } \\
\text { Needlework }\end{array}$ & 120 & 105 & 70 & 70 \\
\hline Music & 60 & 60 & 60 & 95 \\
\hline Physical Education & 90 & 70 & 70 & 70 \\
\hline Health Education & 15 & 15 & 15 & 15 \\
\hline Assembly & 30 & 30 & 30 & 30 \\
\hline Total & 1250 & 1395 & 1305 & 1475 \\
\hline
\end{tabular}

1 Minor adjustments may be made by schools

2 Education for Living 
Table II

The Primary School Curnculum (Basic Course)

(Students who can not cope with two languages)

(A) Curriculum for B1 to B4(a)

\begin{tabular}{|l|c|c|c|c|}
\hline \multirow{2}{*}{ Subjects } & \multicolumn{4}{|c|}{ Number of hours per week } \\
\cline { 2 - 5 } & B1 hrs. & B2 hrs. & B3 hrs. & B4(a) hrs. \\
\hline Language & 8 & 8 & 7 & 7 \\
Arithme tic & 5 & 5 & 5 & 5 \\
Handwork/Handcraft & 3 & 4 & $51 / 2$ & $51 / 2$ \\
Civic Training/ & $11 / 2$ & $1 \frac{1}{2}$ & $11 / 2$ & $11 / 2$ \\
Moral Education & $11 / 2$ & $11 / 2$ & $11 / 2$ & $1 \frac{1}{2}$ \\
Physical Education & $1 / 2$ & $1 / 2$ & $1 / 2$ & $1 / 2$ \\
Music & $1 / 2$ & $1 / 2$ & $1 / 2$ & $1 / 2$ \\
Health Education/Assembly & 3 & 3 & $21 / 2$ & $21 / 2$ \\
Second Language, Spoken & $23 \mathrm{hrs}$. & $24 \mathrm{hrs}$. & $24 \mathrm{hrs}$. & $24 \mathrm{hrs}$. \\
\hline Total (per week) & & & & \\
\hline
\end{tabular}

(B) Curriculum for B4(b)

\begin{tabular}{|l|c|}
\hline \multicolumn{1}{|c|}{ Subjects } & Hours \\
\hline Language & 4 \\
Arithmetic & 3 \\
Workshop Practice/Domestic Science & 12 \\
Workshop Ethics/Work Safety & 2 \\
Physical Education & 1 \\
Music & $1 / 2$ \\
Health Education/Assembly & $1 / 2$ \\
Second Language, Spoken & 2 \\
\hline Total (per week) & 25 hours \\
\hline
\end{tabular}




\section{APPENDIX II \\ INTERNATIONAL SYMPOSIUM ON BILINGUAL EDUCATION}

Robert Black College

University of Hong Kong

18-21 December, 1976.

\section{PROGRA M M E}

Friday, December 17

Reception of overseas participants

Saturday, December 18

9.00 a.m.

$9.30-9.40$ a.m.

9.40 a.m. -12.10 p.m.

2.00 p.m. -5.00 p.m.

\section{Registration}

Opening remark by Mr. K. Topley, Director of Education.

I: Plenary Session: Bilingual Education in Perspective

Chairman: Professor R. Lord

Speakers: Mr. E. Kvan

Professor M.A. Brimer

Dr. E. Kuo

Dr. B. T'sou

II: Plenary Session: Regional Reports

Chairman: Professor M. Hashimoto

Speakers: Dr. N. Tsuji

Professor P. Manomaivibool

Dr. K.B. Lim

Mr. S.C. Loo

Discussant: Mr. A. Peyraube

4.15 p.m. -5.00 p.m. $\quad$ III: Group Discussion

Chairman: Dr. B. T'sou

5.00 p.m. -5.30 p.m. $\quad$ Reporting back to assembly 
Sunday, December 19

9.30 a.m. -12.30 p.m. VI: Panel: Bilingual Education and Curriculum Development in Post-secondary Education.
Chairman: Dr. J. Chan
Speakers: Dr. Y.S. Cheung*
Professor L. Ramish
Dr. G. Fu
Mr. P. Barnes
Discussant: Mr.C.S. Chan*
Professor R. Lord
Open Discussion

Monday, December 20

9.00 a.m. - 10.30 a.m. V: Panel: Bilingual Education and Curriculum Development in Primary and Kindergarten Education

Chairman: Dr. Y.F. Kong

Speakers: Miss S. Hsia

Mr. W. Szeto*

Miss S. Chan*

Discussant: Mr. C. de Linde

Open Discussion

10.50 a.m. - 12.45 a.m. VI: Panel: Bilingual Education and Curriculum Development in Secondary Education

Chairman: Mr. W. Cheng

Speakers: Mr.S.C. Loo*

Mr. Y.W. Fung*

Miss T. Leung

Discussant: Mr. A. Hinton

Open Discussion

2.30 p.m. -5.00 p.m. $\quad$ VII: Panel: Testing and Assessment in Bilingual Education

Chairman: Dr. D. Ho

Speakers: Dr. J.W.C. Chan

Mr. C. Long

Dr. L.M. Lee

Discussant: Mr. C. de Linde

Open Discussion 


\section{STUDIES IN BILINGUAL EDUCATION}

\section{Tuesday, December 21}

9.30 a.m. -12.30 p.m. VIII: Panel: Chinese Curriculum Development, with Special Reference to the Bilingual Context of Hong Kong

Chairman: Professor G.B. Downer

Speakers: Professor P. Manomaivibool

Professor Y. Ohkochi

Mr. S.H. Mak

Miss W.L. Lo*

Discussant: Professor M. Hashimoto

Open Discussion

Closing remarks by Co-chairmen: Professor R. Lord

Dr. B. T'sou

* The presentation will be in Chinese.

Interpreters: Mrs. W. Poon

Dr. B. T'sou

Mr.F.Y. Yu

An exhibition of books and audio-visual equipment is held during the period of the Symposium at the Swire Lounge above the Dining Hall. 


\section{APPENDIX III \\ INTERNATIONAL SYMPOSIUM ON BILINGUAL EDUCATION LIST OF PARTICIPANTS}

I. Mr. D.R. Anderson

English Department, United College, Chinese University of Hong Kong, Hong Kong.

2. Mr.P. Barnes Department of Languages, Hong Kong Poly technic, Hong Kong.

3. Miss J. Brandon St. Stephen Girls' School, Hong Kong.

4. Professor M.A. Brimer School of Education, University of Hong Kong, Hong Kong.

5. Mr. A. Brown

Department of Education, Hong Kong.

6. Mr. Chan Che-shing Department of Languages, Hong Kong Polytechnic, Hong Kong.

7. Mrs. C.M.Y. Chan Language Centre, University of Hong Kong, Hong Kong.

8. Dr. Jachin Chan Hong Kong Baptist College, Hong Kong.

9. Dr. J. Chan

Research, Testing and Guidance Centre,

Education Department, Hong Kong.
10. Mr. N. Chan

Department of Chinese, Grantham College of Education, Hong Kong.

11. Miss S. Chan S.K.H. Kei Hin (Epiphany) Primary School, Kowloon, Hong Kong.

12. Miss C.T. Chang Department of Languages, Hong Kong Poly technic, Hong Kong.

13. Mr. E.P. Chen Government Training Division, Hong Kong.

14. Mrs. A. Chang English Section, Advisory Inspectorate, Education Department, Hong Kong.

15. Mr. W. Cheng Grantham College of Education, Kowloon, Hong Kong.

16. Miss Cheung Man-wai Liu Ming Choi College, Hong Kong.

17. Miss R. Cheung

English Section, Advisory Inspectorate, Education Department, Hong Kong.

18. Mr. Cheung Yat-sing United College, Department of English, Chinese University of Hong Kong, Hong Kong. 
19. Mr. Chia Shih-yar Chinese Language (Research) Centre, Nanyang University, Singapore.

20. Miss L. Chung Department of English Studies and Comparative Literature, University of Hong Kong, Hong Kong.

21. Professor G.B. Downer Department of Chinese, University of Leeds, Leeds, England.

22. Mr. D. Faure History Department, New Asia College, Chinese University of Hong Kong, Hong Kong.

23. Dr. A. Fok

Language Centre, University of Hong Kong, Hong Kong.

24. Miss Fok Ka-yu Buddhist Wong Fung Ling College, Hong Kong.

25. Mr. C.W. Fung Department of Chinese, Northcote College of Education, Hong Kong.

26. Mr. C.D. Godwin English Department, New Asia College, Chinese University of Hong Kong, Hong Kong.

27. Mr. Fung Yee-wang School of Education, University of Hong Kong, Hong Kong.
28. Professor M. Hashimoto

Chinese Section, National Institute for the Study of Languages and Cultures of Asia and Africa, Tokyo, Japan.

29. Mr. A. Hinton School of Education, Chinese University of Hong Kong, Hong Kong.

30. Dr. D. Ho Department of Psychology. University of Hong Kong, Hong Kong.

31. Mrs. S. Ho

Headmistress,

St. Francis of Assissi's Primary Schools, Kowloon, Hong Kong.

32. Dr. B. Hong-fincher Department of East Asian and Indo-Pacific Languages, Australian National University, Canberra, Australia.

33. Miss S. Hsia Sir Robert Black College of Education, Kowloon, Hong Kong.

34. Dr. R.S.W. Hsu Language Centre, University of Hong Kong, Hong Kong.

35. Dr. H.B. von Huene Language Centre, University of Hong Kong, Hong Kong.

36. Mrs. E. Ip Department of Languages, Hong Kong Polytechnic, Hong Kong. 
7. Dr. A. King

Sociology Department,

New Asia College,

Chinese University of Hong Kong,

Hong Kong.

38. Dr. Y.F. Kong

Northcote College of Education, Hong Kong.

39. Dr. E. Kuo

Department of Sociology, University of Singapore,

Singapore.

40. Rev. E. Kvan

Department of Psychology, University of Hong Kong, Hong Kong.

41. Mrs. H. Kwok

Department of English Studies and Comparative Literature, University of Hong Kong, Hong Kong.

42. Mrs. R. Lau Principal Curriculum Planning Officer, Department of Education, Hong Kong.

43. Mr. M.K. Lee

Government Training Division, Hong Kong.

44. Mr. P. Lee

Examination Section, Education Department, Kowloon, Hong Kong.

45. Miss T. Leung

English Language Centre, Education Department, Hong Kong.

46. Professor Lim Kiat-boey Regional Language Centre, Singapore.
47. Mr. C de Linde Institute Britannique de Paris, 11 rue de constantine 75007 Paris, France.

48. Professor Liu Chun-jo Department of Chinese, University of Minnesota, Minneapolis, Minnesota, U.S.A.

49. Mr. T.H. Liu

Language Centre, University of Hong Kong, Hong Kong.

50. Mr. Liu Ming Yale-in-China Chinese Language Centre, New Asia College, Chinese University of Hong Kong, Hong Kong.

51. Mr. Lo Wai-luen St. Paul's School (Lamtin), Kowloon, Hong Kong.

52. Mr. C. Long

Department of Languages, Hong Kong Polytechnic, Hong Kong.

53. Mr. S.C. Loo Chinese Language (Research) Centre, Nanyang University, Singapore.

54. Professor R. Lord Language Centre, University of Hong Kong, Hong Kong.

55. Mrs. C. Low English Section, Department of Education, Hong Kong. 
56. Professor Ma Meng

Department of Chinese, University of Hong Kong, Hong Kong.

57. Mrs. W. MacCallum German Swiss International School, Hong Kong.

58. Miss W. Maccoun Department of Languages, Hong Kong Poly technic, Hong Kong.

59. Mr. Mak Sik-hon

Chinese Language Teaching Centre, Hong Kong.

60. Professor P. Manomaivibool Department of Oriental Languages, Chulalongkorn University, Bangkok 5, Thailand.

61. Mrs. G.B. Markey University of Auckland, Auckland, New Zealand.

62. Dr. A. Morrale University of Palermo, Palermo, Italy.

63. Mr. C.A. Miao Language Centre, University of Hong Kong, Hong Kong.

64. Mrs. L. Mok Department of Education, Hong Kong.

65. Miss Mok Sau-king Department of English, Grantham College of Education, Kowloon, Hong Kong.

66. Mrs. B.M. Murray

Sir Robert Black College of Education, Kowloon, Hong Kong.
67. Mr. S. Nelsson Department of Chinese, University of Stockholm, Stockholm, Sweden.

68. Professor Y. Ohkochi Department of Foreign Languages, Osaka University of Foreign Studies, Osaka, Japan.

69. Mrs. C.R. Ortmeyer New Asia College, Chinese University of Hong Kong, Hong Kong.

70. Dr. A. Peyraube Centre National de la Recherche Scientifique (Centre de Recherches Linguistiques sur L'Asie Orientale), Paris, France.

71. Mr. Phoom Mun-kwong Chinese Language (Research) Centre, Nanyang University, Singapore.

72. Mr. Poon Hon-hung Department of Education, (Secondary Schools Places Allocation) Kowloon, Hong Kong.

73. Mrs. W. Poon Department of Languages, Hong Kong Poly technic, Hong Kong.

74. Mr. Poon Yan-kwok School of Education, University of Hong Kong, Hong Kong.

75. Professor L. Ramish English Language Centre, Nanyang University, Singapore. 
76. Mr.P. Sanderson

Department of Languages, Hong Kong Poly technic, Hong Kong.

77. Mrs, C.M. Sieh Department of Languages, Hong Kong Polytechnic, Hong Kong.

78. Mr. Sin Kam-wai Hong Kong Professional Teacher Union, Kowloon, Hong Kong.

79. Dr. Siu Ping-kee School of Education, Chinese University of Hong Kong, Hong Kong.

80. Mr. So Fai-cho Principal Inspector (Chinese), Department of Education, Hong Kong.

81. Miss P. So English Department, Northcote College of Education, Hong Kong.

82. Mr. Szeto Wah G.T.C. Past Students' Association's Kwun Tong School, Kowloon, Hong Kong.

83. Mr. K. Topley

Department of Education, Hong Kong.

84. Dr. B.K. T'sou Language Centre, University of Hong Kong, Hong Kong.

85. Mrs. S.L. T'sou

School of Education, University of Hong Kong, Hong Kong.
86. Dr. N. Tsuji

National Institute for the Study of Languages and Cultures of Asia and Africa,

Tokyo, Japan.

87. Mrs. M. Arana-Ward Language Centre, University of Hong Kong, Hong Kong.

88. Mr. M. Westcott The British Council, London, England.

89. Miss V. Wong Government Training Divison, Hong Kong.

90. Mr. Yao Teh-huai Department of Mathematics, University of Hong Kong, Hong Kong.

91. Miss D. Yu Department of Chinese, University of Hong Kong, Hong Kong.

92. Mr. Yu Fong-ying Language Centre, University of Hong Kong, Hong Kong.

93. Mr. L.Z. Yuan c/o Asia Foundation, San Francisco, Calif., U.S.A.

94. Miss R. Zi

Department of Languages, Hong Kong Polytechnic, Hong Kong. 


\section{APPENDIX IV}

\section{ASIAN ROUND TABLE CONFERENCE ON CHINESE LANGUAGE AND LINGUSITICS}

December 21, 1976

Introductory Remarks: B.K. T'sou

Session I: Chairman: M.J. Hashimoto

G.B. Downer

(University of Leeds, U.K.)

Contribution of Taishan(台山) Phone logy to Reconstructions in Ancient Chinese

S.Y. Chia

(Nanyang University, Singapore)

星加坡常用漢字的特徽

N. Tsuji

(Chinese University of Hong Kong, Hong Kong, and A.A.*)

An Outline Phonology of Guangxi Cantonese

M.K. Phoon

(Nanyang University, Singapore)

星加坡華語語音特徵

J. Chan

(Hong Kong Baptist College, Hong Kong)

Some Remarks on Cantonese Phonology

Y. Ohkochi

(Osaka University of

Foreign Studies, Japan)

有關漢諱的「存在句」

December 22, 1976

Session II

M.J. Hashimoto

(A.A. *)

On the Typo-Geography of Asian Languages

T.C. Tang

(National Taiwan Normal University, Republic of China)

S.C. Loo

(Nanyang Unıversity, Singapore)

星加坡中學生用字錯誤抽樣

P. Manomaivibool

A Contrastive Analysis of Some Sentence

(Chulalongkorn University, Thailand)

A. Peyraube

(C.N.R.S., France)

Final Particles in Chinese and Thai

Some Characteristics of the Non-

Standard Chinese in the Peking Area

S. Huang

(National Taiwan University,

Normal States and the Speaker's Realm Republic of China)

On the Semantics of Lai and $\mathrm{Qu}$ in Mandarin Chinese

* National Research Institute of Asian and African Language and Cultures 
37197 L86

M룤ㄹㄹ

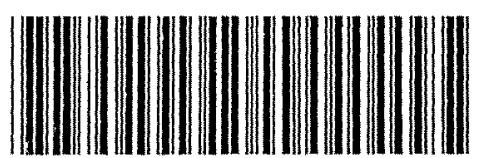

